\title{
Applications of Ethylene Vinyl Acetate as an Encapsulation Material for Terrestrial Photovoltaic Modules
}

\author{
E.F. Cuddihy \\ C.D. Coulbert \\ R.H. Liang \\ A. Gupta \\ P. Willis \\ B. Baum
}

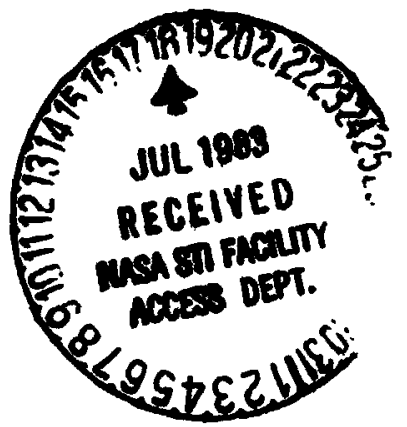

April 15, 1983

Prepared for

U.S. Department of Energy

Through an Agreement with

National Aeronautics and Space Administration

by

Jet Propulsion Laboratory

California Institute of Technology

Pasadena. Calıfornı

JPL PUBLICATION 83.35 


\title{
Applications of Ethylene Vinyl Acetate as an Encapsulation Material for Terrestrial Photovoltaic Modules
}

\author{
E.F. Cuddihy \\ C.C. Coulbert \\ R.H. Liang \\ A. Gupta
P Willis
B. Baum
}

tpril 15. 1983

Prepared for

U S Department of Energy

Through an Agreement with

Natıonal Aeronautıcs and Space Administration

by

Jet Propulsion Laboratory

California Institute of Tecinnology

Pasadena. Califo...na

JP'. PUBLICATION 8.3.35 


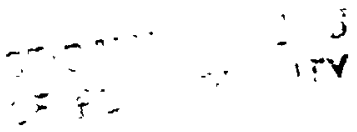

Prepared by the Jet Propulsion L.aboratory, California Insiltute of Technologi. for the U.S. Department of Energy through an dgreement uth the National Aeronautics and Space Administration.

The JPI Flat-Plate Solar Atray P:oject is sponsored by the $\mathbf{L}$ S. Department of Energy and is part of the Photwoltak Energy Systems Program to initate a major effort toward the development of cost-competitue solar arrays.

This repert was prepared ds an account of work sponsored by an agency of the United States Government Nether the Unted States Ciovernment nor any agenty thereof. nor any of their employees. makes any warranty. express or implied. or assumes any legal liability or responsibility for the accuracs. completeness, or usefulnes of an! usformation, apparatus, product, or process diclosed, or represents that its use nould not infringe prisately ou ned rights.

Reference herein to any specific commerial product, process, or sersice by irade name, trademark, manufacturer, or other wise, does not necessarily constituie or imply its endorsement, recommendation. or fatoring by the United States Ciovernment or any agency thereot The siews and opinuons of authors expressed here:n do not necessarils state or reflect those of the United States ciovernment or ans agenst thereof

This publicatwen reports on work done under NASA I ask RD.152. Amendment 66, DOE NASA IAA NO DE-AI0I-76I-720356. 


\section{ABSTRACT}

Terrestrial photovoltaic modules must undergo substantial reductions in cost in order to become economically attractive as practical devices for large-scale production of electricity. Part of the cost reductions must be realized by the encapsulation materials that are used to package, protect, and support the solar cells, electrical interconnects, and other ancillary components. As many of the encapsulation materials are polymeric, cost reductions necessitate the use of low-cost polymers. The performance and current status of ethylene vinyl acetate, a low-cost polymer that is being investigated as an encapsulation material for terrestrial photovoltaic modules, are described. 

CONTENTS

I. INTRODUCTION ...................... 1

II. ENCAPSULATION POTTANT: DE INITION AND REQUIREMENTS . . . . . 3

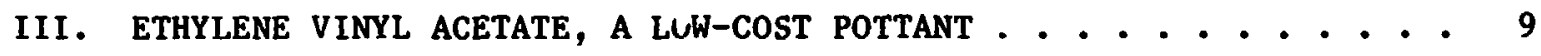

A. HISTORICAL DEVELOPMENT ................. 9

B. CURE AND PROCESSING ................. 10

1. Cure .................. 10

2. Processing .............. 12

c. MATERIAL PROPERTIES ................ 20

D. CHEMICAL STRUCTURE OF ElvaX 150 EVA . . . . . . . 21

E. PRIMERS AND ADHESIVES ................ 29

F. ENCAPSULATION ENGINEERING ............. 35

G. EVA AGING STUdIES ................... 41

1. Functional Properties ............. 43

2. Known Aging Behavior of EVA ......... 45

3. Experimental EVA Aging Programs ......... 47

4. Aging Surmary .............. 60

H. ADVANCED EVA STUDIES ............... . . 62

1. Curing Agent Studies............. 63

2. UV-Absorbing Additives.......... 66

REFERENCES ........................ 69

\section{$\underline{\text { Figures }}$}

1. Flat-Plate Module Design Classifications ........ 2

2. Encapsulation Materials: Module Construction Elements ... 2 
3. Laboratory-Measured Cure Conditions for Ethylene

Vinyl Acetate Formulation No. A-9918 . . . . . . . . 12

4. Double Vacuum-Bag Fixture . . . . . . . . . . . . 14

5. Experimental Double Vacuum-Bag Assembly . . . . . . . . . 14

6. Vacuum-Bag Fixture Heated in Hydraulic Press . . . . . . . 17

7. Module Fabrication: Temperature-Pressure Schedule . . . 18

8. Average Solar Transmittance of Cured EVA A-9918 (390-1105 nm) . . . . . . . . . . . . . 22

9. Dynamic Modulus (E) of Eihylene Vinyl Acetate A-9918 at a Frequency of $110 \mathrm{~Hz}$. . . . . . . . . . . . . 23

10. Loss Tangent ( $T a n$ ) of Ethylene Vinyl Acetate A-9918 at a Frequency of $110 \mathrm{~Hz}$. . . . . . . . . . . . . 2

11. Densities of Elvax EVA Resins versus Vinyl Acetate Content .................. 25

12. Speculations on the Polymeric Structure of Elvax 150 EVA: Block Copolymer . . . . . . . . . . . . 26

13. Melting Point vs Molecular Weight of Polyethylene . . . . . 30

14. Structural Analysis: Deflection and Thermal Stress . . . 36

15. Computer-Predicted Stresses in Encapsulated Silicon Solar Cells Resulting From Thermal Expansion Dif :rences in a Glass-Superstrate Module for $\Delta \mathrm{T}$ of $100^{\circ} \mathrm{C}$. . . . . . .

16. Computer-Predicted Stresses in Encapsuiated Silicon Solar Cells Resulting From Thermal Expansion Differences in a Steel-Substrate Module for $\Delta \mathrm{T}$ of $100^{\circ} \mathrm{C} . . .$. . .

17. Computer-Predicted Stresses in Encapsulated Silicon Solar Cells Resulting From Thermal Expansion Differences in a Wooden-Sub t trate Module for $\Delta \mathrm{T}$ of $100^{\circ} \mathrm{C}$. . . . . . .

18. Computer-Predicted Stresses in Encapsulated Silicon Solar Cells Resulting From Deflection of a 4-ft-Square Glass-Substrate Module Under a Uniform Load of $50 \mathrm{lb} / \mathrm{ft}^{2}$.....................

19. Computer-Predicted Stresses in Encapsulated Silicon Solar Cells Resulting From Deflection of 4-ft-Square Stee 1 Panels of Three Different Thicknesses Under a liniform Load of $50 \mathrm{lb} / \mathrm{ft}^{2}$. . . . . . . . . . . . . 
20. Computer-Predicted Stresses in Encapsulated Silicon Solar Cells Resulting From Deflection Under a Uniform Load of $50 \mathrm{lb} / \mathrm{ft}^{2}$ of an Unribbed, 4-ft-Square, 1/4-in.-Thick Hardboard, and a Ribbed, 4-ft-Square, 1/8-in.-Thick Hardboard ................ 40

21. UV-Visible Absorption Spectra of Each Component in

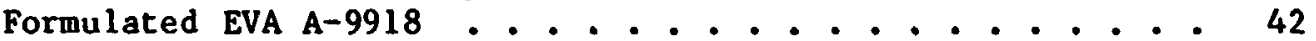

22. Thermal Degradation of Elvax Vinyl Resins . . . . . . . 46

23. Thermal Decomposition of Lupersol 101 Peroxide . . . . . 54

24. Concentration of Residual Lupersol 101 Peroxide Curing Agent in EVA A-9918 as a Function of Photothermal Aging at 6 suns, $30^{\circ} \mathrm{C}$, in Air ........... 56

25. Depletion of Lupersol 101 From Crosslinked EVA A-9918 at $30^{\circ} \mathrm{C}, 6$ suns in Air-Circulated Oven . . . . . . . . . 57

26. Change in Percentage of Transmission at $400 \mathrm{~nm}$ of EVA A-9918 Films as a Function of Dark Thermal Aging at $105^{\circ} \mathrm{C}$, and of Photothermal Aging at 6 suns, $105^{\circ} \mathrm{C} . .$.

1. Evolving Specifications and Requirements for Compounded Pottant Materials

2. Candidate Encapsulation Naterials Being Evaluated Experimentally by FSA . . . . . . . . . . . . . . 7

3. Formulation of Evaluation-Ready Ethylene Vinyl Acetate . . . 11

4. Peroxide Curing of a Series of EVA Resins . . . . . . . 13

5. Basic Assembly of Materials Required for Vacuum-Bag Processing of Substrate and Superstrate Modules . . . . . 16

6. Properties of Elvax 150 and Cured A-9918 EVA . . . . . . 19

7. Water Absorption of Various Du Pont Ethylene Vinyl Acetate (Elvax) Resins...... . . . . . . . . . 24

8. Water-Vapor Transmission Rates (WVTR) $\approx$ E Ethylene Vinyl Acetate Resins... . . . . . . . . . . . . . 25

9. Composition of Elvax 150 When Assumed to be a Block Copolyme- as Depicted in Figure 12 . . . . . . . . .

10. Glass, Metal, and Polyester Primers, and Tedlar Adhesive for A-9918 EVA... . . . . . . . . . . . . . . . 31 
11. Adhesive Bonc Strengths for A-9918 EVA Bonded to Various Materials . . . . . . . . . . . . 32

12. Structural Parameters Used in Encapsulation Engineering Computer Studies . . . . . . . . . . . . . 36

13. EVA Aging Program at Springborn Laboratories . . . . . . 48

14. EVA Aging Program at Jet Propulsion Laboratory . . . . . . 49

15. Properties of Cured A-9918 EVA as a Function of Exposure Time to RS/4 UV at $55^{\circ} \mathrm{C}$............. 51

16. Thermal Aging of Cured A-9918 EVA in Circulating-Air Ovens . . . . . . . . . . . . . 52

17. Volatile Loss of Cyasorb UV-531 at $90^{\circ} \mathrm{C}$. . . . . . . 62

18. Cure of A-9918 EVA at Various Times and Temperatures with Four Different Peroxide Curing Agents as Monitored by Gel Content in wt \%.............. 65

19. Flash Points of the Four Lupersol Peroxide Curing Agents . . . . . . . . . . . . . . . 67

20. Chemically Attachable U1traviolet Screening Agents . . . . 68 


\section{SECTION I}

\section{INTRODUCTION}

Photovoltaic (PV) modules contain strings of electrically interconnected solar cells capable of producing practical quantities of electricity when irradiated by sunlight. Silicon solar cells are fragile and are especially sensitive to brittle failure in tension and bending. In addition, the electrically conductive metallization materials (functioning as grids, interconnects, bus bars, and terminals) must be protected from atmospheric corrosion or cther deteriorating interaction with the terrestrial environment. In short, the silicon snlar cells must be mechanically supported, and the electrically conductive metallization materials must be isolated from environmental exposure.

Encapsulation materials are defined as all construction materials (excluding cells and electrical conductors) required in a PV module to provide mechanical support and environmental isolation. Farly encapsulation efforts to identify a single material that could satisfy all of the encapsulation requirements and needs were unsuccessful (References 1, 2, and 3). The understanding evolved that more than one material would have to be assembled ill a composite package to fabricate an encapsulation module satisfying all of the requirements.

After an examination of all commercial and experimental flat-plate module designs, it was found that these designs could be separated into two basic classes (see Figure 1). These are designated as substrate-bonded and superstrate-bonded designs, referring to the method by which the solar cells are supported mechanically. In the substrate design, the cells are supported by a structural substrate panel, and in the superstrate design the cells are supported by a transparent structural superstrate (i.e., glass).

From these two design options, nine basic encapsulation construction elements can be identified, which are illustrated in Figure 2 along with their designations and encapsulation functions. Fabricated modisles need not usc all nine of these construction elements, but combinations of these basic elements are incorporated in most module designs. However, all experimental and commercial modules of any design employ an elastomeric pottant. Refore 1980 , almost all commercial modules used either polyvinyl butyral (PVB) or silicone as pottant materials.

One objective of the Flat-Plate Solar Array Project (FSA), managed by the Jet Prcpulsion Laboratory (JPL) for the U.S. Department of Energy (DOE), was to demunstrate technical feasibility and 20-yr service life potential of photovoltaic modules fabricated with the lowest-costing materials that could fulfill the functions of encapsulation construction elements. Under this guideline, jour low-cost elastomers have been identified or developed for potential application as pottant materials (References 2 through 8 ). One of the low-cost elastomers is ethylene vinyl acetate (EVA). This document describes the current status of EVA as an encapsulation pottant for terrestrial photovoltaic modules. 


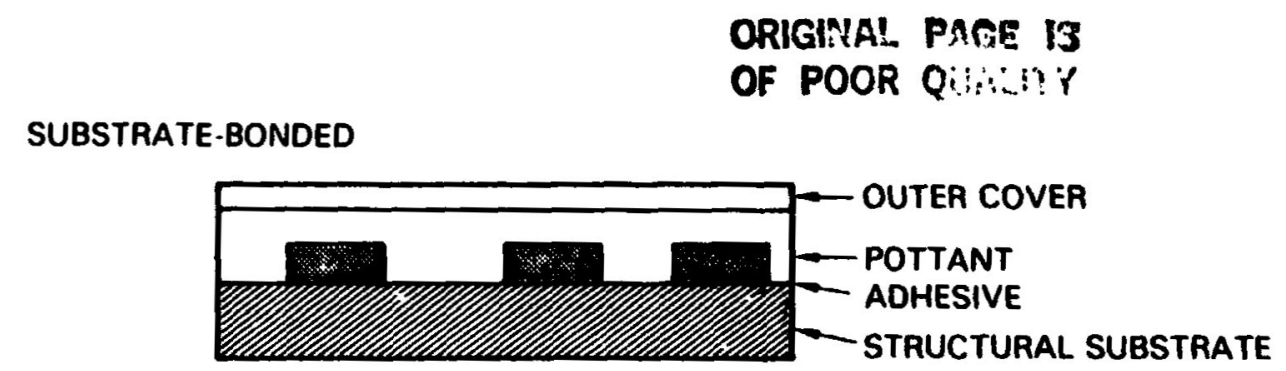

SUPERSTRATE-BONDED

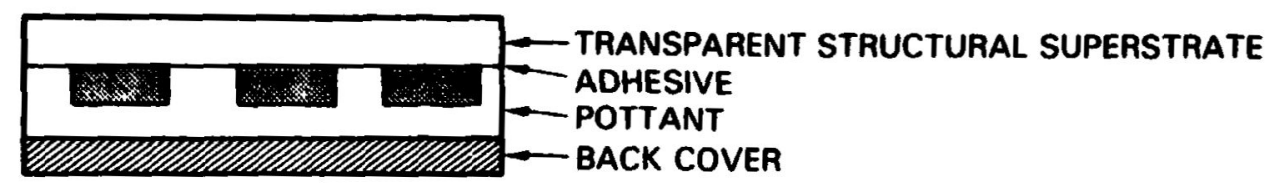

Figure 1. Flat-Plate Module Design Classifications

MODULE SUNSIDE

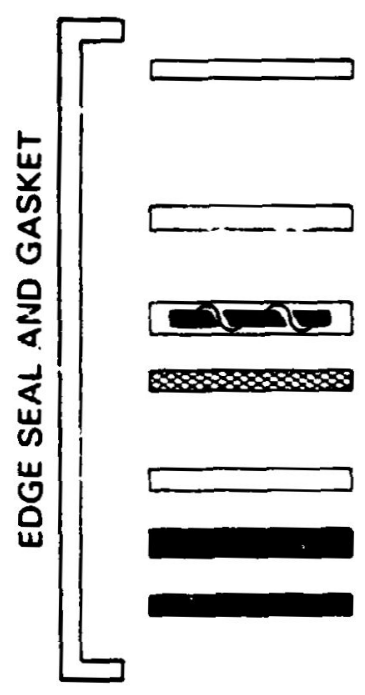

LAYER DESIGNATION

SURFACE

(1) MATERIAL

(2) MODIFICATION

FRONT COVER

POTTANT

POROUS SPACER

DIELECTRIC

SUBSTRATE

BACK COVER

\section{FUNCTION}

LOW SOILING,

EASY CLEANABILITY, ABRASION RESISTANT, ANTIREFLECTIVE

UV SCAEENING,

STRUCTURAL SUPERSTRATE

SOLARCELL ENCAPSULATION

AIR RELEASE,

MECHANICAL SEPARATION

ELECTRICAL ISOLATION

STRUCTURAL SUPPORT

MECHANICAL PROTECTION, WEATHERING BARRIER,

INFRARED EMITTER

PLUS NECESSARY PRIMER-ADHESIVES

Figure 2. Encapsulation Materials: Module Construction Elements 


\section{SECTION II}

\section{ENCAPSULATION POTTANT: DEFINITION AND REOUIREMENTS}

The central core of an encapsulation system is the pottant, a transparent, polymeric material that is the actual encapsulation material $i$. module. As there is a significant difference between the thermal-expans:coefficients of polymeric materials and of silicon cells and metallic interconnects, stresses developed from the thousands of daily thermal cycles can result in fractured cells, broken interconnects, or cracks and separaticns in the pottant material. To avoid these problems, the pottant material must not overstress the cell and interconnects, and must itself be resistant to fracture. From the results of a theoretical analysis (Reference 9), experimental efforts (References 1 and 3 ), and observations of the materials of choice used for pottants in commercial modules, it was concluded that the pottant must be a low-modulus, elastomeric material.

Also, these materials must be transparent, processible, and comercially available, and desirably low in cost. In many cases, the commercially available candidate material may not be physically or chemically suitable for direct encapsulation use, and therefore must also be amenable to low-cost

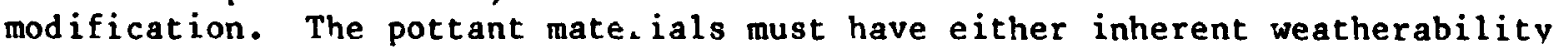
(retention of transparency and mechanical integrity under weather extremes) or the potential for long life that can be provided by cost-effective protection incorporated into the material or the module design.

In a fabricated module, the pottant provides three critical functions for module 1 ife and reliability:

(1) Maximum optical transmission in the silicon solar-cell sensitivity wavelength range of 0.4 to $1.1 \mu \mathrm{m}$.

(2) Retention of a required level of electrical insulation to protect against electrical breakdown, arcing, etc., with the associated hazards of electrical fires and other dangers to human safety.

(3) The mechanical properties to maintain spatial containment of the solar cells and interconnects, and to resist mechanicai creep. The mechanical properties also must not impose undue mechanical stresses on the solar cell.

When exposed to o'stdoor weathering, polymeric materials can undergo degradation that could affect their optical, mechanical, and electrical insulation properties. Outdoors, polymeric materials can degrade from one or more of the following weathering actions (Reference 10):

(1) Ultraviolet (UV) photooxidation.

(2) UV photolysis.

(3) Thermal oxidation.

(4) Hydrolysis. 
For expected temperature levels (References 9, 11, 12, and 13) in operating modules, up to $60^{\circ} \mathrm{C}$ in a rack-mounted arzay and possibly up to $80^{\circ} \mathrm{C}$ on a rooftop, three generic classes of transparent polymers are generally resistant to the above weathering actions: silicones, fluorocarbons, and polymethyl methacrylate (PMMA) acrylics. of these three, only silicones, which are expensive, ave been available as low-modulus elastomers suitable for pottant application.

Therefore, all other transparent, low-modulus elastomers will in general be sensitive to some degree of weathering degradation. However, less weatherable and lower-costing materials can be considered for pottant application if the module design can provide the necessary degree of environmental protection. For example, a hermetic design such as a glass superstrate with metal-foil back cover and appropriate edge sealing will essentially isolate the interior pottant from exposure to oxys $n$ and water vapor, with the glass itself providing a level of UV shielding. As an illustration, polyvinyl butyral (PVB) would undergo rapid deterioration if directly exposed outdoors to oxygen, water vapor, and UV, but when isolated within the core of a double-glass automotive windshield, PVB lasts virtually forever. PVB is used as a lamination pottant in many commercial glass-superstrate PV modules.

The situation is different, however, for a substrate module that employs a weather-stable plastic-film front cover. Because all plastic films are permeable to oxygen and water vapor '. Reference 14), the pottant is exposed to oxygen and water vapor, and also to UV if the plastic film is non-UV screening. Because isolation of the pottant from oxygen and water vapor is not practical in this design option, it becomes a requirement that the pottant be intrinsically resistant to hydrolysis and thermal oxidation at service temperatures, but sensitivity to UV is allowable if the weather-stable front-cover plastic film can provide UV shielding. (Comercial UV-screening plastir have been identified for this application, and are under study.)

Therefore surveys (Reference 3) were done to identify the lowest-costing, transparent, low-modulus elastomers with expected resistanc. to hydrolysis and thermal oxidation at temperatures up to $80^{\circ} \mathrm{C}$, but these materials were allowed to be sensitive to UV deterioration. It was envisioned that if such a set of lowest-costing pottant candidates were selected $r$ ohe basis of a less-protective substrate-medule design, they would also b .." in a potentially more-protective glass-superstrate design.

In addition to the foregoing requirements for candidate pottant selection, these materials must also be capatle of being tabricated into modules by industrial fabrication methods. Therefore, the materials must be readily usable on commercial equipment. The two industrial fabrication techriques in common "se are lamination and carring.

The general plan for the FSA development of pottants encompasses two discrete steps:

(1) Evaluation Readiness: An intermediate stage of development wherein the material can be handled, processed, and fabricated into modu!s. by participating industrial manufacturers. Although 
falicability using $c$ :mercial equipment becomes the key criterion for this level of deveiopment, the material will be fully compounded with trial anticxidants, UV stabilizers, other necessary additives, and complete with recommended processing conditions and primers and adhesives.

(2) Application Readiness: The final stage of development in which the material will incorporate improvements ia the intermediatestage material generated by:

(a) Feedback on nandling, processing, and fabricability of the intermediate-stage matrial by participating $\mathrm{PV}$ manufacturers.

(b) Results of eccelerated, abbreviated, and outdoor testing of the material and of modules fabricated with the material.

The following list outlines some of the features of a pottant ready for application evaluation:

(1) Fastest possible fabrication sycle:

(a) Lowest possible cure temperature.

(b) Fastest possible cure time.

(2) Self-priming.

(3) Specification of peak-service temperatures for 20-yr life in various module designs (superstrate end substrate).

Although pottants may be developed to this stage by FSA, further $r \in f i n e m e n t s$ could be mace by material or module manufacturers who may devise additional modificatior-

- ised on FSA pottant experience, certain specifications and requirements for pot ants are emerging; these 11 shrwn in Table 1.

Ethylene vinyl acetate has been developed to the evaluation-ready stage, and is currently being advanced toward the application-ready stage. The evaluation-ready version of EVA is now commercially available. This document describes the development, properties, and status of the evaluation-ready version of EVA, and additionally reports on early efforts and preliminary results arising from activities related to apolication readiness. Table 2 is a master list of mat:rials being evaluated experimentally for all module construction elements (Figure 2) by FSA. A description of each of these materials is reported in more detail in Reference 8 . 
Table 1. Evolving Specifications and Requirements for Compounded Pottant Materials

\begin{tabular}{|c|c|}
\hline Characteristic & Specification or Requirement \\
\hline Glass transition temperature $\left(T_{g}\right)$ & $<-40^{\circ} \mathrm{C}$ \\
\hline $\begin{array}{l}\text { Total hemispherical light transmission } \\
\text { through a } 20 \text {-mil-thick film integrated } \\
\text { over the wavelength range from } 0.4 \mu \mathrm{m} \\
\text { to } 1.1 \mu \mathrm{m}\end{array}$ & $>90 \%$ of incident \\
\hline Hydrolysis & None at $80^{\circ} \mathrm{C}, 100 \% \mathrm{RH}$ \\
\hline Resistance to thermal oxidation & Stable up to, $5^{\circ} \mathrm{C}$ \\
\hline Mechanical creep & None at $90^{\circ} \mathrm{C}$ \\
\hline $\begin{array}{l}\text { Tensile modulus as measured by initial } \\
\text { slope of stress-strain curve }\end{array}$ & $<3000 \mathrm{lb} / \mathrm{in} .2$ at $25^{\circ} \mathrm{C}$ \\
\hline Fabrication temperature & $\begin{array}{l}\leq 170^{\circ} \mathrm{C} \text { for either lamination or } \\
\text { liquid pottant systems }\end{array}$ \\
\hline $\begin{array}{l}\text { Fabrication pressure for lamination } \\
\text { pottants }\end{array}$ & $\leq 1$ atm \\
\hline Chemical inertness & $\begin{array}{l}\text { No reaction with embedded copper } \\
\text { coupons at } 90^{\circ} \mathrm{C}\end{array}$ \\
\hline UV absorption degradation & None at wavelength $>0.35 \mu \mathrm{m}$ \\
\hline Hazing or clouding & None at $80^{\circ} \mathrm{C}, 100 \% \mathrm{RH}$ \\
\hline $\begin{array}{l}\text { Minimum thickness on either side of } \\
\text { solar cells in fabricated modules }\end{array}$ & $6 \mathrm{mils}$ \\
\hline Odor, human hazards (toxicity) & None \\
\hline
\end{tabular}


Table 2. Candidate Encapsulation Materials Being Evaluated

Experimentally by FSA

\begin{tabular}{|c|c|c|c|}
\hline Function & Material & Type & Source \\
\hline \multirow{2}{*}{$\begin{array}{l}\text { Low-Soiling } \\
\text { Surface } \\
\text { Material }\end{array}$} & $\begin{array}{l}\text { Fluorinated } \\
\text { silane }\end{array}$ & $L-1668$ & $3 M$ \\
\hline & $\begin{array}{l}\text { Perfluorodecanoic } \\
\text { acid }\end{array}$ & $\begin{array}{l}\text { With E-3820 } \\
\text { primer }\end{array}$ & Dow Corning \\
\hline \multirow[t]{4}{*}{$\begin{array}{l}\text { UV Screening } \\
\text { Front Cover }\end{array}$} & $\begin{array}{l}\text { Low-iron tempered } \\
\text { float glass }\end{array}$ & $\begin{array}{l}\text { E.g., Sunadex } \\
\text { glass }\end{array}$ & ASG \\
\hline & $\begin{array}{l}\text { UV-screening } \\
\text { acrylic films }\end{array}$ & $\begin{array}{c}\text { Acrylar } \mathrm{X}-22416 \\
2 \text { mils thick }\end{array}$ & $3 M$ \\
\hline & & $\begin{array}{l}\text { Acrylar } \mathrm{X}-22417 \\
3 \text { mils thick }\end{array}$ & $3 M$ \\
\hline & $\begin{array}{l}\text { UV-screening PVF } \\
\text { fluorocarbon film }\end{array}$ & $\begin{array}{l}\text { Tedlar } 100 \text { BG 30UT } \\
\text { I mil thick }\end{array}$ & Du Pont \\
\hline \multirow[t]{4}{*}{ Pottant } & EVA & A-9918 & $\begin{array}{l}\text { Springborn, } \\
\text { Du Pont, and } \\
\text { Rowland, Inc. } \\
\text { (Berlin, CT) }\end{array}$ \\
\hline & $\begin{array}{l}\text { Ethylene methyl } \\
\text { acrylate (EMA) }\end{array}$ & $A-11877$ & Springborn \\
\hline & $\begin{array}{l}\text { Poly-n-butyl } \\
\text { acrylate (PnBA) }\end{array}$ & $B A-13870$ & Springborn \\
\hline & Polyurethane & $z-2591$ & $\begin{array}{l}\text { Development } \\
\text { Associates, } \\
\text { North Kingston, } \\
\text { R.I. }\end{array}$ \\
\hline Porous Spacer & $\begin{array}{l}\text { Craneglas non- } \\
\text { woven E-glass } \\
\text { material }\end{array}$ & $\begin{array}{l}\text { Type } 230,5 \mathrm{mils} \\
\text { thick }\end{array}$ & $\begin{array}{l}\text { Electrolock, inc. } \\
\text { (Chagrin Falls, } \\
\text { OH) }\end{array}$ \\
\hline $\begin{array}{l}\text { Dielectric } \\
\quad \text { Film }\end{array}$ & $\begin{array}{l}\text { Candidates are the } \\
\text { front and back } \\
\text { cover plastic } \\
\text { film }\end{array}$ & & \\
\hline
\end{tabular}


Table 2. Candidate Encapsulation Materials Being Evaluated Experimentally by FSA (Cont ${ }^{\circ} d$ )

\begin{tabular}{|c|c|c|c|}
\hline Function & Material & Type & Source \\
\hline \multirow[t]{3}{*}{ Substrates } & Mild steel & Cold-rolled & Various \\
\hline & Hardboards & $\begin{array}{l}\text { Super-Dorlux, } \\
1 / 8 \text { in. thick }\end{array}$ & Masonite \\
\hline & & $\begin{array}{l}\text { Duron, } \\
1 / 8 \text { in. thick }\end{array}$ & U.S. Gypsum \\
\hline \multirow[t]{5}{*}{ Back Covers } & $\begin{array}{l}\text { White-pigmented } \\
\text { plastic film }\end{array}$ & $\begin{array}{c}\text { Tedlar } 150 \text { BL30WH, } \\
1.5 \mathrm{mils} \text { thick }\end{array}$ & Du Pont \\
\hline & $\begin{array}{l}\text { White-pigmented } \\
\text { plastic film }\end{array}$ & $\begin{array}{c}\text { Tedlar } 400 \text { BS2OWH, } \\
4.0 \mathrm{mils} \text { thick }\end{array}$ & Du Pont \\
\hline & $\begin{array}{l}\text { White-pigmented } \\
\text { plastic film }\end{array}$ & $\begin{array}{l}\text { Scotchpar } 10 \mathrm{CP} \text { White } \\
1.0 \mathrm{mil} \text { thick }\end{array}$ & $3 M$ \\
\hline & $\begin{array}{l}\text { White-pigmented } \\
\text { plastic film }\end{array}$ & $\begin{array}{l}\text { Scotchpar } 20 \text { CP White } \\
2.0 \text { mils thick }\end{array}$ & $3 M$ \\
\hline & $\begin{array}{l}\text { White-pigmented } \\
\text { plastic £ilm }\end{array}$ & $\begin{array}{c}\text { Korad } 63000 \text { White, } \\
3.0 \mathrm{mils} \text { thick }\end{array}$ & Xcel Corp. \\
\hline \multirow[t]{2}{*}{$\begin{array}{l}\text { Edge Seal and } \\
\text { Gasket }\end{array}$} & $\begin{array}{l}\text { Butyl edge-sealing } \\
\text { tape }\end{array}$ & 5354 & $3 \mathrm{M}$ \\
\hline & $\begin{array}{l}\text { EPDM gasket- } \\
\text { sealing tape }\end{array}$ & $E-633$ & $\begin{array}{l}\text { Pawl ing Rubber } \\
\text { Co. (Pawl ing, } \\
\text { NY) }\end{array}$ \\
\hline
\end{tabular}




\title{
SECTION III
}

\author{
ETHYLENE VINYL ACETATE, A LOW-COST POTTANT
}

\section{A. HISTORICAL DEVELOPMENT}

EVA is a copolymer of ethylene and vinyl acetate typically sold in pellet form by Du Pont Co. and U.S. Industrial Chemicals, Inc. (U.S.I.). The Du Pont trade name is Elvax; the U.S.I. trade names are Ultrathene and Vynathene. The cost of EVA typically ranges between $\$ 0.60$ and $\$ 0.70$ per $1 \mathrm{~b}$ (1980 dollars). All comercially available grades of EVA were evaluated, and four candidates, based on maximum optical ransmission, were identified: Elvax 150, Elvax 250, Elvax 4320 and Elvax 4355 (Reference 3). Because EVA is thermoplastic, processing into a module is best accomplished by vacuum-bag lamination with a film of EVA. Based on film extrudability and transparency, the best choice became Elvax 150, at a cost (for high-volume purchases) of about $\$ 0.65 / 1 \mathrm{~b}$. Elvax 250 was a close second choice.

Elvax 150 softens to a viscous melt above $70^{\circ} \mathrm{C}$, and therefore is not suitable for temperature service above $70^{\circ} \mathrm{C}$ when employed in a fabricated module. A peroxide cure system was developed for Elvax 150 that results in a temperature-stable elastomer (References 3 and 6); Elvax 150 was also compounded with an antioxidant and UV stabilizers, which improved its weather stability but did not affect its transparency.

In addition to clear EVA, a white-pigmented EVA film was formulated (with $\mathrm{ZnO}_{2}$ and $\mathrm{TiO}_{2}$ ) that can be positioned on the back side of the solar cells in a module layup. The pigment provides a 1 ight-reflecting iackground for those module areas not covered by solar cells and increases module power output by internal reflection.

The development of Elvax 150 toward evaluation readiness involved two trial compounding formulations. The first formulation became available in the fall of 1978, and several module manufactures evaluated it by fabricating modules using their own commercial soldr cells. The processing technique in all cases was vacuum-bag lamination. Ths manufacturers reported certain advantages of EVA when compared to PVB, a laminating film material in comnon use within the PV module industry. The reported advantages were:

(1) Its cost is lower.

(2) Its appearance is better.

(3) It has better clarity.

(4) It obviates cold storage.

(5) It has dimensional stability.

(6) It has processing advantages:

(a) It requires less time. 
(b) It obviates the use of a pressure autoclave.

(7) It has good flow properties and volumetric fill.

Continued experimentation with the first trial EVA formulation resulted in identification of a better antioxidant (Naugard-P) for Elvax 150, which is now used in the second formulation of EVA, and which is the evaluation-ready version (Reference 6). The formulations for the clear and white-pigmented evaluation-ready EVA films are listed in Table 3. These ingredients are compounded in Elvax 150 pellats, followed by extrusion at $85^{\circ} \mathrm{C}$ to form a continuous film. The thickness of the clear film is nominally 18 mils; the white-pigmented film is nominally 14 mils thick. The selected curing system is inective below $100^{\circ} \mathrm{C}$, so that film extruded at $85^{\circ} \mathrm{C}$ undergoes no curing reaction. The extruded film retains the basic thermoplasticity of the Elvax 150. Therefore, during vacuum-bag lamination, the material will soften and process as a conventional laminating resin. A complete description of the EVA curing properties and of the the EVA lamination process follows in the next section.

Clear EVA films of Springborn Laboratories, Inc., Formulation A-9918 are available from two sources: Rowland, Inc.*, and Springborn.

B. CURE AND PROCESS ING

1. Cure

The EVA copolymer (Elvax 150, Du Pont) is cured with an aliphatic peroxide curing agent, Lupersol 101 . This was selected because of its negligible decomposition and cure activity at $85^{\circ} \mathrm{C}$ to $90^{\circ} \mathrm{C}$, the temperature range at which the EVA is extruded to a film. Trial experimentation (Refer ave 3) established that the Naugard-P antioxidant does not interfere with its curing properties at elevated temperatures, nor is the antioxidant consumed as a result of the peroxide curing reaction. Many candidate peroxide curing agents were eliminated (Reference 3 ) because of these detrimental interactions with the antioxidants.

Laboratory experiments with the Lupersol 101 peroxide curing agent established a time-temperature relationship for achieving acceptable and repeatable cure of EVA. The cure curve is shown in Figure 3. The criterion for acct, table cure was the achievement of mechanical-creep resistance of the cure EVA at $90^{\circ} \mathrm{C}$, which corresponded to a gel content greater than $65 \%$. $T$ laboratory experiments involved very rapid heating of the A-9918 EVA to a specified cure temperature, typically in less than $1 \mathrm{~min}$, followed by monitoring of the level of cure (gel content) as a function of cure time at constant temperature. Under these laboratory conditions, about $20 \mathrm{~min}$ at $150^{\circ} \mathrm{C}$ was required to achieve acceptable cure, and the required cure times were obseried to increase by a factor of nearly three for every $12^{\circ} \mathrm{C}$ decrear, in cure temperature, and vice versa. Laboratory experiments also

nowland, Inc.

Spruce Brook Industrial Park

Berlir. CT 06037

(203) 828-6364 
Table 3. Formulation of Evaluation-Ready Ethylene Vinyl Acetate

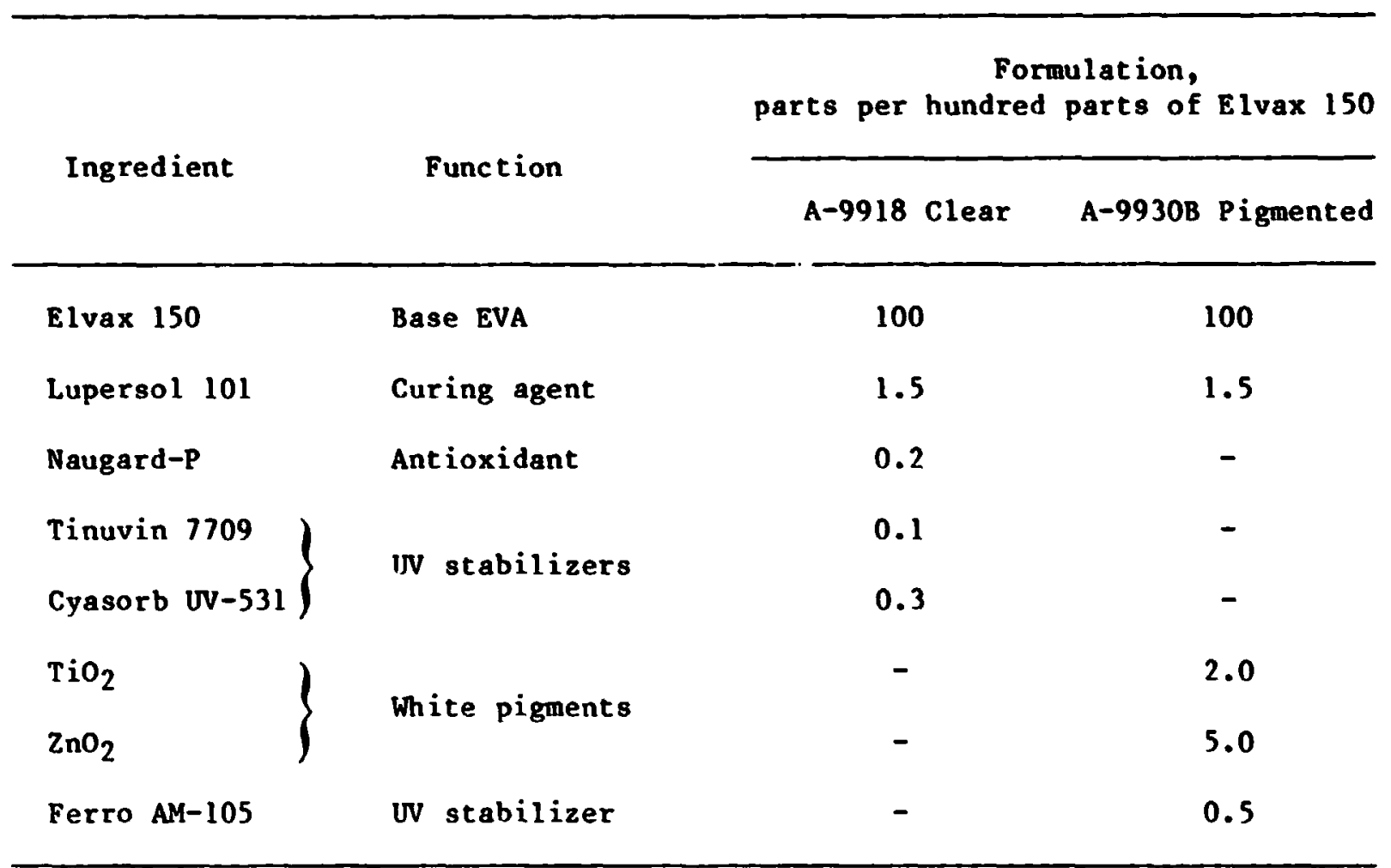

indicated that the Elvax 150 EVA copolymer could not be cured acceptably with Lupersol 101 below $120^{\circ} \mathrm{C}$.

Volatile decomposition products generated by the thermal decomposition of the peroxide are prevented from forming permanent gas bubbles in the cured EVA by action of the lamination pressure. Laboratory experiments have adequately shown that 1 atm of lamination pressure at $150^{\circ} \mathrm{C}$ prevents the thermally decomposing peroxide from forming permanent ly trapped gas bubbles in the cured EVA. However, use of lamination pressures at less than 1 atm at $150^{\circ} \mathrm{C}$ may lead to insufficient containment pressure, resulting in trapped gas bubbles in the cured EVA. At lower pressure $(<1$ atm) lamination, this may be corrected by trial-and-error lowering of the peak cure temperature, but will also necessitate progressively longer cure times for the EVA to reach a minimum ge 1 content of $65 \%$.

A preliminary insight into the chemistry of the EVA/peroxide-curing mechanism is provided by a laboratory test (Reference 15) that involved curing, with Lupersol 101, a series of EVA resins varying in vinyl acetate content. Included in the series was a pure polyethvlene, which for the purpose of this test was considered to be an EVA with zero wt \% vinyl acetate. The cure results are shown in Table 4, which reveals that the cure reaction requires the vinyl acetate group; the pure polyethylene without vinyl acetate groups did not cure. Further, the efficiency of cure, as indicated by gel content, appears to be virtually independent of vinyl acetate content. 


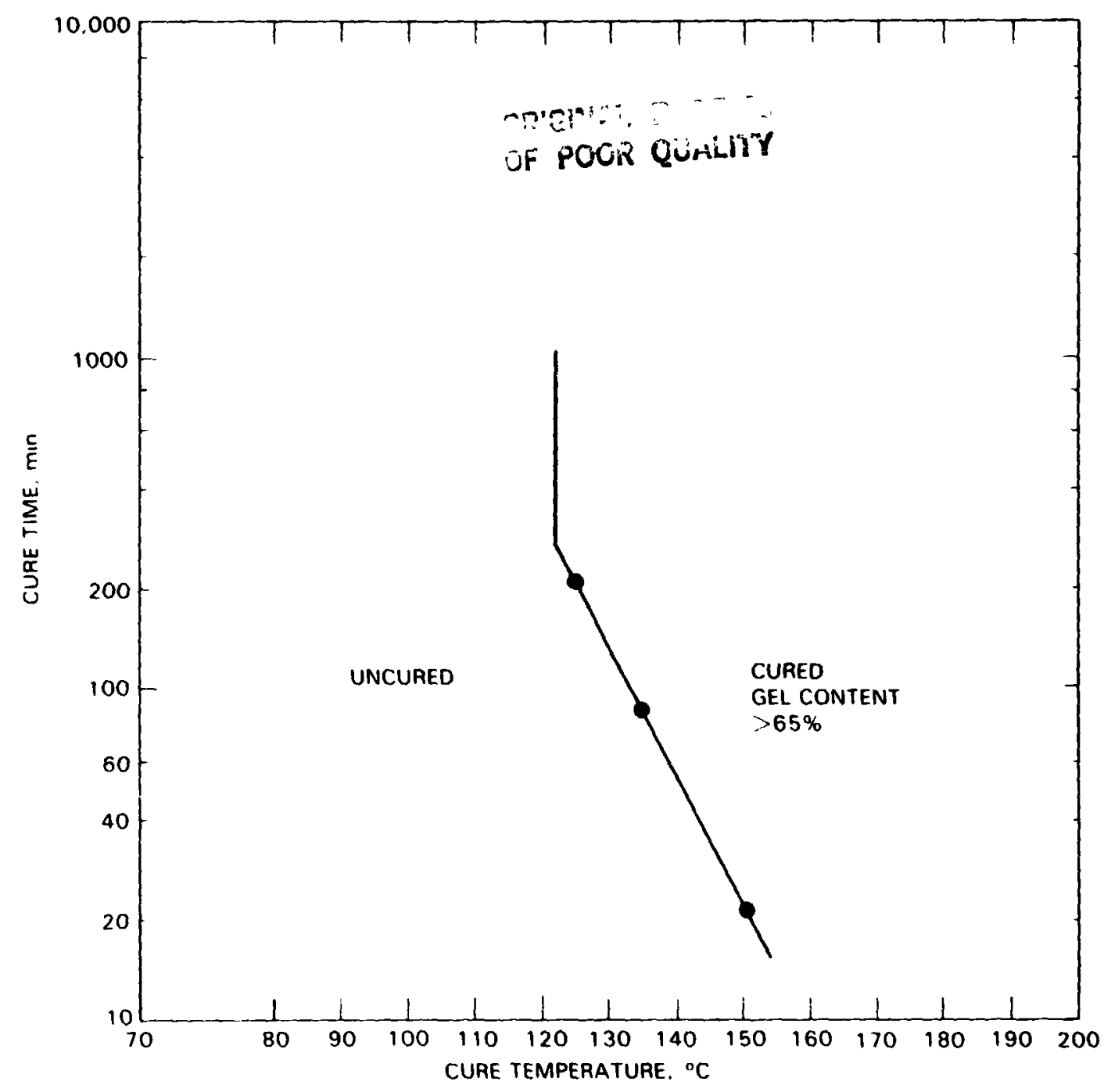

Figure 3. Laboratory-Measured Cure Conditions for Ethylene Vinyl Acetate Formulation No. A-9918

Exact details of the chemical curing reaction between the vinyl acetate groups and the peroxide have yet to be learned.

\section{Processing}

A successful and predictable moduie-fabrication process for FVA pottant has been achieved through a double vacuum-bag technique (Reference 7). To implement this technique, a special piece of equipment was built. The apparatus, schematically shown in Figure 4 and detailed in Figure 5 , consists of a double-sectioned aluminum picture frame, closed at the top and bottom by aluminum plates. A flexible polymer diaphragm separates upper and lower cavities, and also function as a vacuum-tight gasket. Each chamber has its own vacuum gauges and valves for its individual evacuation. The top-cover plate is permanently attached and sealed to the top cavity with bolts and a 
Table 4. Peroxide Curing of a Series of EVA Resinsa

\begin{tabular}{lcc}
\hline Resin & $\begin{array}{c}\text { Vinyl Acetate, } \\
\text { wt \% }\end{array}$ & Gel Content, \% \\
\hline Elvax 150 & 33 & 75 \\
UE-646-04 & 28 & 79 \\
Elvax 240 & 28 & 71 \\
Elvax 250 & 28 & 83 \\
Elvax 350 & 25 & 73 \\
Elvax 420 & 18 & 62 \\
Elvax 450 & 18 & 86 \\
Elvax 550 & 15 & 82 \\
Elvax 650 & 12 & 66 \\
Elvax 750 & 9 & 61 \\
PE-831 & 0 & 0 \\
\hline
\end{tabular}

$a_{\text {All }}$ polymers cured with 1.5 parts of Lupersol 101 per hundred parts of resin at $150^{\circ} \mathrm{C}$ for $20 \mathrm{~min}$.

silicone rubber gasket. The lower plate is removable and seals to the bottom of the lower frame piece with a silicone-rubber 0-ring gasket. The diaphragm material used is a high-temperature nylon $\mathrm{film}, 0.003 \mathrm{in}$. thick, which is flexible but not elastic. Conceivably, other types of films would work well in this application.

The module assembly is placed under the flexible diaphragm, in the lower cavity. The top surface of the module assembly is positioned flush with the top edge of the lower cavity, by stacking a necessary number of thin metal plates in the bottom of the lower cavity. The double vacuum-bag design enables initial exposure of the module assembly to a vacuum without simultaneous compression of the diaphragm, thus greatly enhancing air exhaustion from the module assembly. To ensure thorough air exhaustion, especially from large-area modules, the use of air-release scrim sheets of material such as Craneglas (Table 2 and Reference 8 ) should be incorporated in the module assembly. Experimentation has demonstrated that a 5-mil-thick Craneglas mat can be positioned above the active surface of the solar cells without optical obstruction (Reference 9). 


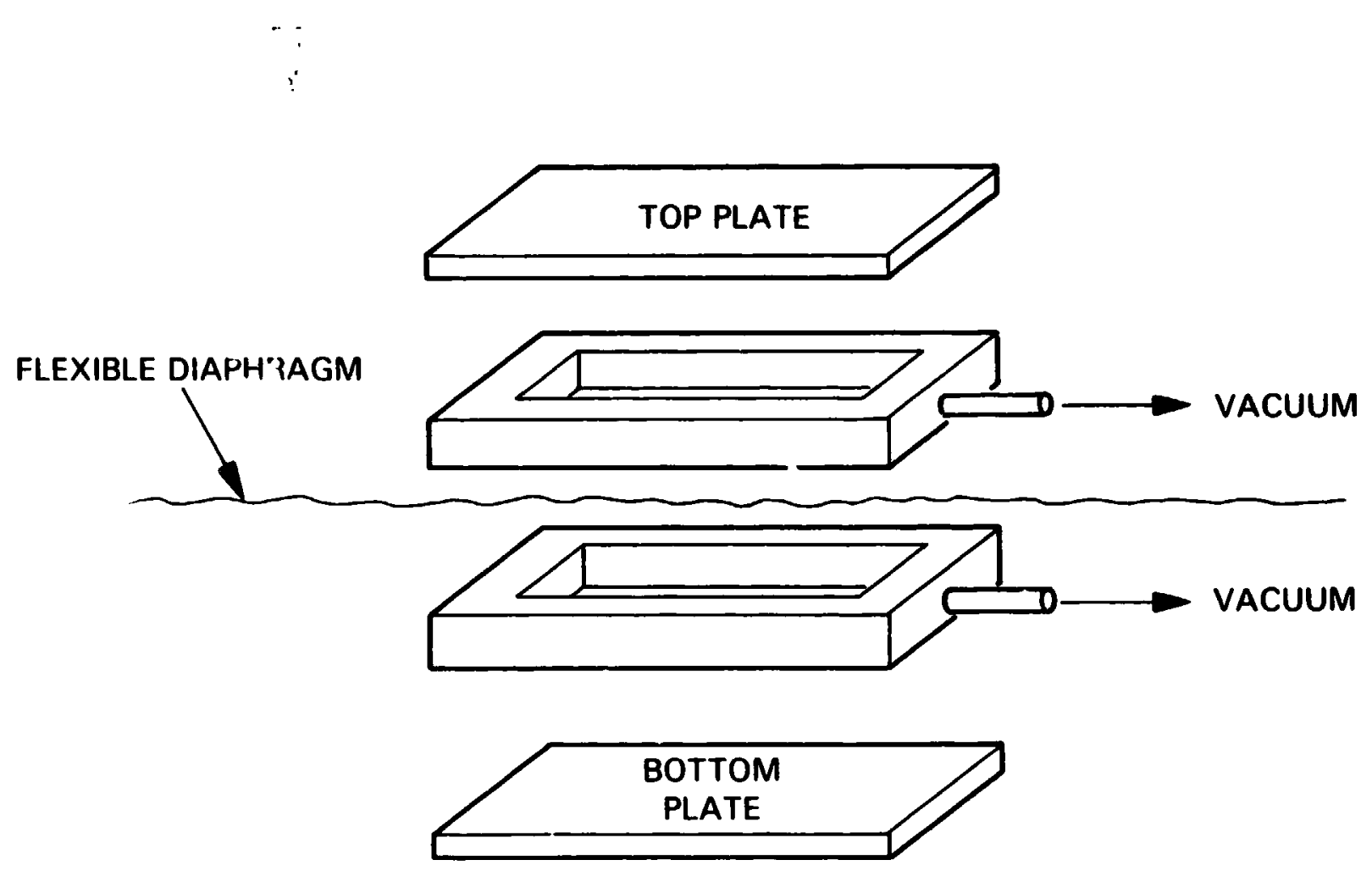

Figure 4. Double Vacuum-Bag Fixture

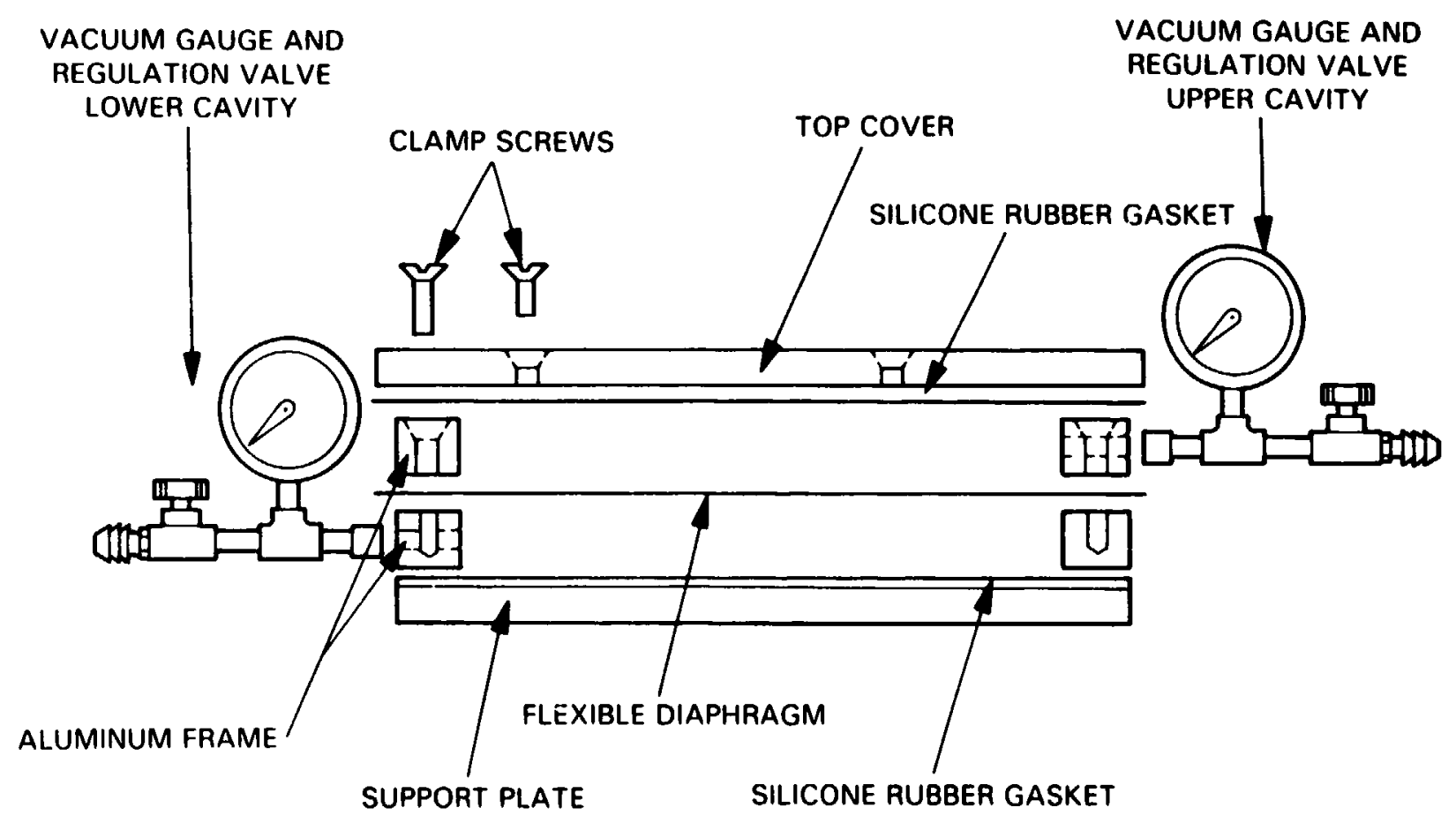

Figure 5. Experimental Double Vacuum-Bag Assembly 
Diaphragm compression $c$ - the module assembly can be done at any stage of the lamination cycle by pressurizing the upper cavity. Compression should be initiated or achieved, however, before the temperature of the EVA reaches $120^{\circ} \mathrm{C}$.

In practice, tiae module components are preassembled into a sandwich before the encapsulation step. The basic assembly of materials required for vacuum-bag processing of substrate and superstrate modules are shown in Table 5 .

Once the basic module components for either design have been assembled, a 10-mil-thick fluorinated ethylene propylene (FEP) release film or an equivalent should be included above and below the assembly. The release films should be cut to match the area of the module. These outer FEP film layers are then taped together over the edges of the module assembly with masking tape to contain the EVA when it softens during the heating cycles. The wrap-around of masking tape is attached to the FEP film layers, rather than to surfaces of the module. Although the edges are taped firmly, entrapped air seems to diffuse out easily. Innovation in equipment design will probably eliminate this taping procedure.

A useful fabrication aid is to include two 5-mil-thick (or thicker) metal (steel or aluminum) plates, one on each side of the taped module assembly. These plates distribute the lamination pressure over the module area, and result in uniformly thick modules, with smooth, wrinkle-free back-cover or front-cover surfaces.

The completed module assembly with taped edges is then placed in the lower cavity of the laminator and a microthermocouple is taped onto the FEP release film at the module center. The thermocouple permits convenient monitoring of the module temperature during the lamination cycle. The flexible diaphragm and upper-cavity fixtures are then positioned.

Both the upper and lower cavity are evacuated at room temperature for 5 to $10 \mathrm{~min}$ before heating, to exhaust the air from within the module assembly. While maintaining continuous vacuum in both the upper and lower cavity, the entire vacuum-bag $f$ ixture is loaded between the preheated $\left(150^{\circ} \mathrm{C}\right)$ platens of a hydraulic press (Figure 6), which serve as the heat source. The ram pressure is just sufficient to close the press and provide good heat transfer to the vacuum-bag fixture. The pressure from the platen should rest only on the frame of the fixture and should not contribute any pressure to the surface of the module.

The time-temperature heating pattern of the module assembly after loading the vacuum-bag fixture into the preheated hydraulic press is shown in Figure 7. Experimentation with this heating process has demonstrated that a dwell time of $10 \mathrm{~min}$ at $150^{\circ} \mathrm{C}$ results in an acceptable EVA cure (1ess than the 20 min determined in the laboratory testing). The reduced dwell time reflects the degree of partial curing that occurs during the heat-up time to $150^{\circ} \mathrm{C}$ (faster or slower heating rates may require adjustment of the dwe 11 time at the peak cure temperature). Samples of EVA taken from modules laminated by this process and associated time-temperature heating patterns exhibit acceptable cure with gel content over $75 \%$. 
Table 5. Basic Assembly of Materials Required for Vacuum-Bag Processing of Substrate and Superstrate Modules ${ }^{a}$

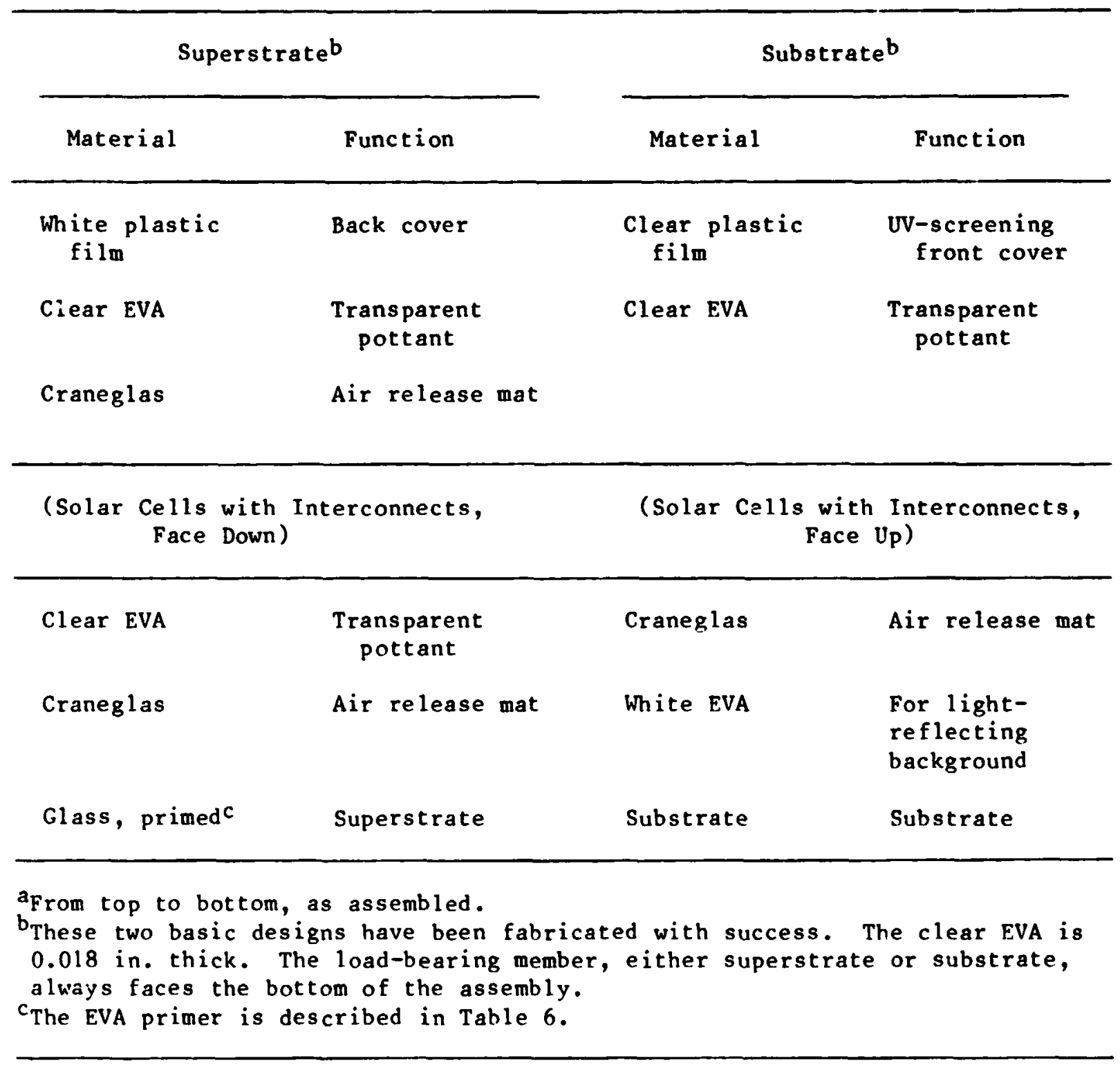

In this process, pressurization of the upper cavity to 1 atm of pressure is initiated when the module assembly temperature reaches $120^{\circ} \mathrm{C}$. A slow pressurization scheme is not mandatory nor necessarily optimal, and users of EVA material may explore alternative pressurization techniques. The doublevacuum-bag fixture provides a capability of limiting pressurization in the upper cavity to less than $1 \mathrm{~atm}$. However, low-pressure $(<1$ atm) lamination has not yet been experimentally investigated to determine the effect of pressure in inhibiting gas-bubbles formation due to peroxide decomposition. 
Cill is.

OF Poin Quintil
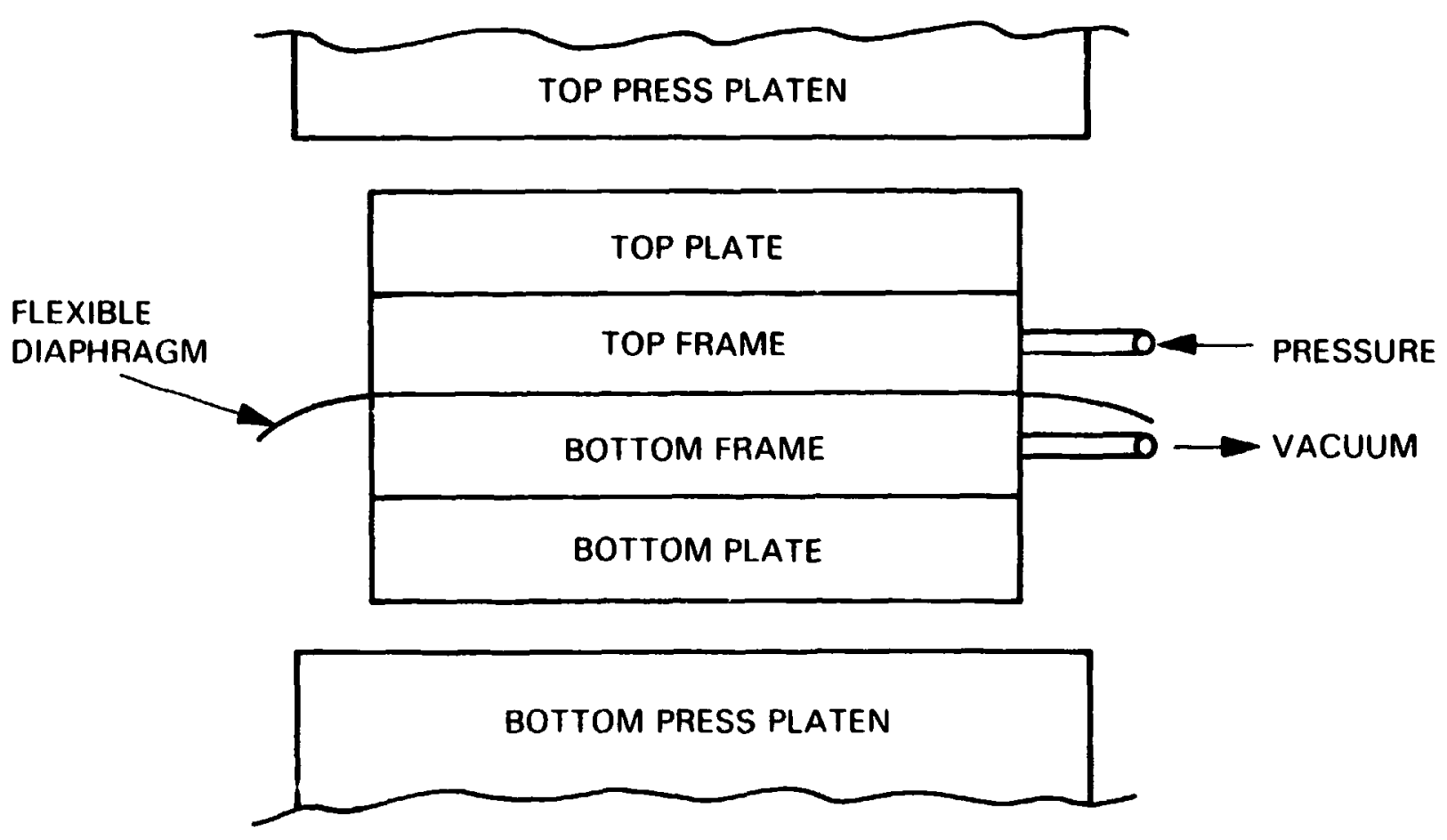

Figure 6. Vacuum-Bag Fixture Heated in Hydraulic Press

After the $10-\mathrm{min}$ dwe 11 at $150^{\circ} \mathrm{C}$, the laminator can be removed from the heating press and permitted to cool in still air. When a temperature of about $40^{\circ} \mathrm{C}$ is reached, the vacuum in the lower cavity mav be released, and the completed module may be removed from the laminator.

Modules prepared by the proceding process have been fully cured, and are bubble-free and of good appearance. No evidence of cell damage has been noticed.

Laboratory testing has not been done to investigate the effects on cure, if any, of the rate of temperature increase that the module assemblv experiences during heating. The average EVA heating rate in this process is about $4^{\circ} \mathrm{C} / \mathrm{min}$.

The laboratory process described above evolved from efforts to achieve E.A module fabrication bv a fast, reproducible process that would not damage solar cells nor incorporate bubbles, voids, or other defects that could be nuclei for module failure or problems. During the development of the EVA lamination process, two problems of significance, trapped bubbles and failure of the EVA to cure, were encountered, which necessitated detailed studies (References 3 and 4 ) of EVA cure technology and an understanding of the origin and elimination of trapped bubbles (i.e., two sources: trapped air, and volatiles from peroxide decomposition). 


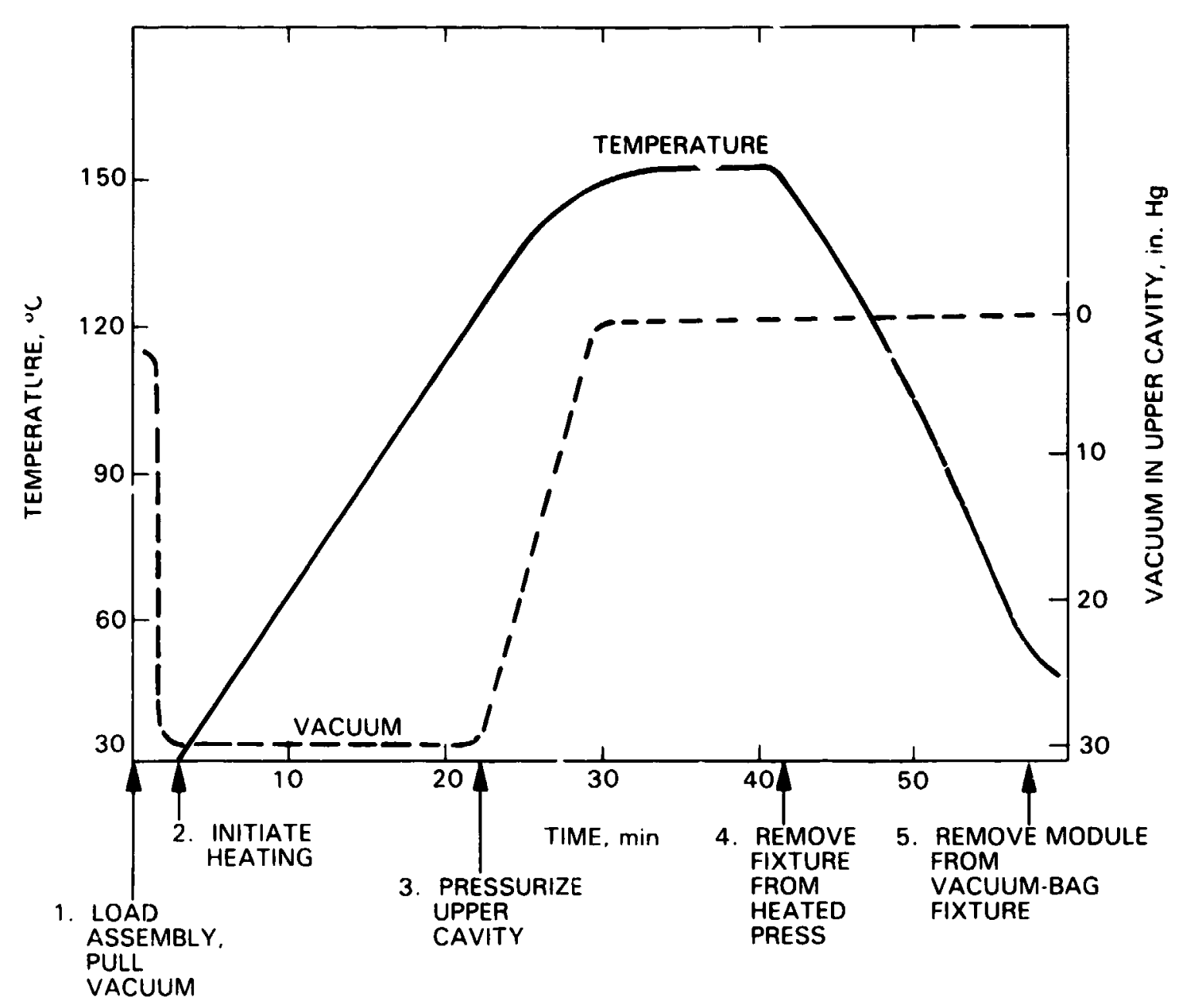

STEPS:

1. LOAD PREASSEMBLED MODULE INTC VACUUM-BAG FIXTURE AND PUMP BOTH CAVITIES DOWN TO $30 \mathrm{in}$. Hg FOR AT LEAST $5 \mathrm{~min}$.

2. LOAD FIXTURE INTO PREHEATED PLATEN PRESS TO HEAT AT APPROXIMATE RATE OF $4^{\circ} \mathrm{C} / \mathrm{min}$ BOTH CAVITIES ARE KEPT UNDER FULL VACUUM.

3. AT A TEMPERATURE OF $120^{\circ} \mathrm{C}$, THE PRESSURE OF THE UPPER CAVITY IS GRADUALLY INCREASED TO ROOM PRESSURE OVER AN 8 TO 10-min PERIOD.

4. THE FIXTURE IS LEFT IN THE PRESS FOR 10 mın AFTER REACHING A TEMPERATURE UF $150^{\circ} \mathrm{C}$. THEN REMOVED WITH THE LOWER CAVITY STILL UINDER VACIJUM.

5. THE MODULE CAN BE REMOVED FROM THE VACUUM-BAG FIXTURE AFTER COOLING FOR ABOUT 10 TO $15 \mathrm{~min}$.

Figure 7. Module Fabrication: Temperat'.re-Piessure Schedule 
ORIGINAL PAGE IS

OF POOR QUA.ITY

Table 6. Properties a ${ }^{2}$ Elvax 150 and Cured A-9918 EVA

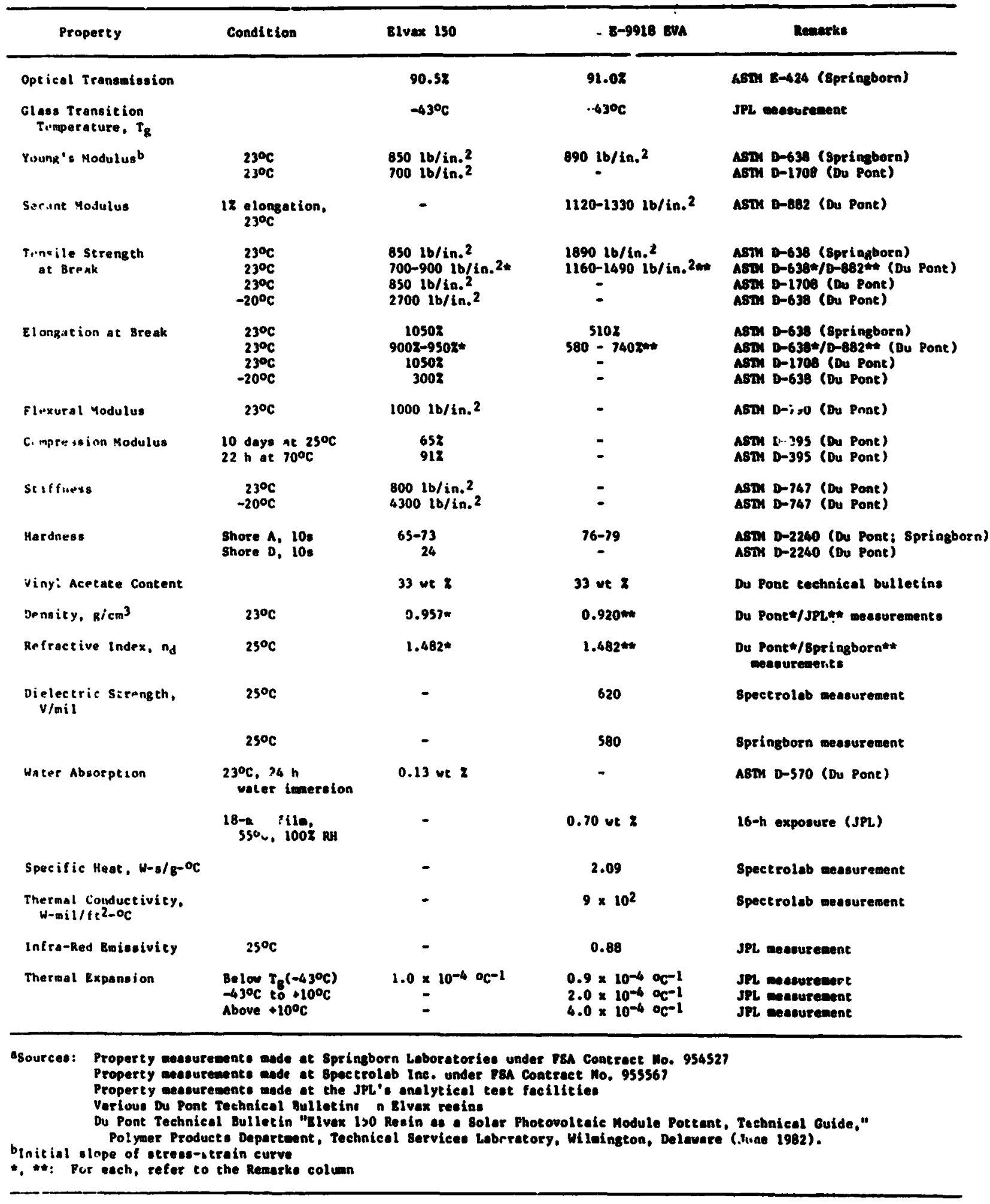


Lesaons learned from the laboratory development indicate that an industrial-scale EVA lamination method must:

(1) Prevent exposure of the EVA during heating to atmospheric oxygen, which was found to interfere chemically with the cure.

(2) Hold the module components physically in place (above $70^{\circ} \mathrm{C}$, and before cure above $120^{\circ} \mathrm{C}$ to tough elastomer, the EVA is in a fluid state).

(3) Apply uniform pressure over the surface area of the module during processing.

(4) Maintain constant vacuum for air and gas removal.

(5) Use air-release spacers (e.8.. Craneglas) in the module assembly to facilitate tocal air removal from module interfaces.

The degree of cure (gel content) of the EVA may be determined by a simple laboratory r: ocedure:

(1) Remove a small piece of cured EVA (1 to 2 g) and weigh on an analytical balance to three decinal places.

(2) Place the specimen in $100 \mathrm{ml}$ of toluene and heat to $60^{\circ} \mathrm{C}$ for 3 hours.

(3) Pour the mixture through a piece of weighed filter paper to catch the gel fraction and permit it to drain completely.

(4) Dry the filter prper and gel íraction at $60^{\circ} \mathrm{C}$ for 3 to 4 hours (no odor of toluene solvent should remain).

(5) Weigh to thrie decimal places and subtract the waight of the filter paper.

(6) The gel content is calculated as:

t gel $=\frac{\text { we ight of EVA residue from toluene }}{\text { we ight of or iginal f.VA specimen }}$

(7) EVA with gel content over $65 \%$ may be regarded as acceptably cured. The described laboratory lamination process has resulted in gel content consistent ly ranging from $75 \%$ to $80 \%$.

\section{MATERIAL PROPERTIES}

A data base of material properties of cured A-9918 EVA is emerging as the material is more intensively studied. Accumulated data on material properties are compiled in Tahle 6, slong with material properties of the uncured and uncompounded $?^{\prime} q x$ 150, for comparison. The quoted properties for cused A-9918 EVA have been .icumulated over time as needs arose for various 
FSA contractors and JPL in-house studies, and in general are distributed throughout a plethora of contractor and JPL documents, and in a recently published Du Pont technical bulletin. The primary sources are listed in the footnote of Taule 6. The properties of Elvax 150 are extracted from Du Pont technical bulletins for that product.

The major effects of crosslinking Elvax 150 are an increase in tensile strength and hardness, and a decrease in elongation-at-break and in density (Table 6). There is a slight increase in optical transmission and Young's modulus. All other properties measured in common are essentially unaffected by crosslinking. Figure 8 is a plot of the optical transmission of cured A-9918 EVA over the wavelength region from $390 \mathrm{~nm}$ to $1105 \mathrm{~mm}$, as reproduced from a Du Pont technical bulletin.

The dynamic mechanical properties of uncured Elvax 150 and cured A-9918 EVA were measured at $110 \mathrm{~Hz}$ on a Rheovibron-dynamic test machine. Dynamic modulus and loss tangent as a function of temperature are plotted in Figures 9 and 10, respectively. The melting of uncured Elvax 150 to a fluid state is observed (Figure 9) to occur around $75^{\circ} \mathrm{C}$ to $80^{\circ} \mathrm{C}$. After curing, the melting of Elvax 150 is prevented (Figure 9). The property of Elvax 150 of becoming fluid at $75^{\circ} \mathrm{C}$ to $80^{\circ} \mathrm{C}$ is why it is important to ensure adequate EVA cure. Without it, EVA in a module application would liquefy and flow at temperatures above $75^{\circ} \mathrm{C}$ to $80^{\circ} \mathrm{C}$.

Tables 7 and 8 are water-related properties of EVA resins reproduced from technical bulletins for those products. Table 7 is a tabulation of water-absorption values of four EVA resins varying in vinyl acetate content, including Elvax 150. In general it is observed that water absorption decreases with decreasing vinyl acetate content. Table 8 is a tabulation of water-vapor-transmission rates for four EVA resins, over a resin density range from 0.930 to $0.945 \mathrm{~g} / \mathrm{cm}^{3}$. Since resin densitv increases with increasing vinyl acetate content (see Table 7 and Figure 11), these data indicate that water-vapor-transmission rates increase with increasing vinyl acetate content. The data could be extrapolated to a resin density of $0.957 \mathrm{~g} / \mathrm{cm}^{3}$ which is the density of Elvax 150, and therefore an estimate of water-vapor transmission rates for that material could be made.

\section{CHEMICAL STRUCTURE OF ELVAX 150 EVA}

This section describes a speculation on the chemical structure of Elvax 150 EVA. A fundamental understanding of its chemical structure can aid in the interpretation of the behavior of material properties that can result from crosslinking and outdoor weathering, and in the selection of potentially more effective anti-oxidants and UV stabilization additives.

EVA resins are reported (Reference 16) to be semicrystalline polymers, with the level of crystallinity being related to the vinyl acetate content. This same reference reports that at and above about $45 \mathrm{wt} \%$ vinyl acetate content, the EVA copolymers become completely amorphous. Elvax 150 with a vinyl acetate content of 33 wt \% (Table 6) is therefore semicrystalline, and it is speculated that crosslinking of the Elvax 150 disrupts the crystallinity, resulting in either a completely amorphous copolymer or one with substantially reduced crystallinity content. 


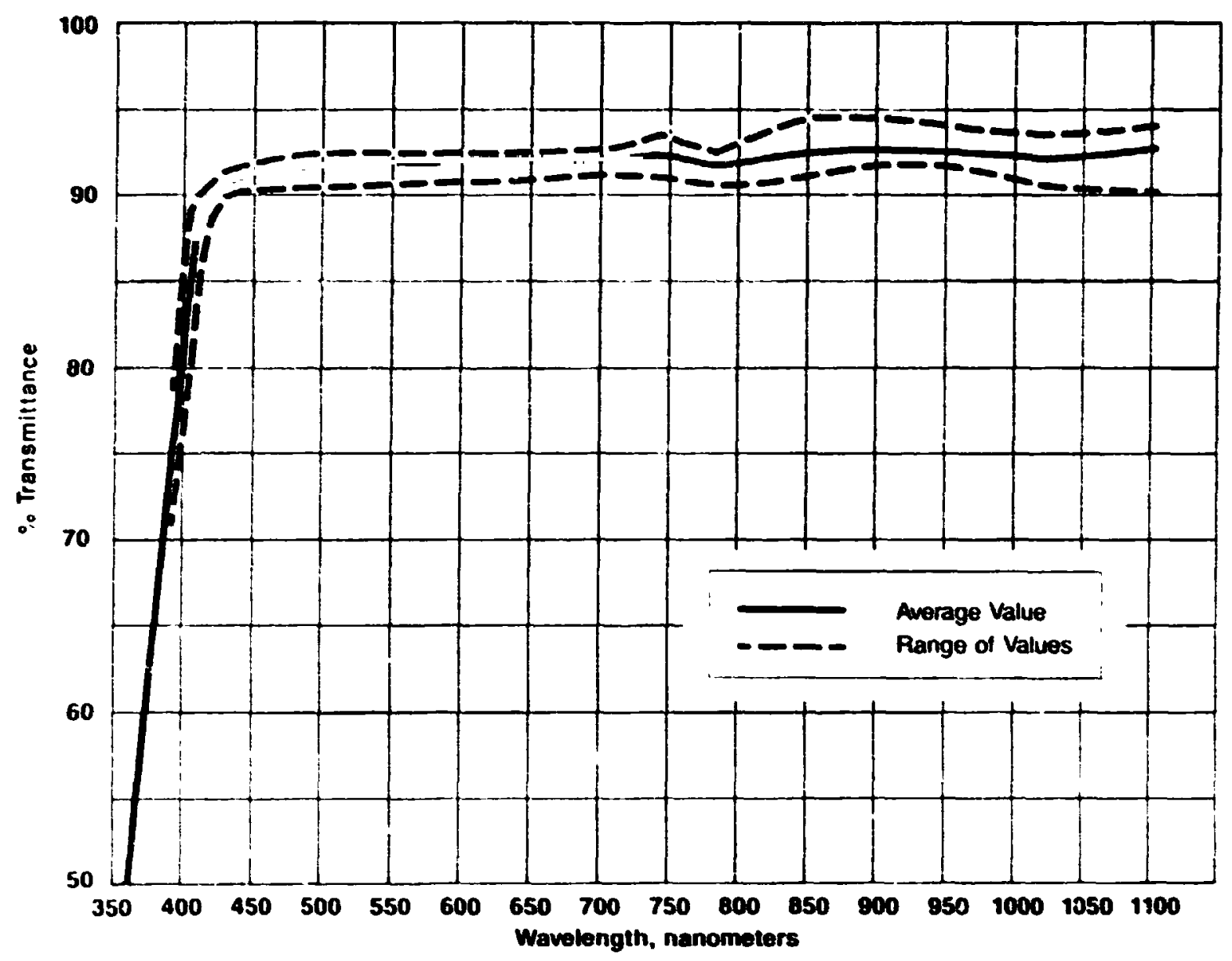

Figure 8. Average Solar Transmittance of Cured EVA A-9918 (390-1105 nm)*

Evidence for this speculation is found to a lesser extent in the slight increase in optical transmission of cured Elvax 150 , but is found primarilv in the substantial reduction in density, from $0.957 \mathrm{~g} / \mathrm{cm}^{3}$ to $0.920 \mathrm{~g} / \mathrm{cm}^{3}$. ordinarily, elastomeric and rubbery materials experience a slight increase in densitv when crosslinked (Reference 17), but Elvax 150's density decreased when crosslinked. It is believed that the density reduction results from the elimination or reduction of crustallinitv when the Elvax 150 is crosslinked.

This observation of a reduction in the density of Elvax 150 upon crosslinking also enables a furtiner speculation about the chemical structure of EVA copolymer resins. Figure 11 is a plot of the room-temperature densities of Elvax EVA resins versus wt\% vinyl acetate content, as extracted from Du Pont technical bulletins for Elvax products. The essentiallv linear plot extrapolates to a densitv near $0.92 \mathrm{~g} / \mathrm{cm}^{3}$ at 0 we s vinyl acetate content, which is coincidental, but is not the explanation for the same density value acquired by the crosslinked Elvax 150. As described below, the extrapolated density

* Renroduced from Du Pont Technical Bulletin "Elvax 150 Resin as a Solar Photovoltaic Module Pottant, Technical Guide," Polvmer Products Department, Technical Services Laboratorv, Wilmington, Delaware, June 1982 . 


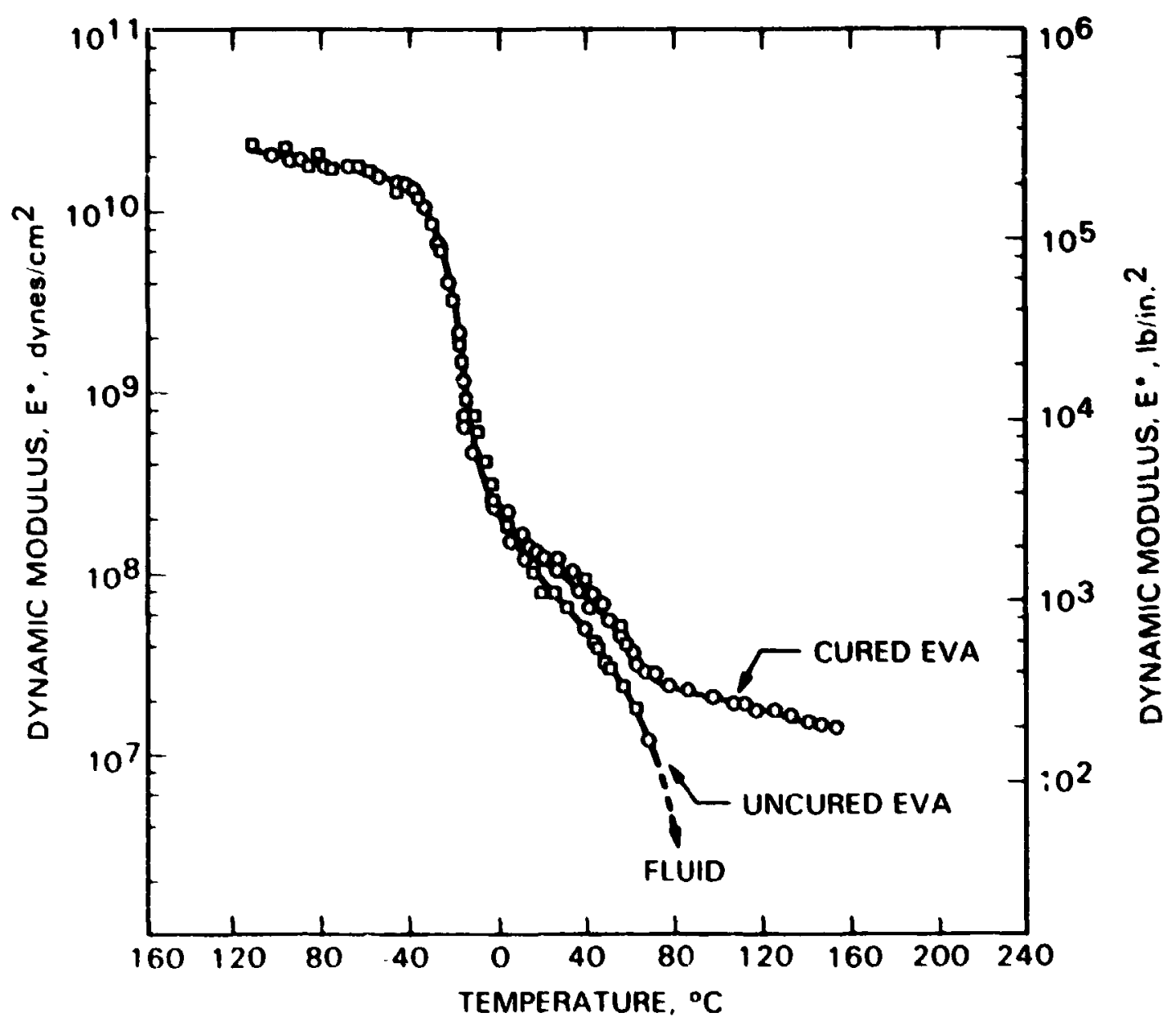

Figure 9. Dvnamic Modulus (E) of Ethvlene Vinvl Acetate A-9918 at a Frequencr of $110 \mathrm{~Hz}$

value of near $0.92 \mathrm{~g} / \mathrm{cm}^{3}$ in this speculation is to be associated with mediumdensitv semicrvstalline polvethvlene. Further, the densitv plot of Figure 11 when extrapolated linearly to $100 \%$ vinvl acetate does not predict a densitv of 1.19. which is that of pure nolvinul acetate at room temperatures.

But the densitv plitt of Figure 11 , and the densitv reduction after having cured Flvax 150, can be explained if it is assumed that EVA ropolvmer resins are block copolymers, having one block which is an amorphous, random copolymer of ethvlene and vinvl acetate, and the other block heing all semicrystalline polvethvlene without anv vinvl acetate component. An illustration of this speculative block copolvmer structure is shown in Figure 1?. With this block copolymer structure, the densities of the separate blocks can be estimated, followed by calculation of the density of the uncured resin and the reduced densitv of the cured F.VA resin, for comparison with the known values.

The densitv eslculations will be carried out for flvax 150, which has a composition of 67 wt $z$ ethvlene and 33 wt $\%$ vinvl acetate. The itensitv of $a$ block copolumer can he estimated from the following equation:

$$
P_{P}=W_{B 1} \rho_{B 1}+W_{B 2} P_{B ?}
$$


ORia:iris He is

OF POOR QUALITY

Table 7. Water Absorption of Various Du Pont Ethylene Vinyl Acetate (Elvax) Resins ${ }^{b}$

\begin{tabular}{lccc}
\hline $\begin{array}{l}\text { Elvax } \\
\text { Resin }\end{array}$ & $\begin{array}{c}\text { Density, } \\
\mathrm{g} / \mathrm{cm}^{3}\end{array}$ & $\begin{array}{c}\text { Vinyl Acetate } \\
\text { Content, }\end{array}$ & $\begin{array}{c}\text { Water rontent, } \\
\text { wi } \%\end{array}$ \\
\hline Elvax 150 & 0.957 & 33 & 0.13 \\
Elvax 260 & 0.955 & 28 & 0.13 \\
Elvax 360 & 0.950 & 25 & 0.11 \\
Elvax 460 & 0.941 & 18 & 0.07 \\
\hline $\begin{array}{l}\text { aASTM D-570, 24-h water immersion at 230 } \\
\text { bSource: Du Pont technical bulletins for Elvax EVA resins }\end{array}$ \\
\hline
\end{tabular}

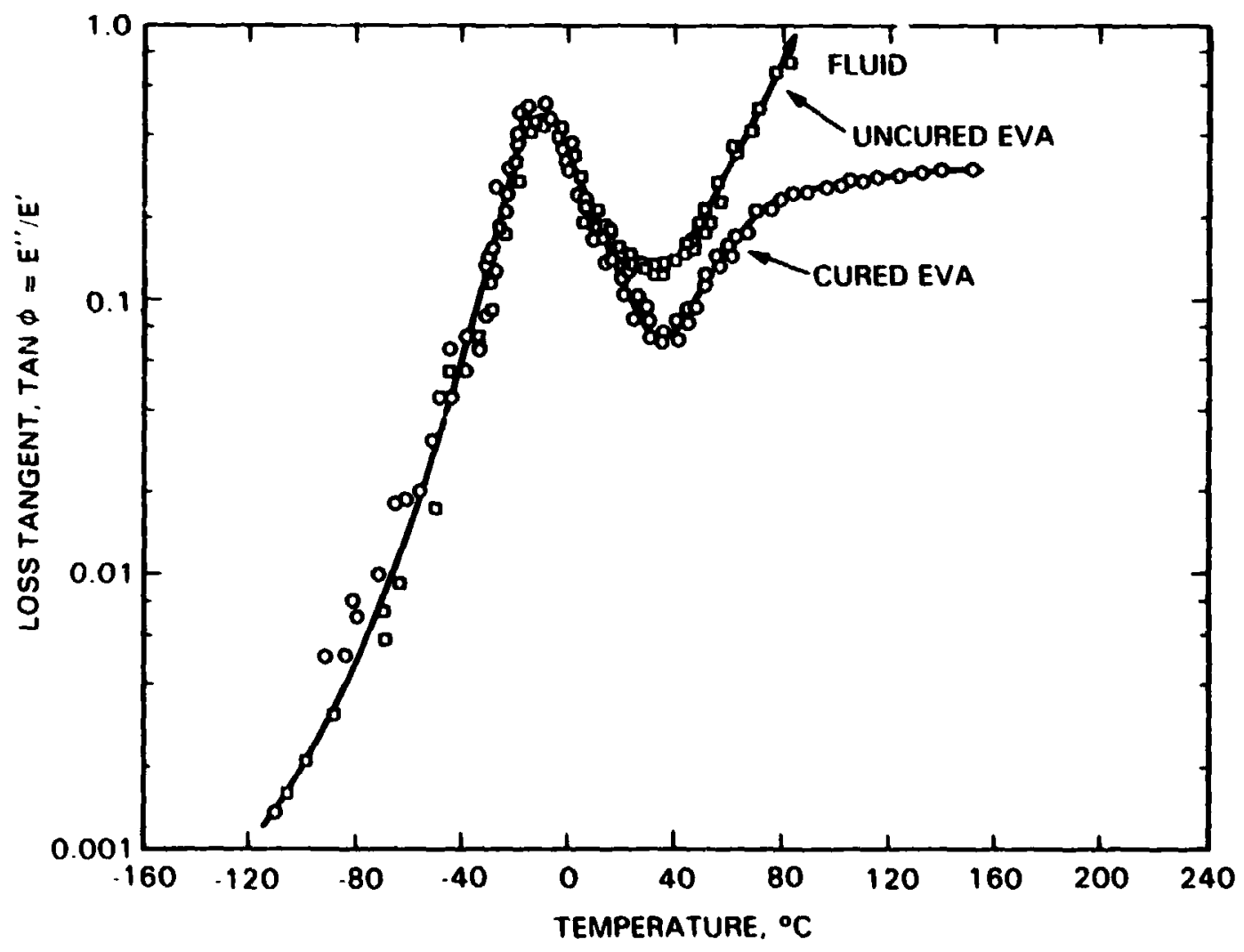

Figure 10. Loss Tangent (Tan $\phi$ ) of Ethylene Vinyl Acetate A-9918 at a Frequency of $110 \mathrm{~Hz}$ 


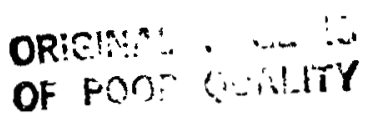

Table 8. Water-Vapor Transmission Rates (WVTR) of Ethylene Vinyl Acetate Resins ${ }^{a}$

$$
\text { WVTR in units of } \frac{\left(\mathrm{g} \mathrm{H}_{2} \mathrm{O}\right)(\mathrm{mils})}{\left(\text { in. }^{2}\right)(\mathrm{h})(\operatorname{mon} \mathrm{Hg})}
$$

\begin{tabular}{ccc}
\hline Resin Density, $\mathrm{g} / \mathrm{cm}^{3}$ & WVTR at $20^{\circ} \mathrm{C}$ & WVTR at $38^{\circ} \mathrm{C}$ \\
\hline 0.930 & $1.75 \times 10^{-5}$ & $2.79 \times 10^{-5}$ \\
0.935 & $3.40 \times 10^{-5}$ & $5.23 \times 10^{-5}$ \\
0.940 & $5.33 \times 10^{-5}$ & $7.63 \times 10^{-5}$ \\
0.945 & $7.14 \times 10^{-5}$ & $10.16 \times 10^{-5}$ \\
\hline
\end{tabular}

aSource: U.S.I. Chemicals Technical Bulletin for Ultrathene EVA Copolymers, Fourth Edition (1972).

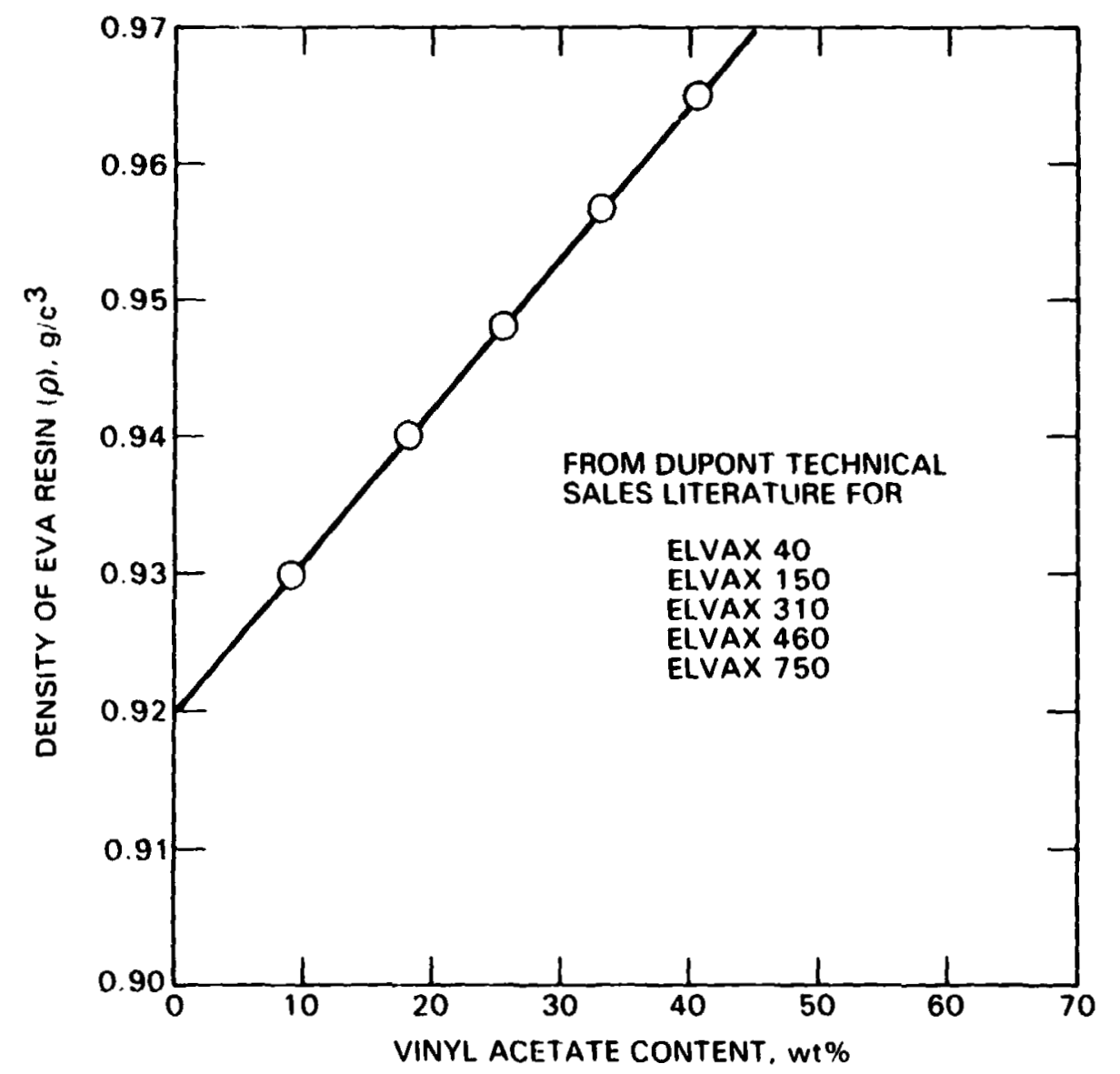

Figure 11. Densities of Elvax EVA Resins versus Vinyl Acetate Content 


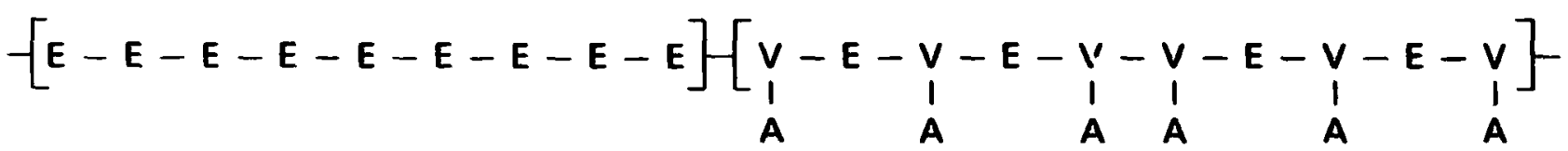

$$
\begin{aligned}
& -\left[\begin{array}{c}
\text { Semicrystalline } \\
\text { Polvethylene Block }
\end{array}\right]\left[\begin{array}{c}
\text { Amorphous Random } \\
\text { Copolymer Block }
\end{array}\right]
\end{aligned}
$$

Figure 12. Speculations on the Polymeric Structure of Elvax 150 EVA: Block Copolymer

where

$$
P_{p}=\text { density of the block copolymer }
$$

$\rho_{\mathrm{B} 1}$ and $\rho_{\mathrm{B} 2}=$ densities of Block 1 and Block 2

$W_{B 1}$ and $W_{B 2}=$ weight fraction of $B$ lock 1 and Block 2 equation:

The density of a random copolymer can be estimated from the following

$$
\rho_{c}=M_{1} \rho_{1}+M_{2} \rho_{2}
$$

where

$$
\begin{aligned}
\rho_{c} & =\text { density of the random copolymer } \\
\rho_{1} \text { and } \rho_{2} & =\text { densities of components } 1 \text { and } 2 \\
M_{1} \text { and } M_{2} & =\text { mol fractions of components } 1 \text { and } 2
\end{aligned}
$$

The density of amorphous polvethylene, which is assumed to be its physical state in the amorphous and random copolymer block, is $0.885 \mathrm{~g} / \mathrm{cm}^{3}$ (Reference 18). Further, all of the vinyl acetate in the Elvax 150 resin is assumed to be in the ccpolymer block, and none in the semicrystalline polyethylene block. Last, and because of the extrapolation of Figure 11 to a density of $0.92 \mathrm{~g} / \mathrm{cm}^{3}$ for 0 wt \% vinyl acetate, it is assumed that this is the density $\mathrm{P}_{\mathrm{B}}$ of the semicrystalline polyethylene block. With this information, and the density and composition of Elvax 150, there are sufficient data to solve Equations (1) and (2) simultaneously for all of the unknowns. The given data and the calculated unknowns are tabulated in Table 9.

These results indicate that the polyethylene block of Elvax 150 is 53 wt \% of the total resin, and the amorphous ethylene vinyl acetate block is 47 wt \% of the total resin. In turn, the composition of the amorphous ethylene/vinyl acetate block is $70 \mathrm{wt} \%$ vinyl acetate and $30 \mathrm{wt} \%$ ethylene, or 43 mol \% vinyl acetate and 57 mol \% ethylene. The density $\rho_{c}$ of the amorphous ethylene/vinyl acetate block is $1.00 \mathrm{~g} / \mathrm{cm}^{3}$. The total ethylene content distributed between the two blocks is 67 wt \% of the Elvax 150, and the vinyl acetate content found only in the amorphous block is 33 wt \% of the Elvax 150 , which was given as a known. 


\section{Cr:Ginitit p:ce is \\ of POOR Quititity}

Table 9. Composition of Elvax 150 When Assumed to be a Block Copolymer as Depicted in Figure 12

A. INPUT DATA

1. Elvax 150

2. Polyvinyl Acetate

3. Polyethylene

B. Calculated Values

1. Polyethylene Block

-- Density, $\rho_{\mathrm{Bl}}=0.92 \mathrm{~g} / \mathrm{cm}^{3}$

-- Wt fraction of resin, $W_{B 1}=0.53$

-- Mol wt $\approx 2500$

2. Ethylene/Vinyl Acetate Copolymer Block

-- Density, $P_{C}=P_{B 2}=1.00 \mathrm{~g} / \mathrm{cm}^{3}$

- Wt fraction of resin, $W_{B 2}=0.47$

-- Mol wt $\approx 2250$

a. Copolymer B: sck Composition (mol fraction):

$\begin{array}{ll}\text { Vinyl acetate: } & M_{1}=0.43 \\ \text { Ethylene: } & M_{2}=0.57\end{array}$

b. Copolymer Block Composition (wt fraction):

Vinyl acetate: $X_{1}=0.70$

Ethylene: $\quad X_{2}=0.30$

Numerically the equation for the density $P_{c}$ of the random and amorphous ethylene vinyl acetate block is

$$
\rho_{c}=(0.43)(1.19)+(0.57)(0.885)=1.00 \mathrm{~g} / \mathrm{cm}^{3}
$$

and numerically the equation for the Elvax 150 resin density $P_{p}$ is

$$
P_{\mathrm{p}}=(0.47)(1.00)+(0.53)(0.92)=0.957 \mathrm{~g} / \mathrm{cm}^{3}
$$

It was speculated above that the crosslinking of Elvax 150 reduces or eliminates crystallinity, as reflected in the reduction of the polymer density from $0.957 \mathrm{~g} / \mathrm{cm}^{3}$ to $0.92 \mathrm{~g} / \mathrm{cm}^{3}$. Since all of the polymer crystallinity is in the polyethylene block, and if it can be assumed that this block is rendered amorphous as a result of the steric discuption associated with crosslinking, then the density of the cured Elvax 150 can be calculated using Equation (1), using a density of $0.885 \mathrm{~g} / \mathrm{cm}^{3}$ for the resultant amorphous polyethylene block. Substituting a value of 0.885 for 0.92 in Equation (4) yields

$$
P_{p}=(0.47)(1.00)+(0.53)(0.885)=0.92 \mathrm{~g} / \mathrm{cm}^{3}
$$


This calculated value of $0.92 \mathrm{~g} / \mathrm{cm}^{3}$ matches the measured density value for the crosslinked Elvax 150 .

The essentially linear relationship between density and vinyl acetate content (Figure 11) can provide another speculation about the general copolymer characteristics of Elvax EVA resins, if it can be assumed that they all contain a semicrystalline polyethylene block of density $0.92 \mathrm{~g} / \mathrm{cm}^{3}$. Equation (1) can be rearranged to the following form:

$$
\rho_{\mathrm{p}}=\frac{\mathrm{V}}{\mathrm{X}_{1}}\left(\rho_{\mathrm{B} 2}-0.92\right)+0.92
$$

where

$$
\begin{aligned}
\rho_{\mathrm{B} 2}= & \text { density of the amorphous ethylene/vinyl acetate block } \\
V= & \text { vinyl acetate content in the total resin, wt } \% \\
\mathrm{X}_{1}= & \begin{array}{l}
\text { vinyl acetate contert in the amorphous ethylene/vinyl } \\
\text { acetate block, wt } \%
\end{array}
\end{aligned}
$$

and 0.92 is the density of the semicrystalline polyethylene block. Equation (6) states that for constant $X_{1}$, and therefore also for constant $P_{B 2}, a$ straight-line relationship between $\rho_{p}$ and $V$ is predicted, with an intercept at $\mathrm{v}=0$ of 0.92 .

Up to 40 wt \% vinyl acetate content, a straight-line relationship, is observed in Figure 11, which suggests for these Elvax EVA resins that the composition of the ethylene/vinyl acetate block in all these resins is essentially constant at 70 wt \% vinyl acetate and 30 wt \% ethylene, and that therefore the vinyl acetate content $V$, based on the total resin, is regulated by variations in the weight-fraction mix of the two blocks.

The glass transition temperature $\left(T_{g}\right)$ of random copolymers can be estimated with the following equation (Reference 19):

$$
\frac{1}{T_{g}}=\frac{W_{1}}{T_{g 1}}+\frac{W_{2}}{T_{g 2}}
$$

where

$$
\begin{aligned}
T_{g} & =g \text { lass transition temperature of the copolymer, } o_{K} \\
T_{g l} \text { and } T_{g_{2}} & =g \text { lass transition temperatures of components } 1 \text { and } 2 \\
W_{1} \text { and } W_{2} & =\text { weight fraction of components } 1 \text { and } 2 \text { in the copolymer }
\end{aligned}
$$

If it is assumed that Elvax 150 is indeed a random copolymer of ethylene and vinyl acetate rather than a block copolymer, as described above, its estimated $\mathrm{T}_{\mathrm{g}}$ using Equation $(7)$ is $-95^{\circ} \mathrm{C}\left(178^{\circ} \mathrm{K}\right)$ :

$$
\frac{1}{T_{g}}=\frac{0.61}{148}+\frac{0.33}{302} ; T_{g}=-95^{\circ} \mathrm{C}\left(178^{\circ} \mathrm{K}\right)
$$




\section{ORIGINAL PAGE IS \\ OF POOR QUALITY}

where, in Equation (8), 0.67 and 148 are respectively the weight fraction of polyethylene in Elvax 150 and its $T_{g}$ in $o_{K}$, and 0.33 and 302 are respectively the weight fraction of polyvinyl acetate in Elvax 150 and its $T_{g}$ in ${ }^{K}$.

Examination of the dynamic mechanical property curves (Figures 8 and 10) reveals no evidence of any transition event at or near $-95^{\circ} \mathrm{C}$. On the other hand, if a block copolymer structure is assumed, then two glass transition events would be expected, one for the polyethylene block and another for the amorphous, random-copolymer ethylene vinyl acetate block. Using Equation (7), the glass transition temperature of the amorphous, random-copolymer block can be estimated as follows:

$$
\frac{1}{T_{g}}=\frac{0.3}{148}+\frac{0.7}{302} ; T_{g}=-43^{\circ} \mathrm{C}\left(230^{\circ} \mathrm{K}\right)
$$

where 0.3 and 0.7 are respectively the weight fractions of ethylene and of vinyl acetate in the block. The estimated $\mathrm{T}_{\mathrm{g}}$ of $-43^{\circ} \mathrm{C}$ matches the temperature associated with a major glass transition temperature event observed in the dynamic mechanical property curves. Evidence for the glass transition temperature of the polyethylene block, $-125^{\circ} \mathrm{C}$, is not observed in the dynamic mechanical rroperty curves, as the starting test temperature for these data measurements, unfortunate $1 y$, was $-115^{\circ} \mathrm{C}$. In general, however, it is known that the glass transition temperature of polyethylene is not readily identifiable from dynamic testing (Reference 20).

Elvax 150 is basically a hot melt, having a melting point in the temperature range of $75^{\circ} \mathrm{C}$ to $80^{\circ} \mathrm{C}$. Accepting that Elvax 150 is a block copolymer, as just described, then this melting point can be assigned to melting of the semicrystalline polyethylene block. Figure 13 is a plot of the melting point $\left(\mathrm{T}_{\mathrm{m}},{ }^{\circ} \mathrm{C}\right)$ of polyethylene as a function of its average molecular weight as reproduced from Reference 21 . Based on this plot, the average molecular weight of the polyethylene block in Fivax 150 can be estimated at about 2000 to 3000 , which corresponds to a melting point in the range of $75^{\circ} \mathrm{C}$ to $80^{\circ} \mathrm{C}$. With this information, and the compositional distribution of ethylene and vinyl acetate in Elvax 150, a molecular weight of about 2250 can be estimated for the amorphous, random-copolymer block.

These efforts to determine the chemical structure of Elvax 150, and perhaps of EVA resins in general, can provide a fundamental input for aiding interpretation of material properties, and changes in material properties that may result from outdoor exposure in a module application. In addition, structural information can be beneficial in guiding research directed toward identifying or developing potentially better antioxidant and UV stabilization systems. For example, the service longevity of Elvax 150 may be enhanced by use of a combination of antioxidants and other stabilization additives, each set of additives optimally selected for a specific block in the Elvax 150.

\section{E. PRIMERS AND ADHESIVES}

The first primer system developed (Reference 22) for EVA was for bonding the cured A-9918 EVA to glass. The composition of this primer is given in Table 10, and is referred to as the glass/EVA primer. Experimental quantities of this primer are available from Springborn Laboratories under the designation A-11861 Primer. As described in more detail below in this 
OR: $: \therefore$ is
OF. POOR Q: $: \therefore$ iTY

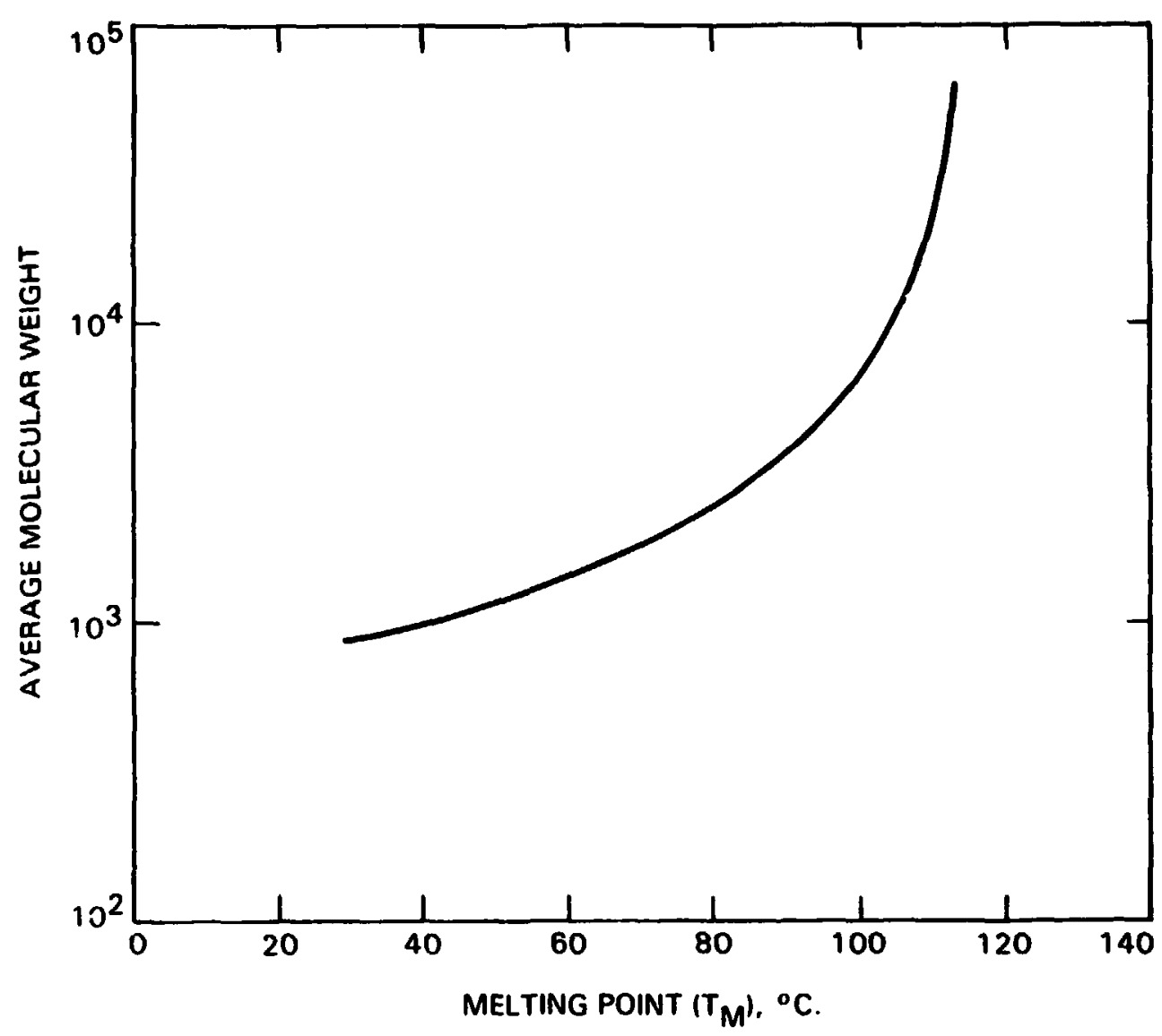

Figure 13. Melting Point vs Molecular Weight of Polyethylene

section, this glass/EVA primer resulted in very strong bonding to glass, under both dry and wet exposure conditions. This favorable experience with glass prompted a follow-on evaluation of this primer system for bonding EVA to many other materials. Imediate difficulties, however, were then encountered with copper, aluminum, Tedlar fluorocarbon films, and Scotchpar polyester films.

As copper and aluminum represent potential low-cost metals for solar-cell metallization, emphasis was next given to developing a primer system for bonding cured A-9918 EVA to these two metals. The composition of this metal/EVA primer is given in Table 10. Another primer system had to be developed separately for bonding cured A-9918 EVA to polyester films such as Scotchpar (3M Co.) and Mylar (Du Pont). The composition of this primer, referred to as the polyester/EVA primer, is given in Table 10.

For bonding cured A-9918 EVA to Tedlar film products, Du Pont identified an acrylic contact adhesive designated 68040 . As supplied by Du Pont, the acrylic adhesive system is a solution in toluene, which is spread on the Tedlar surface and then allowed to dry. The resultant adhesive coating is dry and nontacky, and the coated Tedlar film can be wound and unwound.

Experimental work with this adhesive system has used a coating thickness of 0.3 to $0.4 \mathrm{mil}$, which has yielded acceptable performance. The contact 
Table 10. Glass, Metal, and Polyester Primers, and Tedlar Adhesive for A-9918 EVA

\begin{tabular}{|c|c|}
\hline Component & $\begin{array}{l}\text { Composition, } \\
\text { parts by wt }\end{array}$ \\
\hline \multicolumn{2}{|l|}{ Glass Primer (A-11861): } \\
\hline z-6030 silane (Dow Corning) & 9.0 \\
\hline Benzyl dimethyl amine & 1.0 \\
\hline Lupersol 101 (Pennwalt) & 0.1 \\
\hline Methanol & 90.0 \\
\hline \multicolumn{2}{|l|}{ Metal Primer: } \\
\hline Z-6030 silane (Dow Corning) & 99 \\
\hline Zinc chromate powder & 100 \\
\hline Benzyl dimethyl amine & 1 \\
\hline Methano1 & 300 \\
\hline \multicolumn{2}{|l|}{ Polyester Primer: } \\
\hline z-6040 silane (Dow Corning) & 5 \\
\hline Resimene 740 (Monsanto) & 95 \\
\hline Isopropanol & 300 \\
\hline
\end{tabular}

Tedlar Adhesive:

68040 Acrylic contact adhesive (Du Pont)

adhesive develops its bonding qualities at the high temperature of the EVA lamination cycle. A PV manufacturer may coat Tedlar optionally with the adhesive as part of its manufacturing operation; or arrange to have the coating put on by an independent coating vendor.

Table 11 is a master table of adhesive bond-strength measurements accumulated to date for cured EVA bonded to a variety of materials, with 


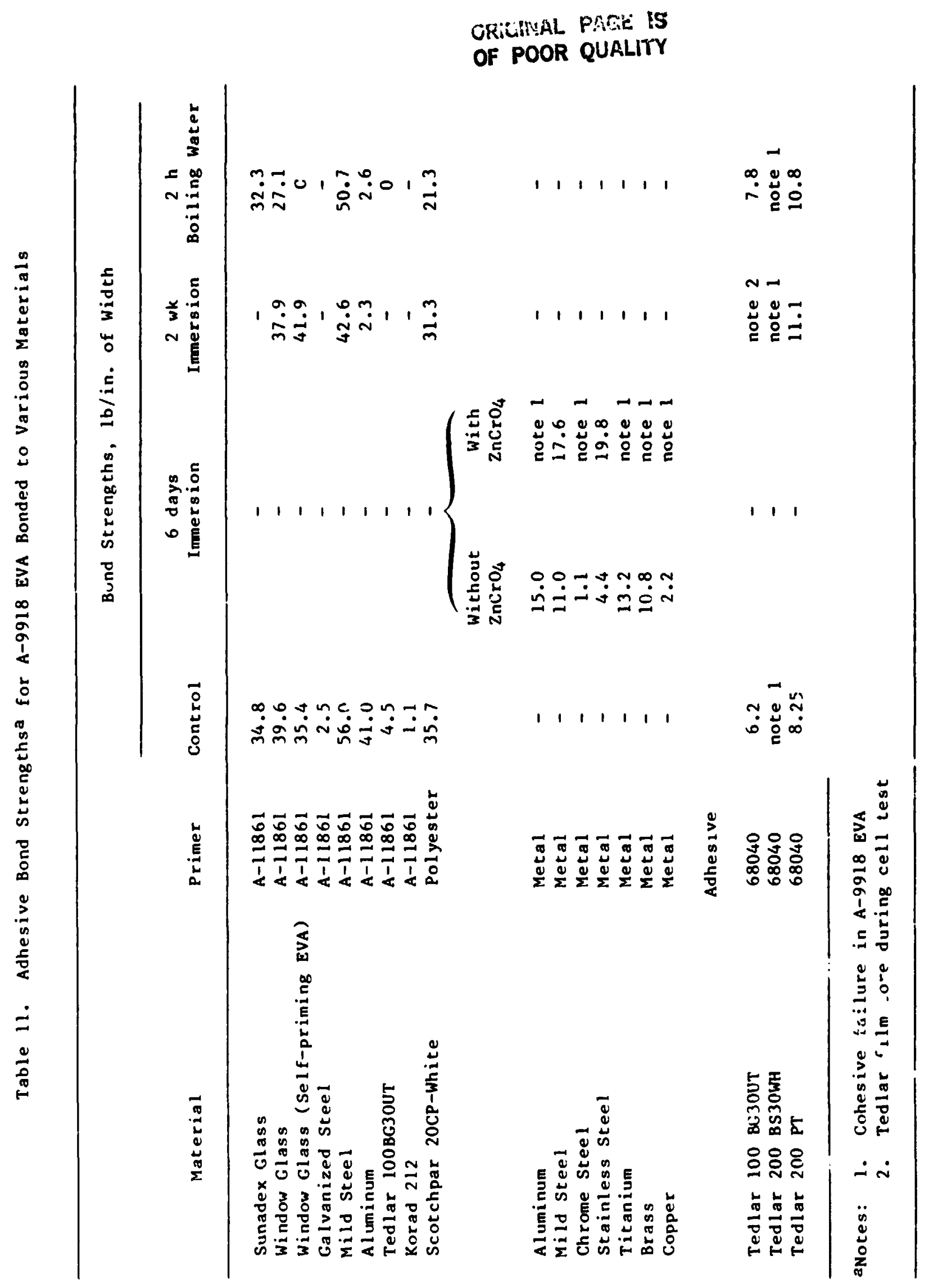


various combinations of the primers and the 68040 adhesive. These data, generated at different experinental laboratories, result from a similar experimental pattern: measurement of control values at ambient conditions, followed by measurement (again at ambient conditions) of specimens that have been immersed in water maintained at room temperature, and of spccimens imnersed in boiling wacer. The singular exception is work carried out with the metal/EVA primer system. For this system, metal/EVA bonded test specimens were prepared both with and without the inc chromate powder in the priner formulation. Bond-strength measurements for these test specimens were made

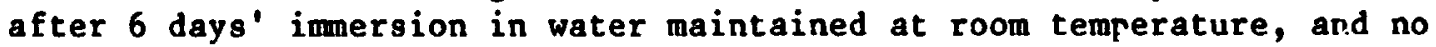
control values were measured.

The glass/EVA primer $(A-11861)$ can be used optionalıy as either a wipe-on primer or as a conpounding additive to generate a self-priming-EVA. If used as a compounding additive, the methanol solvent is not used, and the three-component mixture is blended into the EVA at a concentration of 1.0 wt \%. A corsept used in the formulation of this primer is that the addition of a small amount $o^{\circ}$ the Lupersol 101 peroxide causes a localized generation of active free radicals during the heating and curing $r f$ the A-9918 EVA, resulting in a substantially higher crosslinking at the polymer-substrate interface.

The glass/EVA primer was tested by priming clean soda-lime glass slides with a thin layer of the primer (wiped on with a moistened pad) and air drying for $15 \mathrm{~min}$. The fully formulated EVA compound (A-99i8) was then compressionmolded and cured against the surface. The resulting specimen was tested for peel strength by ASTM D-903. The results (Tabie II) were excellent, yielding an average peel strength of $39.6 \mathrm{lb} / \mathrm{in}$. of width. Duplicate specimens placed in boiling water for 2 hours and evaluated by the same process vielded an average peel strength of $27 \mathrm{lj} / \mathrm{in}$. of width, still excellent adhesion. A quantity of the prime- formulation was prepared without the alcohol diluent and blended into the standard A-9918 EVA formulation at ? wt \% to test the self-priming effect. The resulting resin was chen compression-molded and cured against a clean glass slide, as before, and tested for peel strength by the same methrf. The average strength was $35.4 \mathrm{lb} / \mathrm{in}$. of width (Table 11). The bond strength of the self-priming EVA after room-tempecature water immersion for 2 wks increased from the initial value of 35.4 to $41.9 \mathrm{lb} / \mathrm{in}$. of width.

As shown in rable 11 , the glass/EVA primer not only gives excellent and di:rable bonds to regular soda-lıme (microscope slides) and low-iron (Sunadex) glass, but also is marginally effective with aluminum, and very effective with mild steel. Aluminum, primed with A-11861, gave an average dry-t,ond peel strength of $41.0 \mathrm{lb} / \mathrm{in}$. of width and the adhesion to mild steel was even higher, with an average dry strength of $56.0 \mathrm{lb} / \mathrm{in}$. of width. This is the $h i g h e s t$ bond strength found between EVA and any other material. The wet-ton' strength is excellent to mild steel and pocr to aluminum. Dry-bond strengths to Tedlar were very low, and virtually zero when wet. The A-11861 primer was essentially ineffective for copper and for Scotchpar polyester film, for both dry and wet exposure conditions. On the other hand, the polyester/EVA primer worked excellently, yielding a dry contro' value of $3 \mathrm{s.3} \mathrm{lb} / \mathrm{in}$., dropping slightly to $31.3 \mathrm{lb} / \mathrm{in}$. after 2 v'ks of room-tempeiature water imersion, and still retained a high value of $21.3 \mathrm{lb} / \mathrm{in}$. after 2 hours of immersion in hoiling water. 
The metal/EVA primer with rinc chromate powder achieved outstanding bonding of cured A-9918 EVA to aluminum and copper (Table 11), with peel testing resulting in cohesive iailure of the EVA, after 6 days of water imersion. Cohesive failure of the cured EVA also occurred for bonding to chrome steel, titanium, and hrass. The metal/EVA primer is apparently not as effective with mild steel as is the glass/EVA primer, A-11861, but the bond strength values of $\approx 17.6 \mathrm{lb} / \mathrm{in}$. is still acceptably high. With the exception of mild steel, the action of zinc rliromate on achieving substantial increases in bond strength can be observed in the performance data given in Table 11.

The two Tedlar films listed in Table 11, Tedlar 100R;30ut and Tedlar 200PT, are clear and trunsparent UV-screening films. The former is $1 \mathrm{mil}$ thick snd the latter is 2 mils thick. The third Tedlar film listed in Table 11. Tedlar 200BS30WH, is a 2-mil-thick white-pigmented film. Th. vond strength data given in. Table 11 seveal that the 68040 adhesive yielde, comparable wet and dry performance for the two UV screening films, ard yielded outstanding performance with the white-pigmented Tedlar film. Involvement of the white-pigment material in enchancing the bond strength can only be conjectured.

With all threp Tedlar films, the adhesive 68040 retained wet-bond strength, as compared with the zero bond strength of the glass/EVA primer $(A-11861)$. For the $1-m i l$ thick Tedlar 100BG30uT, the bond strength after 2 wks of room-temperature water immersion had apparently increased to a level where peel testing resulted in tearing of the Tedlar film.

One of the low-cost structural panel materials being investigated for module application is mild steel (Table 2), specifically cold-rolled mild stcel. However, the concern with this material in an outdoor application is corrosion. An approach to corrosion prevention is adhesively bonding white-pigmented plastic films to both surfaces of a mild-steel panel. A trial film/adhesive/priner system has evolved, which consists of the following layers of materials on mild steel:

$\begin{array}{ll}\text { Outer film } & \text { Scotchpar 20CP-White } \\ \text { Primer } & \text { polyester/EVA primer } \\ \text { Adhesive } & \text { cured A-9918 EVA } \\ \text { Primer } & \text { metal/FVA frimer } \\ \text { Pancl } & \text { mild steel }\end{array}$

Panels 0 . mild steel coated with this film/adhesive/primer system have survived more than 4,500 hours of cont inuous exposure to salt spray (ASTM B-117) without any evidence of corrosion. Unprotected mild steel, on the other hand, begins to corrode within hours after exposure to salt spray. This use of EV, as an alhesive offers another possible application area for this low-cost material in cerrestrial photovoltaic modules. 


\section{F. ENCAPSULATION ENG INEERING}

An engineering analysis of encapsulation systems (Reference 9) was done to assess the effect of pottant properties and thickness on solar-cell stresses induced by thermal expansion and panel-bending loads. One of the goals of this analysis is a generation of guidelines for minimum material usage for each of the construction elements.

The analyses for structural adequacy showed that the thermal expansion or wind deflection of photovoltaic modules can result in the development of mechanical stresses in the encapsulated solar cells sufficient to cause cell breakage. The thermal stresses are developed from differences in the thermal expansion properties of the load-carrying panel and the solar ceils. However, the analysis also showed that solar-cell stresses generated by either thermal expansion differences or wind deflection can be reduced by increasing the thickness $t$ of the pottant, or by using pottants with lower Young's modulus E. In other words, the analysis indicates that the load-carrying panel can be considered to be the generator of stress, and that the pottent acts to dampen the transmission of the stress to the cells.

Computer predictions of the specific values of $t$ and $E$ have been carried out to date only for the analysis of a 4-ft square module, predicting the stress distribution throughout a module when deflected by a $100-\mathrm{mi} / \mathrm{h}$ wind ( $50 \mathrm{lb} / \mathrm{ft}^{2}$ loading pressure), and predicting the stress distribution throughout a module set up by thermal-expansion stresses when the module is heated or cooled through a temperature difference of $100^{\circ} \mathrm{C}$. For both cases, a zero-stress state was assumed to exist throughout the module before deflection or thermal stressing.

Construction details of the module that was analyzed are:

(1) Module dimension: $1.2-\mathrm{m}(4 \times 4-\mathrm{ft})$ square.

(2) Solar cells: $10 \times 10-\mathrm{cm}$ square $(4 \times 4$ in. $\times 0.015$ in. thick).

(3) Spacing between solar cells: $1.3 \mathrm{~mm}(0.050 \mathrm{in.})$.

For the deflection analysis, the perimeter of the module is assumed to be constrained and restricted from being twisted or deflected out of planarity. Thus, as the module deflects under a uniform wind-pressure load, the edges always remain in the plane of the undeflected, initially flat module.

Structural analysis was done on three encapsulation systems: glass superstrate, wooden substrate and mild-steel substrate designs. The structural proper: ies oi the giass, wood, and mild steel were fixed input data. The pottant was treated as a variable, expressed in terms of its Young's modulus $E$, and thickness $t$. Output data consisted of the prediction of the maximum stress developed in the solar cells, calculated as a function of pottant modulus and pottant thickness between the cells and the structural panel. The structural analysis model is summarized in Figure 14 and the structural properties used as fixed input data are given in Table 12. For the silicon solar cells, the maximum allowable stress in bending is $80001 \mathrm{~b} / \mathrm{in.}{ }^{2}$, and the maximum allowable stress in tension (thermal expansion) is $5000 \mathrm{ib} / \mathrm{in} .{ }^{2}$ (References 8,9 , and 23). 
OF POCR Quin?

Table 12. Structural $\mathrm{Pa}$. reters Used in Encapsulation Engineering Computer Studi.

\begin{tabular}{llcc}
\hline Material & $\begin{array}{c}\text { Modulus, } \\
1 \mathrm{~b} / \text { in. }^{2}\end{array}$ & $\begin{array}{c}\text { Thermal } \\
\text { Coefficient, } \\
\text { in./in. }{ }^{\circ} \mathrm{C}\end{array}$ & $\begin{array}{c}\text { Allowable } \\
\text { Stress, } \\
\text { lb/in }\end{array}$ \\
\hline Tempered Glass & $10 \times 10^{6}$ & $9.2 \times 10^{-6}$ & 13,000 \\
Wood & $0.8-1.2 \times 10^{6}$ & $7.2 \times 10^{-6}$ & 2500 \\
Silicon & $17 \times 10^{6}$ & $4.4 \times 10^{-6}$ & $5000-8000$ \\
Steel & $30 \times 10^{6}$ & $10.8 \times 10^{-6}$ & 28,000 \\
\hline
\end{tabular}

The computer-predicted results are shown in Figures 15 through 20 . The computer-predicted data traces for a Young's modulus E of $10001 \mathrm{~b} / \mathrm{in} .^{2}$ essentially corres;ond to those of cured A-9918 EVA, which has a Young's modulus $\mathrm{E}$ of (nominaliy) $890 \mathrm{lb} / \mathrm{in} .{ }^{2}$ ar $25^{\circ} \mathrm{C}$ (Table 6).

For the thermal stress analyses $\left(\Delta T=100^{\circ} \mathrm{C}\right)$ (Figures 15,16 , and 17), the computer predictions indicate that a minimum thickness of 2 mils of EVA is

INPUT PROPERTIES

MODULUS

TENSILE STRENGTHS

THERMAL-EXPANSION COEFFICIENT

PANEL THICKNESS

SOLAR-CELL ALLOWABLE STRESSES

(a) DEFLECTION, $8000 \mathrm{lb}$ in. 2

(b) LINEAR (THERMAL), $5000 \mathrm{lb}$ in. ${ }^{2}$

\section{PRIMARY OUTPUT}

GENERATED STRESS IN SOLAR CELLS AS A FUNCTION OF POTTANT THICKNESS BETWEEN CELLS AND STRUCTURAL PANEL

\section{MODULE DESIGN FEATURES}

$1.2 \times 1.2-\mathrm{m}$ SQUARE

$10 \times 10-\mathrm{cm}$ SQUARE CELLS

1.3-mm CELL SPACING

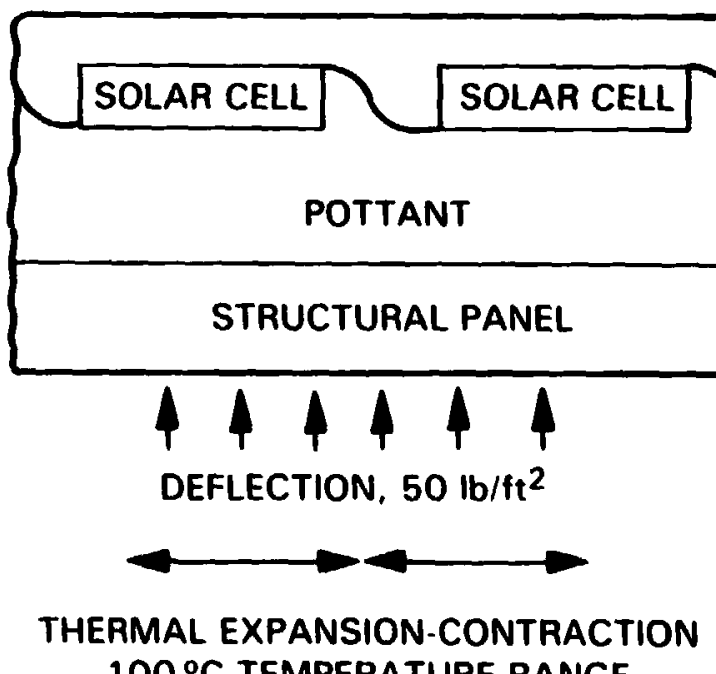

$100^{\circ} \mathrm{C}$ TEMPERATURE RANGE

Figure 14. Structural Analysis: Deflection and Thermal Stress 


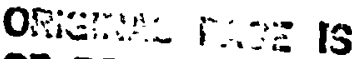

OF. PCOR QUñLitY

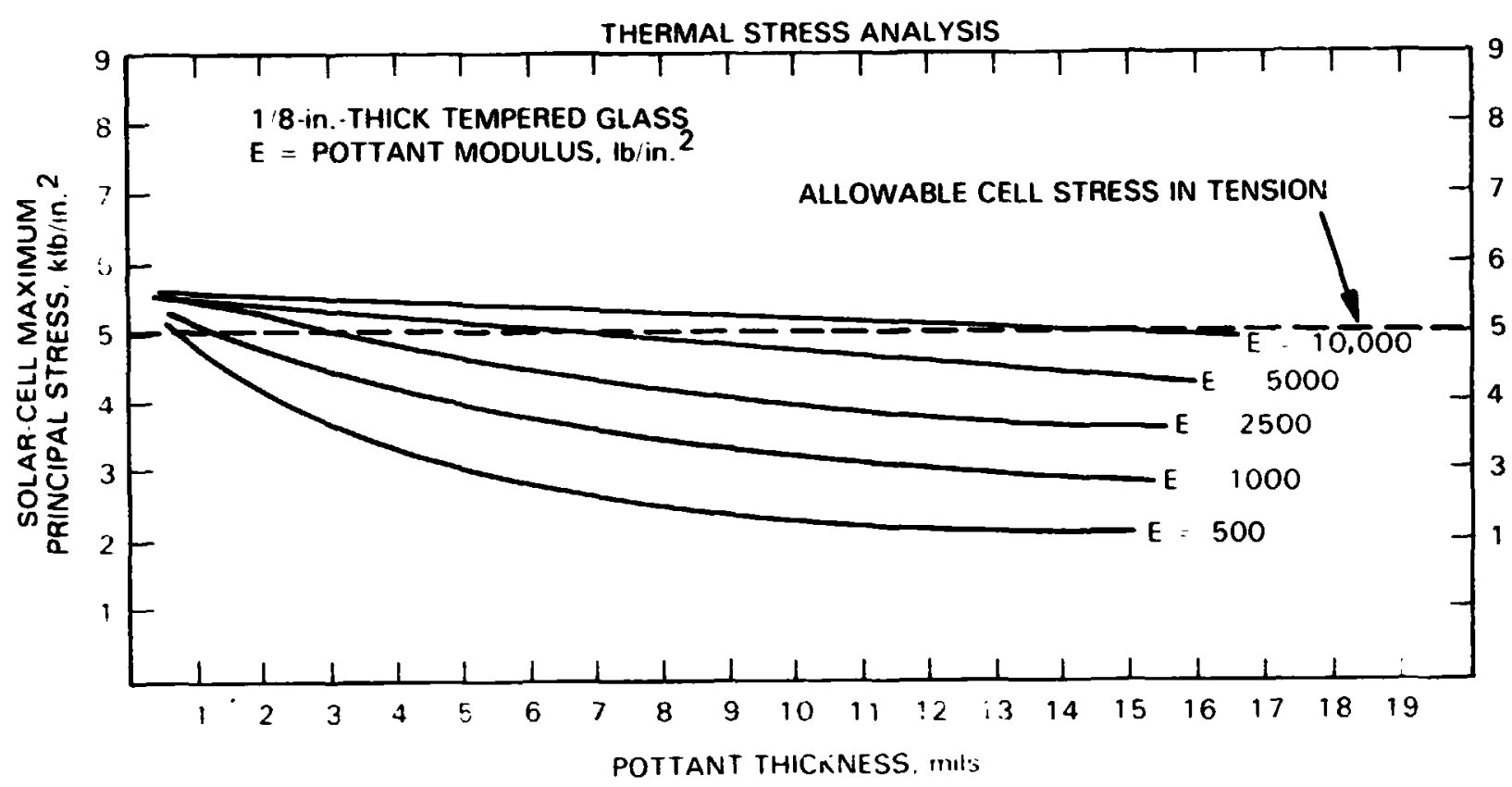

Figure 15. Computer-Predicted Stresses in Encapsulated Silicon Solar Cells Resulting From Thermal Expansion Differences in a Glass-Superstrate Module for $\Delta \mathrm{T}$ of $100^{\circ} \mathrm{C}$

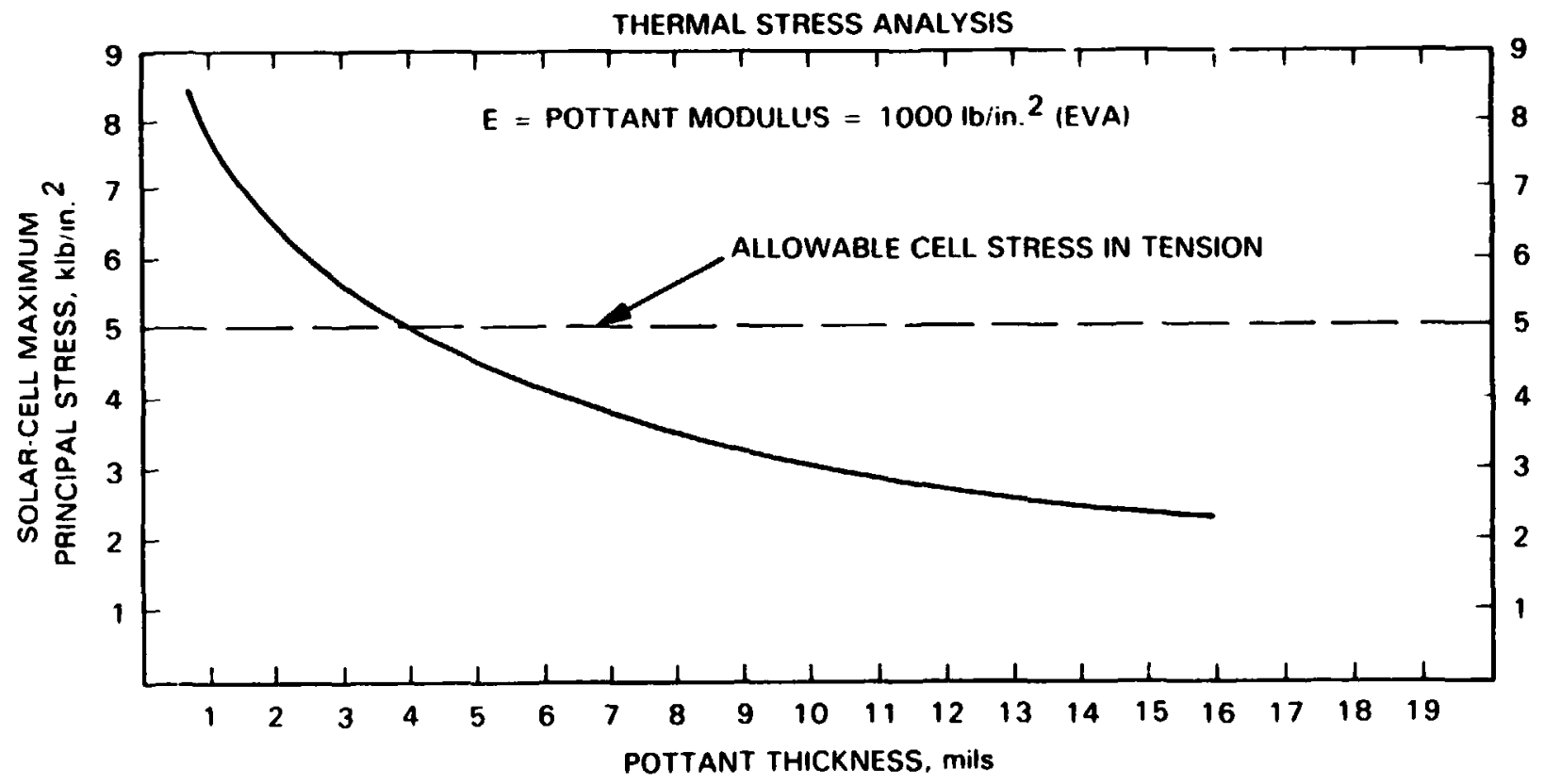

Figure 16. Computer-Predicted Stresses in Fncapsulated Silicon Solar Cells Resulting From Thermal Fxpansion Differences in a Steel-Substrate Module for $\Delta T$ of $100^{\circ} \mathrm{C}$ 


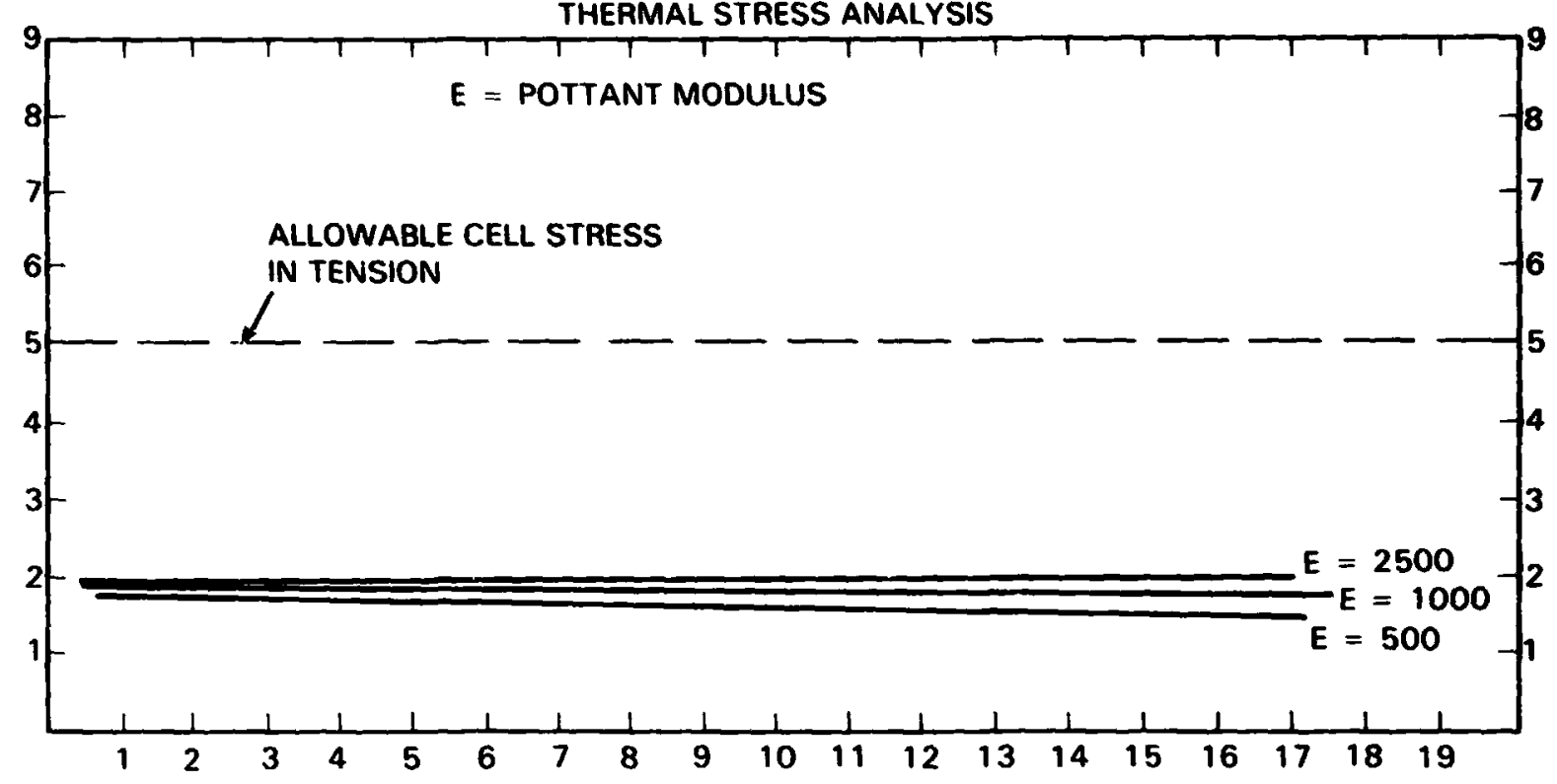

POTTANT THICKNESS, mils

Figure 17. Computer-Predicted Stresses in Encapsulated Silicon Solar Cells Resulting From Thermal Expansion Differences in a Wooden-Substrate Module for $\Delta \mathrm{T}$ of $100^{\circ} \mathrm{C}$

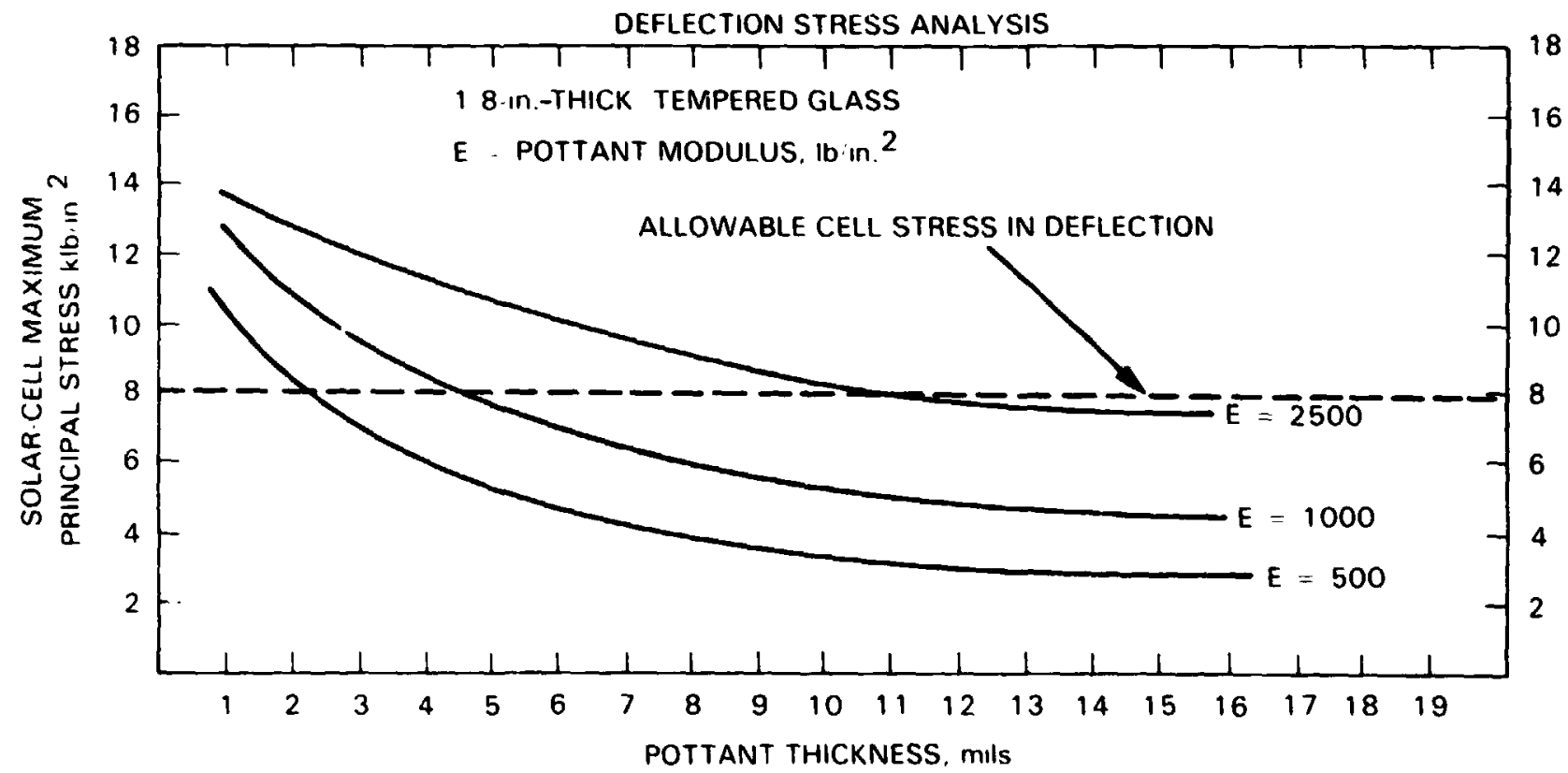

Figure 18. Computer-Predicted Stresses in Fncapsulated Silicon Solar Cells Resulting From Deflection of a 4- $\mathrm{ft}$-Square GlassSubstrate Module Under a Uniform I,oad of $501 \mathrm{~b} / \mathrm{ft}^{2}$ 


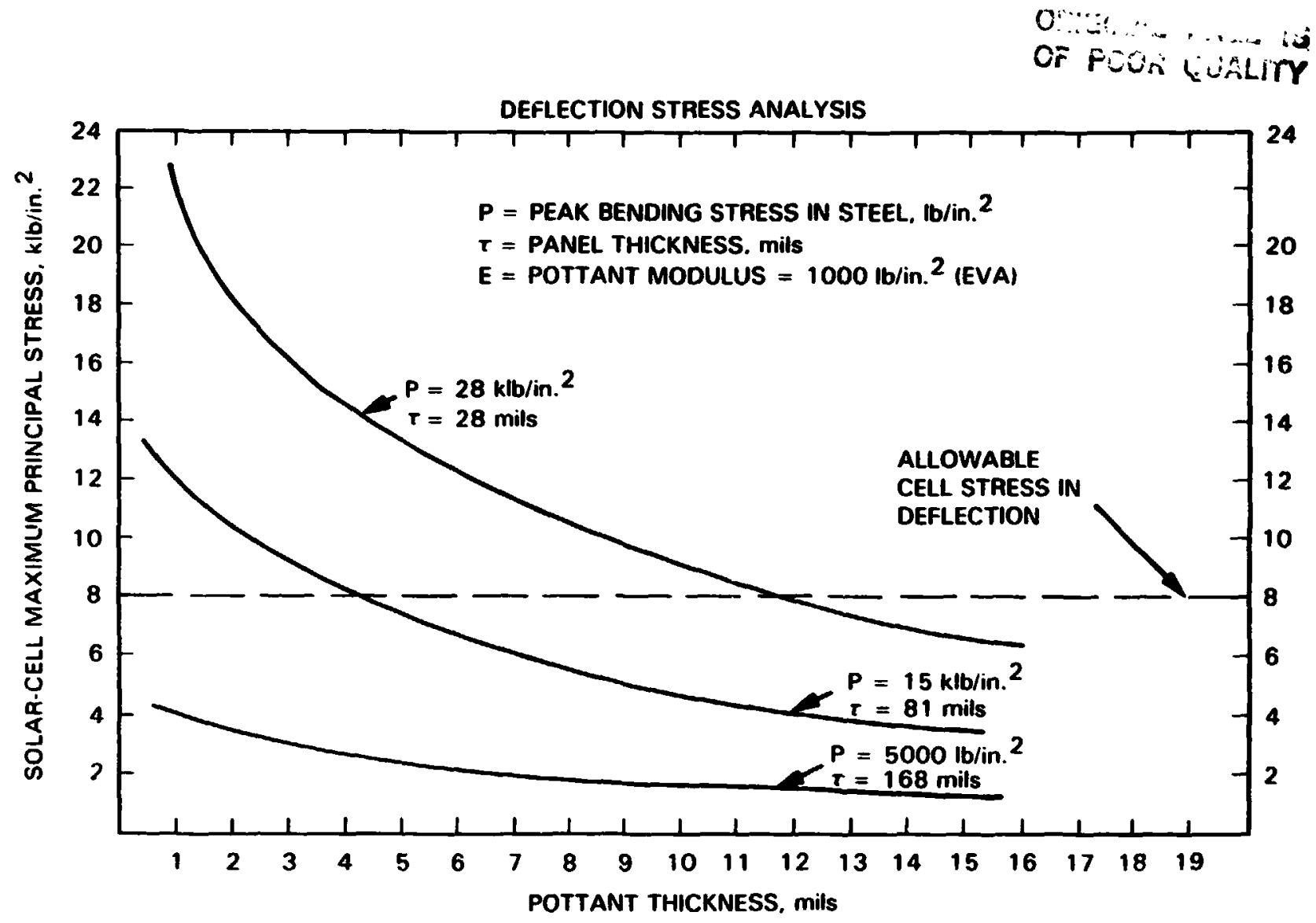

Figure 19. Computer-Predicted Stresses in Encapsulated Silicon Solar Cells Resulting from Deflection of 4-ft-Square Steel Panels of Th: ee Different Thicknesses Under a Uniform Load of $50 \mathrm{lb} / \mathrm{ft}^{2}$

required between the solar cells and a glass superstrate panel, and that a minimum thickness of $4 \mathrm{mils}$ of EVA is required between the solar cells and a mild-steel substrate panel. These minimum thickness requirements are typically satisfied in a practical module, as the commercial thickness of EVA laminating film is $18 \mathrm{mils}$, which thins to about $10 \mathrm{mils}$ in the module after lamination (References 5, 6, and 8). For the wooden-substrate panel (Figure 17) the closer match of their thermal expansion coefficients (Table 12) virtually eliminates any dependence on the EVA pottant thickness to reduce solar-cell stresses. Technology is being developed to virtually eliminate stresses due to expansion and contraction caused by humidity.

For wind deflection of a 1/8-in. thick glass superstrate module (Figure 18), a minimum thickness of 4 to $5 \mathrm{mils}$ of EVA is required. This is thicker than needed for thermal stressing (Figure 15), and therefore deflection, rather than thermal stressing, controls the pottant-thickness requirements for a glass-superstrate module. Figure 19 plots the computer-predicted stresses in solar cells for mild-steel pane $1 \mathrm{~s} 28 \mathrm{mils}, 87 \mathrm{mils}$, and $168 \mathrm{mils}$ thick. As the steel panels become thicker, their stiffness against wind deflection increases, thus reducing the thickness requirements of the EVA pottant. Deflection analysis of a 1/8-in.-thick wooden-substrate module indicated that a wooden panel of this thickness would fracture under a wind loading of $501 \mathrm{~b} / \mathrm{ft} 2$, but that a 1/4-in. wooden panel would not. However, for a 1/4-in.-thick wooden panel, a 


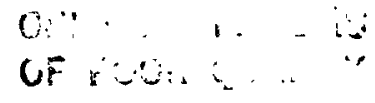

minimum thickness of $13 \mathrm{mils}$ of EVA is required, which exceeds the typical thickness of $10 \mathrm{mils}$ ordinarily achieved in present-day modules when using an 18 -mil laminating film. This deflection analysis indicates that a wooden substrate panel would have to be ribbed on its back side in order to increase its structural stiffness against wind deflection. The computer analysis of a ribbed, 1/8-in.-thick wooden panel design is shown in Figure 20, which indicates that this design approach results in sufficient panel stiffness to virtually eliminate any dependence on the EVA to reduce solar-cell stresses.

Further analysis of these computer results indicaced that all of these data traces could be merged into reduced-variable master curves (Reference 24), which revealed that the pottant's ability to dampen sular-cell stresses is, in general, directly related to the ratio of its thickness to modulus, $t / E$. Using the data for the wind deflection of glass-superstrate modules as an illustration (Figure 18 ) the $t / E$ ratio associated with the maximum allowable solar-cell stress of $8000 \mathrm{lb} / \mathrm{in.} 2$ is about 222 ; e.g.,

$$
\frac{500}{2.25}=\frac{1000}{4.5}=\frac{2500}{11.25}=222
$$

This capability of expressing the structural engineering requirements of a pottant in a simple ratio of thickness to modulus enables a cost-comparison basis for candidate pottant materials. For example, compared to EVA, a higher-costing pottant with a higher Young's modulus would be much more costly to use, for reasons of both higher materials cost and the need for greater thickness. On the other hand, a higher-costing pottant having a lower Young's modulus may be just as cost effective because of an allowed reduced thickness.

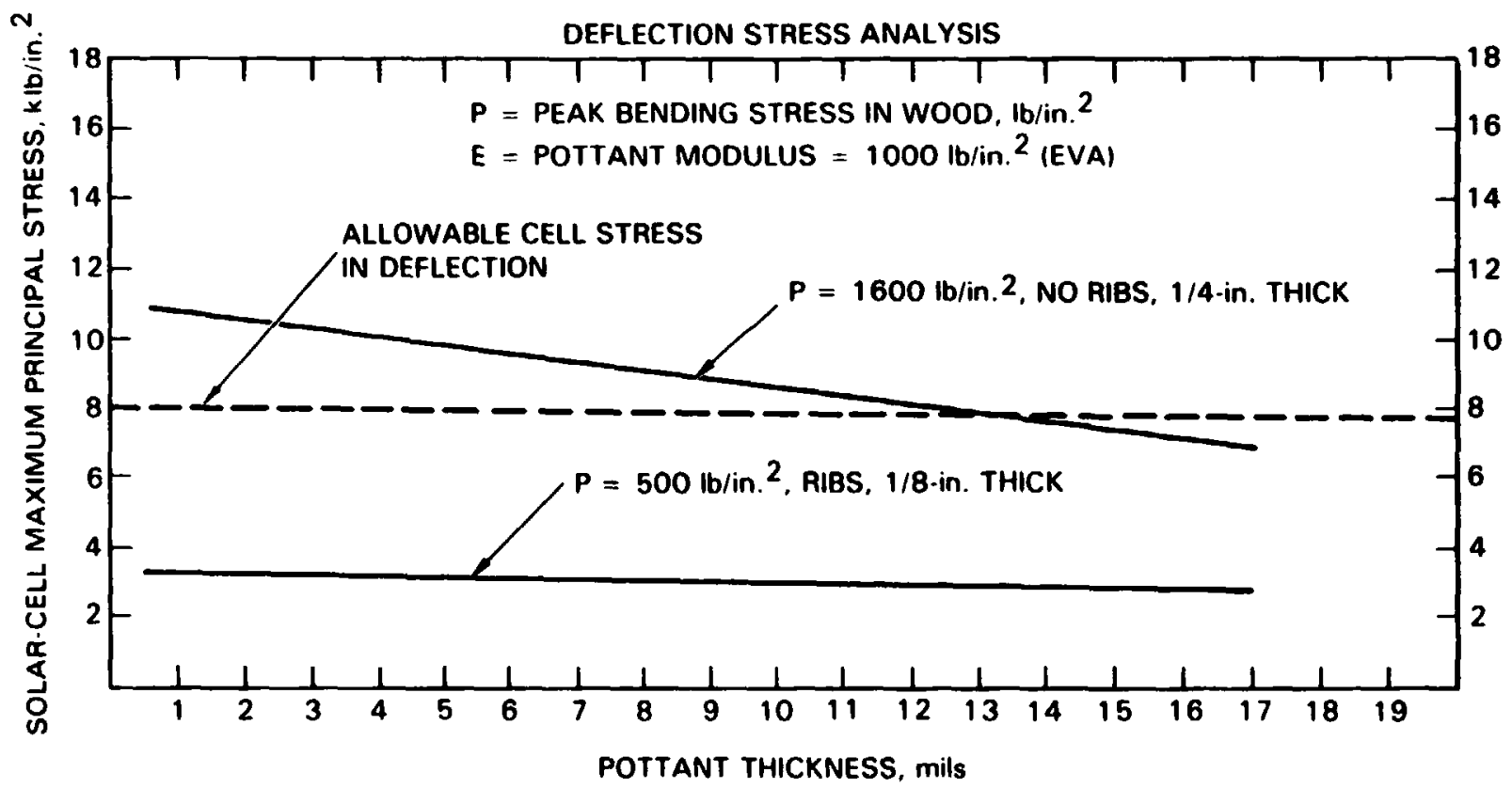

Figure 20. Computer-Predicted Stresses in Encapsulated Silicon Solar Cells Resulting from Deflection Under a Uniform Load of $501 \mathrm{~b} / \mathrm{ft}^{2}$ of an Unribbed, 4-ft-Square, 1/4-in.-Thick Hardboard, and a Ribbed, 4-ft-Square, 1/8-in.-Thick Hardboard 


\section{G. EVA AGING STUDIES}

This discussion is divided into four parts. The first part describes those functional properties of pottant materials identified to date as critical to module performance and life. The upper and lower bounds on these properties as currently perceived are described, and therefore an assessment of the allowable magnitude of the changes from initial values of these properties over the service life of a module can be appreciated. It is expected that additional critical properties may be identified from future aging studies or outdoor weathering experience.

The second part describes the known aging behavior of ethylene vinyl acetate resins at elevated temperatures, as reported in Du Pont technical literature for these products. The third part describes various experimental aging programs at different laboratories, and documents the aging results accumulated to date. It will be noticed that the properties being monitored for aging trends do not necessarily include all of the functional properties to be described in Part 1 . This is because the various experimental aging programs were started, and were well under way, long before the need to monitor all of these specific properties was recognized.

The fourth part is a beginning effort at generating a unifying and fundamental hypothesis of the mechanisms of EVA aging.

With respect to the weather aging of a pottant in a PV module, the module design philosophy as described in Section II is to shield or isolate the pottant from exposure to those UV wavelengths that would activate UV photooxidation of the pottant. Alternatively, the pottant could be isolated from oxygen by being used in a hermetic module having, for example, a glass-superstrate cover and a metal-foil back cover. In essence, by eliminating exposure to harmful UV wavelengths and/or oxygen, the aging behavior of a pottant should be associated with purely thermal effects, such as thermal oxidation in a non-hermetic module, or possibly thermal decomposition in a hermetic module. UV protection (isolation) in a non-hermetic PV module is to be provided by use of a UV-filtering outer cover glass or plastic film, and by the use of UV absorbers (e.g., Cyasorb UV 531) compounded into the pottant. Thus some of the issues that must be considered in any study relating to the potential service life of a pottant are:

(1) Identification for a non-hermetic design of the deleterious UV wave lengths.

(2) Permanence of the UV protection schemes.

(3) Thermal aging behavior of the pottant, including the effects of antioxidants.

The UV absorption spectra of all of the components in A-9918 EVA, including the base material Elvax 150, are given in Figure 21. The peak UV absorption for Elvax 150 occurs at about $280 \mathrm{~nm}$, and thereafter, with increasing wavelength, its UV absorption decreases, first rapidly in the range of $280 \mathrm{~nm}$ to about $310 \mathrm{~nm}$, and then very gradually to become virtually zero (non-UV-absorbing) near $360 \mathrm{~nm}$. Since only absorbed UV wavelengths can activate UV-related reactions, the absorption spectra indicate that the deleterious UV wavelengths for Elvax 150 would be those less than $360 \mathrm{~nm}$. The protective UV-absorbing additive, Cyasurb UV 531, absorbs strongly in this 


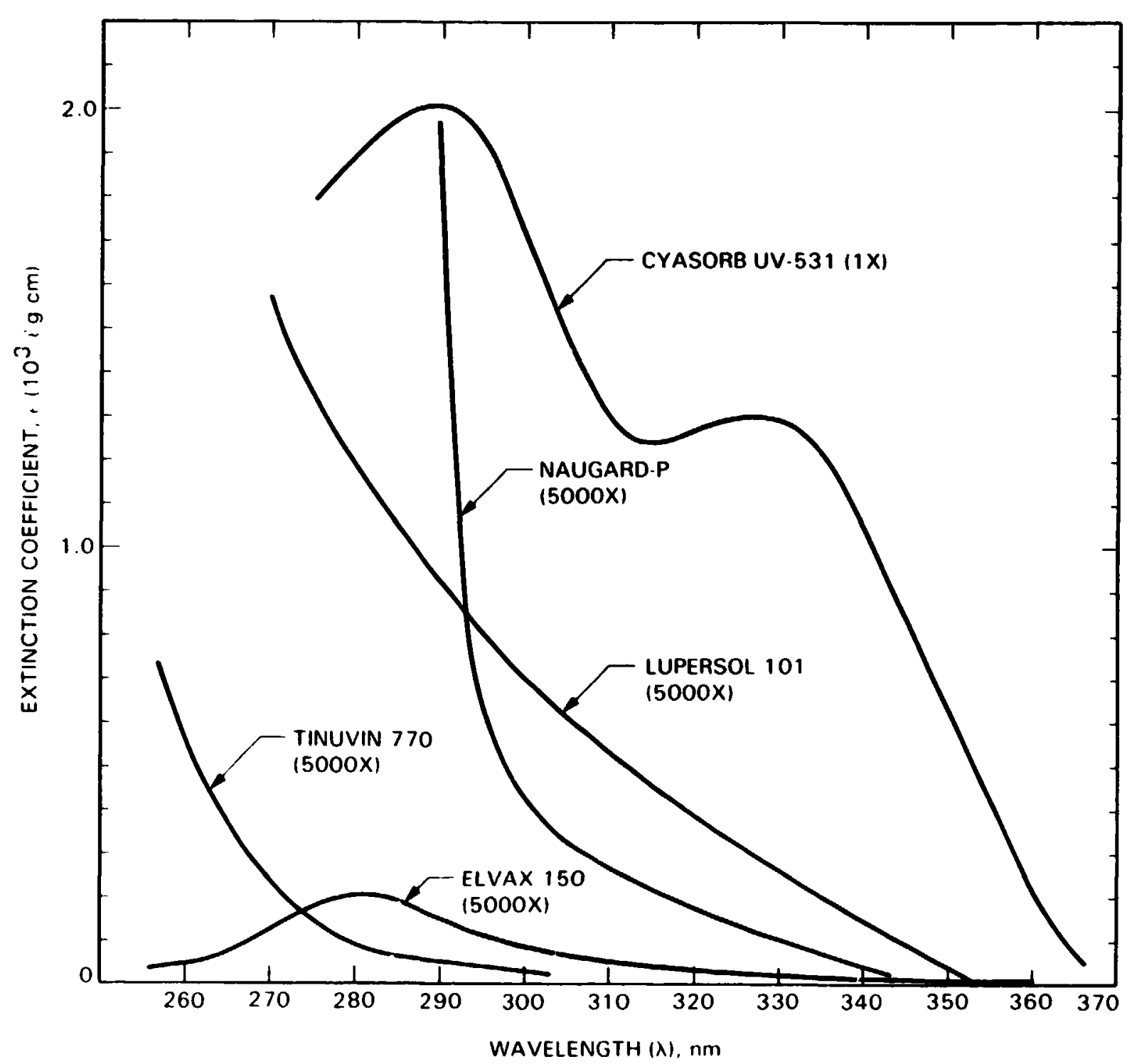

Figure 21. UV-Visible Absorption Spectra of Each Componeut in Formulated EVA A-9918

wavelength region, and therefore is expected to provide UV protection for the Elvax 150. However, since Cyasorb UV 531 is a compound of low molecular weight, a concern with this .taterial is the potential for physical loss, and therefore loss of one element of the UV-protection scheme. Physical loss of Cyasorb UV-531 could occur, for example, by migration to module surfaces, where it could then be removed by rain or lost by evaporation. The other element of the UV-protection scheme involves UV-filtering glass or plastic film front covers. Glass will typically absorb UV wavelengths at and below 310 to $315 \mathrm{~nm}$; therefore the requirement for a UV-absorbing additive such as Cyasorb UV-531 to protect EVA in the UV wavelength $r$ nge between 315 mn and $360 \mathrm{~mm}$ becomes a necessity for a non-hermetic glass module. If Cyasorb UV-531 were to become depleted, glass alone without an oxygen barrier back cover may not be adequate to protect the EVA against UV photooxidation. The candidate UV-filtering plastic films, Acrylar and Tedlar, essentially absorb \& ll UV 
wave lengths below $360 \mathrm{~nm}$ (Reference 10), and therefore offer promise of providing total UV protection for the EVA. However, if these films were to lose their UV-absorbing property gradually during outdoor service, and since all plastic films are permeable to oxygen, then a UV-absorbing additive such as Cyasorb UV-531 provides backup protection against UV photuoxidation.

Therefore, in terms of the permanence of the UV protection schemes, whether glass without an oxygen barrier back cover or plastic-film front cover, any loss of the UV-absorbing additive compounded into EVA could become critical. This consideration has prompted three basic studies:

(1) Analysis for Cyasorb UV-531 in EVA specimens being aged

(2) Investigation of aging effects on the UV-absorbing properties of the plastic films (Reference 10)

(3) Identification or development of UV-absorbing additives intrinsically resistant to physical loss (see Section III, H2).

\section{Functiona 1 Properties}

An FSA goal is to demonstrate a technical expectation of a potential 20-yr service life for terrestrial PV modules. When operating outdoors, peaking temperature levels from $55^{\circ} \mathrm{C}$ to $60^{\circ} \mathrm{C}$ can be expected for rack-mounted modules, and possibly up to $80^{\circ} \mathrm{C}$ to $85^{\circ} \mathrm{C}$ if a module is flush-mounted on an industrial or residential rooftop. As encapsulation pottants such as EVA are a component part of a module, then EVA if used must survive for $20 \mathrm{yr}$ the continued and daily thermal cycling to these peaking temperature levels. That is, what must survive for $20 \mathrm{yr}$ are those properties of FVA that are functionally required for module performance. Further, as it might be expected that these required functional properties may change through aging over $20 \mathrm{yr}$, tileir property value limits, both minimum and maximum, must be specified, which also aids in estimating allowable rates of change for comparison against actual rate of change observed in aging tests.

As of this writing, four functional properties required of a pottant such as EVA have been identified:

(1) Maximum optical transmission in the silicon solar-cell operating wavelength range of 0.4 to $1.1 \mu \mathrm{m}$.

(2) Necessary mechanical properties to maintain spatial containment of the solar cells and interconnects and to resist mechanical creep. The level of mechanical properties also must not exceed values that would impose undue mechanical stresses on the solar cell.

(3) Retention of a required level of electrical insulation to frotect against electrical b-eakdown, arcing, etc., with the associated dangers of electrical fires, and hazards to human safety.

(4) Chemical inertness with encapsulated components such as the cells, metallization, interconnects, and electrical wiring.

Freshly cured and unaged A-9918 EVA has a total integrated light transmission of near $91.0 \%$ (Table 6). The value of $91.0 \%$ is not corrected for 
surface reflection losses (Fresnel losses), which would be in the order of $8 \%$ for normal incident light. Ideally, aging should not result in a decrease in light transmission, which would then directly result in a decreased power output from the solar cells. Currently, it is a goal that the module power output shall not decrease after $20 \mathrm{yr}$ to less than $75 \%$ of the initial "raiue. Power decrease from a module can occur from light obscuration associated with surface soiling, a decline in efficiency of performance of the cells themselves resulting from corrosion effects, interconnect failures, and other circuit problems, and/or from a decrease in light transmission of the pottant (e.g., EVA) caused by aging. If, of the initial 100\% of module power output, $5 \%$ of loss is allocated to soiling (References $25,26,27$ ), $10 \%$ of 10 ss to cel1s and circuit problems, then the remaining $10 \%$ of allowed loss can be tentatively allocated to loss of light transmission of the pottant. For EVA, this would roughly amount to a decrease from an initial measured value of $91.0 \%$, to no less than $82 \%$. It is not expected that weather-caused aging would result in an increase in optical transmission.

Two mechanical properties have been identified as critical: creep and Young's modulus. With respect to creep, EVA must be cured (crosslinked) in order to develop resistance against melt, flow, and creep at service temperatures higher than $70^{\circ} \mathrm{C}$. Trial-and-error experimentation showed that EVA must be cured to a minimum gel content of $65 \%$ in order to develop creep resistance at $90^{\circ} \mathrm{C}$. The temperature of $90^{\circ} \mathrm{C}$ was adopted on the basis of a module qualificarion test developed at JPL, which thermally cycled vertically aligned modules between $-40^{\circ} \mathrm{C}$ and $+90^{\circ} \mathrm{C}$ (Reference 28). For gel content less than $65 \%$, the EVA in a vertically aligned module world creep and flow at the upper temperature of the thermal-cycle test. Gel content of properly cured A-9918 EVA will typically be in excess of $75 \%$, with attendent creep resistance at $90^{\circ} \mathrm{C}$. Aging of cured A-9918 EVA should not result in a reduction in gel content below $65 \%$, over the expected service lifetime of $20 \mathrm{yr}$, especially for sloped-rooftop applications where peak service temperatures in the order of $80^{\circ} \mathrm{C}$ to $85^{\circ} \mathrm{C}$ can be expected.

With respect to Young's modulus, encapsulation engineering analysis (see Section III, F) has indicated that the level of mechanical stresses developed in encapsulated solar cells, arising from wind-caused module deflections or thermal expansion mismatches, can be decreased either by increasing the thickness of pottant between the cells and the structural panel, or by reducing the Young's modulus of the pottant. The analytical modeling enabled the development of connective relationships between the thickness $t$ of the pottants, its tensile modulus $E$, and the maximum allowable stress levels in solar cells, in order to reduce the $r i s k$ of solar cell bieakage. The attenuating factor for pottants is related to the ratio of thickness to modulus, $t / E$, and as noted above, increasing $t$ or decreasing $E$ acts to reduce solar-cell stresses. A consequence of this analytical modeling is the indication that for most practical module designs having a pottant thickness of about $10 \mathrm{mils}$, the tensile modulus of the pottant as measured at $25^{\circ} \mathrm{C}$ probably should not exceed $3000 \mathrm{lb} / \mathrm{in} .^{2}$. The tensile modulus of properly cured, unaged A-9918 EVA is in the order of $890 \mathrm{lb} / \mathrm{in.}{ }^{2}$ (Table 6).

Analytical modeling is helping to provide an upper bound to Young's modulus, but an absolute lower bound has not yet been determined. Nevertheless, if aging were to lower the Young's modulus of A-9918 EVA, that would be the mechanically favored direction. 
For chemical inertness, quantifiable techniques and measurement methods nave not yet been worked out, nor has an organized and specifically directed aging program to evaluate chemical inertness been initiated. However, some early and very preliminary crial testing (Reference 15) was carried out at $130^{\circ}$ with clean, shiny copper discs encapsulated in cured A-9918 EVA. At this aging temperature, strong yellowing discoloration of the EVA and tarnishing of the copper discs was visible within 90 hours. For these tests, the metal/EVA primer (Table 10) developed for bonding EVA to copper was not used. A major aging program on chemical inertness is being planned.

For electrical insulation, current FSA requirements call out the following for a pottant material (Reference 29):

(1) Minimum thickness to withstand breakdown from a dc voltage difference of $3000 \mathrm{~V}$ across the thickness. The average dielectric strength C: EVA is about $600 \mathrm{~V} / \mathrm{mil}$ (Table 6). and therefore a minimum $5 \mathrm{mils}$ of thickness is needed. In practice however, the typical thickness of EVA in a module exceeds $10 \mathrm{mils}$. If this manufacturing practice were to continue, and aging were to reduce the dielectric streingth of EVA a lower-bound value in the order of $250 \mathrm{~V} / \mathrm{mil}$ becomes apparent.

(2) Leakage current across the thickness direction of the pottant at 1500 volts dc shall be less than $50 \mu \mathrm{A}$. The leakage current at 1500 volts dc across a 10-mil-thick sheet of cured, unaged A-9918 EVA is less than $0.2 \mu \mathrm{A}$. There fore, the upper-bound allowable from the weather aging of A-9918 EVA is $50 \mu \mathrm{A}$, per the present requirement callout.

\section{Known Aging Behavior of EVA}

Du Pont Technical Bulletin 0820.2 reports $i^{\prime}$ at the purely thermal degradation of ethyl. vinyl acetate resins, in the absent of oxygen and water vapor, proceeds by the conversion of acetate groups to acetic acid, followed by crosslinking at the resultant sites of unsaturation, and ultimately gelation. The thermal degradation rate versus temperature for the conversion of acetate groups to asetic acid is shown in Figure 22, which is reproduced from Technical Bulletin 0820.2. Note that significant conversion only occurs at very high temperatures, which can occur during certain high-temperature processing operations, but that at temperatures close to roof-top temperatures, $200^{\circ} \mathrm{F}\left(93.3^{\circ} \mathrm{C}\right)$, the conversion rate is an almost negligibly low value of $6.3 \times 10^{-10 \%}$ per minute $(\log k=-9.2)$. If the EVA were sustained continuously at $200^{\circ} \mathrm{F}\left(93.3^{\circ} \mathrm{C}\right)$ for $20 \mathrm{yr}$ in the absence of oxygen and water vapor, this would correspond to a net conversion of only $0.006 \%$ of the acetate groups to acetic acid. On an absolute weight basis, this would correspond after $20 \mathrm{yr}$ to an acetic acid accumulation of less than 0.002 wt \% in the A-9918 EVA pottant. A hermetic module design comprising a glass superstrate and a metal-foil back cover essentially would isolate the EVA fottant from exposure to atmospheric oxygen and water vapor, and with only a few hours per day at which the module would be at rooftop peaking temperatures, a problem associated with acetic acid generation over 20 yr appears remote. No problem is expected with a hermetic module design at array peaking temperatures of $55^{\circ} \mathrm{C}$ to $60^{\circ} \mathrm{C}$. 


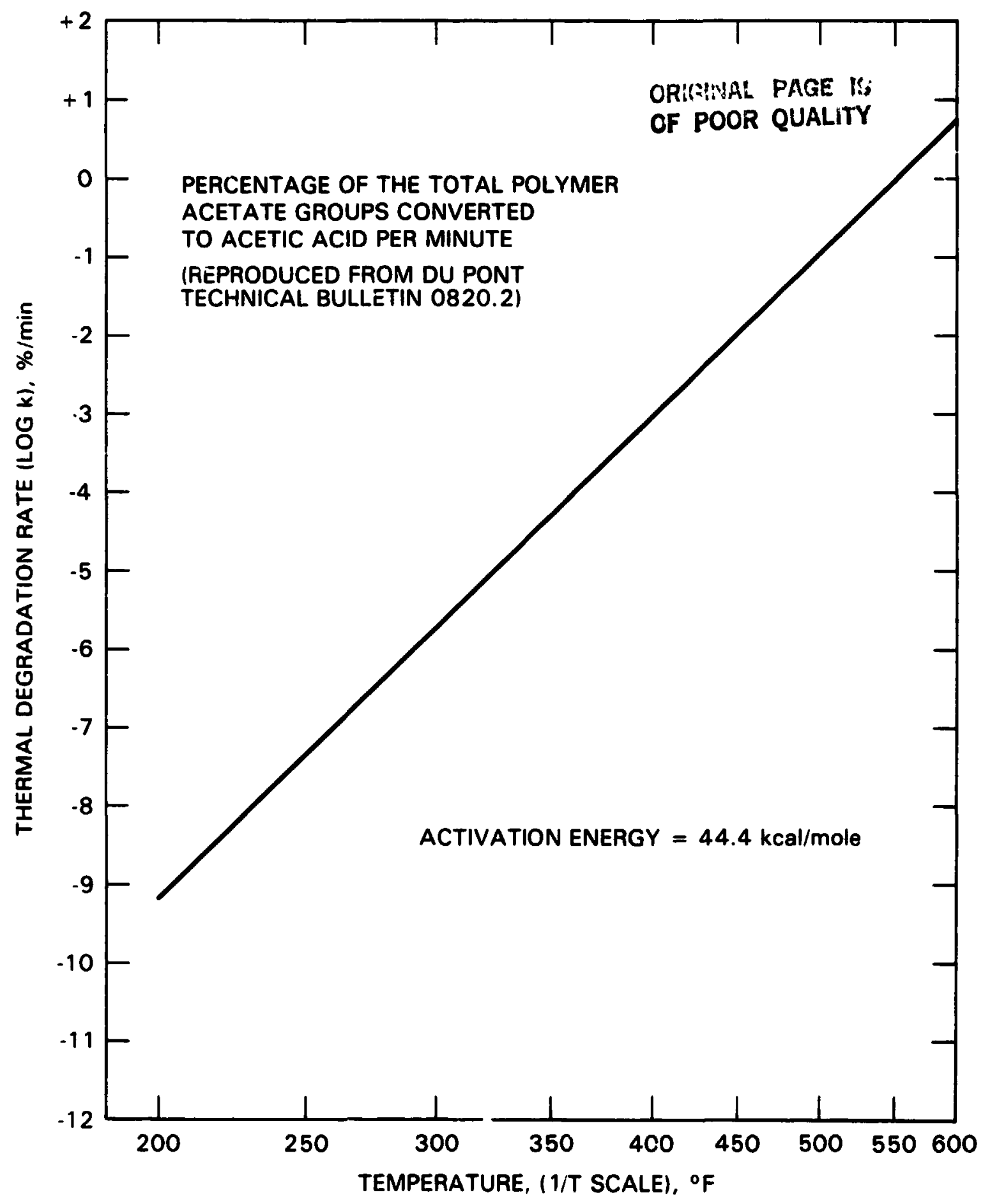

Figure 22. Thermal Degradation of Elvax Vinyl Resins

in a substrate design with a plastic film froit cover however, exposure of the F.VA pottant to atmospheric oxygen and water vapor can occur, as all plastic films are permeable by these gases (Reference 14). A search of public . Iterature has not as yet uncovered any reports or articles on the effects, if any, of atmospheric oxygen and/or water vapor on acetic acid generation. 
Therefore, chemical analysis tor acetic acid is included as part of the EVA exp srimental aging studies. The concern with acetic acid generation, if it should occur in any quantity, is twofold: first, the potential for chemical *irosion of any metals encapsulated within the EVA (chemical inertness), and secord, the potential for loss of the EVA's electrical insulation effectiveness, through an increase in leakage current and/or a decrease in dielectric strength.

\section{Experimenta1 EVA Aging Programs}

The aging behavior of both Elvax 150 and the cured A-9918 EVA are being studied at Springborn Laboratories and at JPL. A summary of their separate aging programs and essential findings to date are given respectively in Tables 13 and 14 . Details of each of these programs will first be separately described, and then their results will be sombined to generate an evolving picture of the aging behavior of this matertal and an assessment of the materials' service-life potential for array and rooftop-module applications.

a. Springborr Laboratories. Springborn has carried out thermal aging (in the dark) of cured A-9918 EVA at $70^{\circ} \mathrm{C}, 90^{\circ} \mathrm{C}$, and $130^{\circ} \mathrm{C}$ in air-circulated ovens, and has exposed Elvax 150 and cured A-9918 EVA to UV light at $55^{\circ} \mathrm{C}$. The UV light source is a General Electric RS/4 sunlamp, which is filtered to remove nonterrestrial wavelengths belcw 2.95 to $300 \mathrm{~nm}$. The UV spectra and intensity from these lamps at the sample location have been measured (Reference 30), and when compared with the peak intensities of AMl.5 natural sunlight, correspond to an average UV intensity of about 1.4 suns. If it is assumed that t. Fical values of tctal annual UV insolation in the Uniter States (Reference 31) were delivered at AMI.5 peak intensities, this would correspond to about 5 hours per 24-hour day to deliver the total annual UV insolation. Thus, defining a l-sun UV day as 5 hours in eaci 24-hour day, then about 1300 hours of exposure to these RS/4 sunlamps operating at 1.4 suns UV intensity represent one year of outdoor UV exposure. $\because$-e UV exposure temperiture of $55^{\circ} \mathrm{C}$ was selected to match array peaking ismperatures. Atmospheric moisture in the RS/4 test chambers and in the air-circulated ovens is that associated with the laboratory environment, typically at $z$ relative humidity of about $50 \%$ to $60 \%$ at $25^{\circ} \mathrm{C}\left(77^{\circ} \mathrm{F}\right)$.

Exposure of unprotected Elvax 150 to $\mathrm{R} 3 / 4$ UV at $55^{\circ} \mathrm{C}$ results within 1000 hours in a visible onset of yellowing, which continues and becomes more intense with continued exposure. The surface of this materiai becomes stick. and tacky, and the physical snape of the specimen eventually manifest.s slump and a tendency to flow. Progressive deterioration led to termination of this aging test at 1500 hours. Exposure of an Elvay 15C sample crosslinked with $1.5 \mathrm{pph}$ of Lupersol 101, but which contailied none of the stabilization additives listed in Table 3 , essentially paralleled the aging behavior of the uncrosslinked Elvax 150. The primary difference was geueral retention of its initial physical form, presumably a result of the effect of crosslinking. Progressive deterioration involving yellowing and su- face stickiness resulced in termination of this aging test also at 1500 hours. Crosslinking of Elvax 150 alone was insufficient to stop or suppress the action of $U J$ photooxidation. 
Table 13. Sumary of EVA Aging Program at Springborn Laboratories

\section{UV Aging}

Temperat ure, $55^{\circ} \mathrm{C}$;

i" ource, RS/4 sunlamps (GE);

A. .ent relative humidity
Elvax 150: terminated after $1500 \mathrm{~h}$; light-yellow color, sticky surface

Elvax 15u cured with Lupersol 101: terminated after $1500 \mathrm{~h}$, lightyellow color, sticky surface

Elvax 150 behind a UV-screening film: system failure forced termination at $\approx 22,000 \mathrm{~h}$. At routine inspection after $21,231 \mathrm{~h}$, Elvax 150 was visually in excellent cond: i on, with no visible color, and a firm and .un-tacky surface

Cured A-9918 EVA: has accumulated nearly $3 \dot{j}, 000 \mathrm{~h}$ of exposure to April, 1982, and is continuing; no visible change; time trend of measured properties given in Table 15

Cured A-9918 EVA specimens only: specimens have accumulated 10 mo $(7200 \mathrm{~h})$ of thermal aging to April 1982, and continuing; no visible change in specimens aged at $70^{\circ} \mathrm{C}$ and $90^{\circ} \mathrm{C}$; definite yellowing and deterioration of specimens aged at $130^{\circ} \mathrm{C}$; time trend of measured properties given in Table 16.
Aging in air-circulated ovens at $70^{\circ} \mathrm{C}, 90^{\circ} \mathrm{C}$ and $130^{\circ} \mathrm{C}$;

Ambient relative humidity

A specimen of uncrosslinked and uncompounded Elvax 150, positioned behind a UV-screening acrylic fi!m, survived more than 21,000 hours of $R S / 4$ exposure at $55^{\circ} \mathrm{C}$ without any visible evidence of yellowing or physical slump, and without any development of surface stickiness or tack. The acrylic film cover filters our. all UV wavelengths shorter tisan 360 to $36 j \mathrm{~nm}$. Unfortunately, within a few hours after the routine visual inspection of this sample at 21.231 hours, the temperature regulator controlling the test temperature a: $55^{\circ} \mathrm{C}$ failed, and the sample was heated to destaction, precluding the planned measurement of mechanical properties of the aged specimen. This test, nevertheless, strongly suggested that th? UV wavelengths necessary for activating UV photooxidation were filtered out by the UV screen, and that withcut these wavelengths incident on the Elvax 150, this material was merely experiencing the equivalent of Jark thermal aging at $55^{\circ} \mathrm{C}$. The evidence therefore further suggests that to the time limit of this exposure. Elvax 150 exhibits natural resistance to thermal oxidation at $55^{\circ} \mathrm{C}$. 
Table 14. Sumary of EVA Aging Program at Jet Propulsion Laboratory

Aging Conditions

Test Specimens and Experimental Status

UV Aging ( 6 suns intensity)

Temperatures: $30^{\circ} \mathrm{C}, 70^{\circ} \mathrm{C}$, $85^{\circ} \mathrm{C}, 105^{\circ} \mathrm{C}$

UV Source: Medium-pressure mercury lamp

Ambient relative humidity
Dark Thermal Aging

$$
\text { Temperatures: } \begin{aligned}
& 30^{\circ} \mathrm{C}, 70^{\circ} \mathrm{C}, \\
& 85^{\circ} \mathrm{C}, 105^{\circ} \mathrm{C}
\end{aligned}
$$

Ambient relative humidity
At Test Temperature $30^{\circ} \mathrm{C}$ :

Elvax 150: terminated after $600 \mathrm{~h}$; developed yellow color, sticky surface, partial crosslinking to generate insoluble gel phase

Cured A-99:8 EVA: terminated after 1400 $h$; only detected changes were harmless depletion of residual peroxide curing agent and trace generation of hydroxyl groups; no other changes

At Test Temperatures $70^{\circ} \mathrm{C}, 85^{\circ} \mathrm{C}, 105^{\circ} \mathrm{C}$ :

Cured A-9918 EVA: terminated after $400 \mathrm{~h}$ at $70^{\circ} \mathrm{C}$ and $800 \mathrm{~h}$ at $85^{\circ} \mathrm{C}$ and $105^{\circ} \mathrm{C}$; in general, for specimens aged at $70^{\circ} \mathrm{C}$ and $85^{\circ} \mathrm{C}$, changes were same as detected at $30^{\circ} \mathrm{C}$, otherwise specimens were in excellent condition, including no visible yellowing; at $105^{\circ} \mathrm{C}$, however, major property changes occurred, and the samples yellowed visibly (see text for details)

Cured A-9918 EVA sealed between UV filtering Pyrex glass covers (with open edges): terminated after $400 \mathrm{~h}$ at $70^{\circ} \mathrm{C}$, and $800 \mathrm{~h}$ at $85^{\circ} \mathrm{C}$ and $105^{\circ} \mathrm{C}$; no visible yellowing in any specimens was detected, and a trace of acetic acid was detected only in the sample aged at $105^{\circ} \mathrm{C}$

At Test Temperature $30^{\circ} \mathrm{C}$ :

Elvax 150: terminated after $500 \mathrm{~h}$, no change

Cured A-9918 EVA: Terminated after $1400 \mathrm{~h}$, to change

At Test Temperatures $70^{\circ} \mathrm{C}, 85^{\circ} \mathrm{C}, 105^{\circ} \mathrm{C}$ :

Cured A-9918 EVA specimens only: terminated after $400 \mathrm{~h}$ at $70^{\circ} \mathrm{C}$, and $800 \mathrm{~h}$ at $85^{\circ} \mathrm{C}$ and $105^{\circ} \mathrm{C}$; no changes at $70^{\circ} \mathrm{C}$ and $85^{\circ} \mathrm{C}$, visible yellowing of sample aged at $105^{\circ} \mathrm{C}$ 
Specimens of cured and fully compounded A-9918 EVA were also directly exposed to RS/4 UV at $55^{\circ} \mathrm{C}$. No UV-screening films or covers were used. This exposure test involved two different lots of cured A-9918 EVA. As a trial experiment, a small piece of cured A-9918 EVA was exposed to RS/4 to assess visually the aging behavior of this material. When this sample passed 3000 hours of exposure without any visual changes, it was decided to initiate exposure of a larger quantity of cured A-9918 specimens in order to monitor optical and mechanical properties as a function of aging time. The initial specimen, designated Lot 1 , was left in the RS/4 chamber to continue accumulating exposure time, and the new batch of cured A-9918 EVA specimens were designated as Lot 2 .

The optical and mechanical properties of Lot 2 A-9918 EVA, with up to 27,000 hours of UV exposure at $55^{\circ} \mathrm{C}$, are given in Table 15. Up to 27,000 hours there was very little change in the measured properties of the cured A-9918 EVA. The sample removed for testing at 27,000 hours was clear, had no visible indications of any yellowing, was firm and non-sticky to the touch, and exhibited no slump or change in its physical form. The lot 1 sample, having then accumulated 30,000 hours of exposure time, was also clear, with no indications of yellowing; it was firm, non-sticky, and without change in its physical form.

Accepting that 1300 hours of $\mathrm{RS} / 4$ exposure at $55^{\circ} \mathrm{C}$ equates to $1 \mathrm{yr}$ of outdoor exposure at $55^{\circ} \mathrm{C}$, then 27,000 to 30,000 hours would correspond to more than $20 \mathrm{yr}$ of outdoor UV exposure. For an array installation having a peaking temperature near $55^{\circ} \mathrm{C}$, these $\mathrm{RS} / 4$ data trends strongly indicate the potential of 20-yr service life for cured A-9918 EVA, used either in a superstrate or substrate module design. Further, as indicated above, Elvax 150 itself appears to be resistant against purely thermal aging at $55^{\circ} \mathrm{C}$, but will yellow and age at $55^{\circ} \mathrm{C}$ when directly exposed to UV. Therefore, the deleterious UV wavelengths activating yellowing and aging by UV photooxidation are apparently filtered out by the UV screening film, and also by the Cyasorb UV-531 in the compounded A-9918 EVA. These aging tests at $55^{\circ} \mathrm{C}$ strongly indicated that the service longevity of EVA in a module operating at array peaking temperatures of near $55^{\circ} \mathrm{C}$ is not related to thermal oxidation concerns, but to the performance of the UV protection schemes.

Thermal aging in dark, air-circulated ovens of a third lot of cured A-9918 EVA was carried out for 10 mo at $70^{\circ} \mathrm{C}, 90^{\circ} \mathrm{C}$, and $130^{\circ} \mathrm{C}$. The test results for these thermally aged A-9918 EVA specimens are given in Table 16. Experimentally, the specimens aged 1 wk, 3 wks, and 2 mo were visually examined, and only their mechanical properties, consisting of tensile strength and of elongation at break, were measured. The test specimen aged for 10 mo at $70^{\circ} \mathrm{C}$ was lost. For the test specimens aged 10 mo at $90^{\circ} \mathrm{C}$ and $130^{\circ} \mathrm{C}$, additional measurements of gel content, optical transmission, and Young's modulus were made.

After 10 mo of thermal aging at $90^{\circ} \mathrm{C}$, there was essentially no change in the A-9918 EVA. This same behavior was observed for the 2 mo of thermal aging at $70^{\circ} \mathrm{C}$. At $130^{\circ} \mathrm{C}$, however, the A-9918 EVA underwent considerable deterioration from thermal oxidation. The material turned brown/orange in color, and experienced significant deterioration of both optical and mechanical properties. A trace of visible yellowing was noted after 1 wk of thermal aging at $130^{\circ} \mathrm{C}$, and was very intense after 2 mo. Without even 
Table 15. Properties of Cured A-9918 EVA as a Function of Exposure Time to RS/4 UV at $55^{\circ} \mathrm{C}$

\begin{tabular}{cccc}
\hline $\begin{array}{c}\text { Lot } 2 \\
\text { Specimens }\end{array}$ & $\begin{array}{c}\text { Total Integrated } \\
\text { Limit } \\
\text { Transmissiona, } \\
\%\end{array}$ & $\begin{array}{c}\text { Tensile Strength } \\
\text { at Break, } \\
\text { lb/in }\end{array}$ & $\begin{array}{c}\text { Elongation } \\
\text { at }\end{array}$ \\
\hline Break, \\
\%ontrol & 91.0 & 1890 & 510 \\
$2,880 \mathrm{~h}$ & 91.0 & 1930 & 631 \\
$5,760 \mathrm{~h}$ & 90.5 & 1340 & 550 \\
$8,640 \mathrm{~h}$ & 90.0 & 1460 & 590 \\
$15,120 \mathrm{~h}$ & 90.0 & 1520 & 570 \\
$27,000 \mathrm{~h}$ & 90.0 & 1870 & 560
\end{tabular}

aMeasured over the wavelength range $350 \mathrm{~nm}$ to $800 \mathrm{~nm}$

considering UV, non-hermetic photovoltaic modules such as substrate designs, which will all ow exposure of the A-9918 EVA encapsulant to atmospheric oxygen, and operating at $130^{\circ} \mathrm{C}$, will probably experience eventual thermal oxidative yellowing and deterioration of the A-9918 EVA.

Ordinarily however, such high temperatures in photovoltaic modules are localized, associated with the overheating of a failed solar cell, which is referred to as solar-cell hot-spotting. The peak temperatures associated with solar-cell hot-spotting can be reduced by the use of bypass diodes in the electrical circuitry, and at the present time, these thermal aging results suggest for A-9918 EVA that the allowable peak temperature of a hot solar cell in a non-hermetic module design probably resides somewhere between $90^{\circ} \mathrm{C}$ and $130^{\circ} \mathrm{C}$. Although the overall thermal aging behavior at $130^{\circ} \mathrm{C}$ of cured A-9918 EVA in a hermetic environment (that is, isolation from atmospheric oxygen and water vapor) has not yet been studied, the known potential for acetic acid generation suggests that the peak temperature of hot solar cells in a hermetic module design should also be limited to less than $130^{\circ} \mathrm{C}$.

With respect to rooftop applications, and with the module design philosophy of shielding the A-9918 EVA from harmful UV, the thermal aging behavior at $90^{\circ} \mathrm{C}$ is initially very encouraging if it is assumed that the temperature of a rooftop-mounted module is at its peak temperature for about 5 hours each day; therefore the 10 mo ( 7200 hours) of thermal aging at $90^{\circ} \mathrm{C}$ corresponds roughly to almost $4 \mathrm{yr}$ of rooftop service. Although encouraging, it is not known at this time whether the 10 mo of thermal oxidative stability at $90^{\circ} \mathrm{C}$ is a natural property of the Elvax 150 , or a result of oxidative 
Table 16. Thermal Aging of Cured A-9918 EVA in Circulating-Air Ovens

\begin{tabular}{|c|c|c|c|c|}
\hline Time & Property & $70^{\circ} \mathrm{C}$ & $90^{\circ} \mathrm{C}$ & $130^{\circ} \mathrm{C}$ \\
\hline $\begin{array}{l}1 \text { wk } \\
(168 \mathrm{~h})\end{array}$ & $\begin{array}{l}\text { Tensile, lb/in. }{ }^{2} \\
\text { Ult. el ongation, } 7\end{array}$ & $\begin{array}{r}2685 \\
595\end{array}$ & $\begin{array}{r}2200 \\
550\end{array}$ & $\begin{array}{r}2000 \\
550\end{array}$ \\
\hline $\begin{array}{l}3 \text { wks } \\
(504 \mathrm{~h})\end{array}$ & $\begin{array}{l}\text { Tensile, lb/in. }{ }^{2} \\
\text { ult. el ongation, \% }\end{array}$ & $\begin{array}{r}1700 \\
670\end{array}$ & $\begin{array}{r}1800 \\
680\end{array}$ & $\begin{array}{r}1240 \\
638\end{array}$ \\
\hline $\begin{array}{l}2 \mathrm{mo} \\
(1344 \mathrm{~h})\end{array}$ & $\begin{array}{l}\text { Tensile, lb/in. }{ }^{2} \\
\text { U1t. el ongation, } \%\end{array}$ & $\begin{array}{r}2370 \\
600\end{array}$ & $\begin{array}{r}2660 \\
784\end{array}$ & $\begin{array}{r}1320 \\
647\end{array}$ \\
\hline \multirow[t]{11}{*}{$\begin{array}{l}10 \mathrm{mo} \\
(7200 \mathrm{~h})\end{array}$} & $\begin{array}{l}\text { Tensile, lb/in. }{ }^{2} \\
\text { Ult. el ongation, } \%\end{array}$ & $\begin{array}{l}\text { specimen } \\
\text { lost }\end{array}$ & $\begin{array}{r}2120 \\
660\end{array}$ & $\begin{array}{r}144 \\
37\end{array}$ \\
\hline & Gel content, $\%$ & & $91 \%$ & 88\% \\
\hline & Color & & $\begin{array}{l}\text { clear, no } \\
\text { yellow }\end{array}$ & $\begin{array}{l}\text { brown/ } \\
\text { orange }\end{array}$ \\
\hline & Optical transmission, $\%$ & & $91 \%$ & $74 \%$ \\
\hline & Tangent modulus, $1 \mathrm{~b} / \mathrm{in}^{2}$ & & 833 & 335 \\
\hline & \multicolumn{4}{|c|}{ Control (Unaged) } \\
\hline & Tensile, $1 \mathrm{~b} / \mathrm{in}^{2}{ }^{2}$ & 2160 & & \\
\hline & Ult. elongation, $\%$ & 677 & & \\
\hline & Tangent modulus, $1 \mathrm{~b} / \mathrm{in} .2$ & 890 & & \\
\hline & Opticai transmission, $\%$ & 91 & & \\
\hline & Gel content, $\%$ & 91 & & \\
\hline
\end{tabular}

protection afforded by the Naugard-P antioxidant. If the latter, oxidative protection will cease once the antioxidant has been sacrifically depleted. Detailed studies in this area are being initiated.

b. JPL. JPL has carried out UV aging and thermal aging (in the dark) of both Elvax 150 and cured A-9918 EVA. The dark and UV aging of Elvax 150 was carried out at $30^{\circ} \mathrm{C}$ only, whereas the dark and UV aging of cured A-9918 EVA were carried out at $30^{\circ} \mathrm{C}, 70^{\circ} \mathrm{C}, 85^{\circ} \mathrm{C}$, and $105^{\circ} \mathrm{C}$. For UV aging at $70^{\circ} \mathrm{C}$, $85^{\circ} \mathrm{C}$, and $105^{\circ} \mathrm{C}$ (but not at $30^{\circ} \mathrm{C}$ ), additional test specimens consisting of cured A- 9918 EVA positioned between UV-filtering Pyrex glass covers were also tested. These specimens were intended to simulate a hermetic module 
design, although the narrow edges of these glass-sandwich specimens were unsealed. The UV light source was a medium-pressure mercury lamp, which generated an output ${ }^{\bar{i}} \bar{i}$ about 6 suns of $U V$ intensity at the sample locations (Reference 10). These lamps were filtered to remove non terrestrial UV wave lengths. Assuming a 1-sun UV day as 5 hours for each 24 hours, then about 300 hours of exposure to this UV source equates with 1 yr of outdoor UV exposure. A sumary of the JPL EVA-aging program is given in Table 14.

The test methods and techniques employed at JPL to monitor material changes due to aging were intended to provide information of a fundamental chemical nature; therefore, in general, engineering properties were not measured. For example, the UV-visible-IR absorption spectra of almost all of the test specimens were monitored primarily to detect changes in absorption spectra for chemical information, rather than to determine optical transmission relative to solar-cell performance. Particular emphasis was given to the sensitive detection of absorbance at $360 \mathrm{~nm}$ and $400 \mathrm{~nm}$. Absorbance at 360 $\mathrm{nm}$ was used to monitor the concentration of Cyasorb UV-53I in the specimens, and absorbance at $400 \mathrm{~nm}$ was used to have a more sensitive monitor of material yellowing that may not be readily visible to the human eye.

Such monitoring at $400 \mathrm{~nm}$ resulted in the detection of what tentatively appears to be two distinctly different yellowing properties. The first is a transient yellowing, generally at low levels of intensity not detectable by the human eye, which is associated with the decomposition of the residual Lupersol 101 peroxide curing agent not consumed during the EVA cure. The second yellowing behavior is associated with thermal and/or UV photooxidation, which can eventually become visible to the human eye, as was observed in the Springborn aging test.

The kinetics of the thermal decomposition of Lupersol 101 peroxide is first-order, and an Arrhenius plot of the temperature dependence of the first-order reaction rate constant is shown in Figure 23. Evidence from the JPL test results indicate that for those A-9918 EVA specimens aged in the dark, and for those specimens exposed to UV but sandwiched between the Pyrex glass covers, the decomposition of the residual Lupersol 101 proceeds thermally in conformance with the rates given in Figure 23. But for those specimens directly exposed to the UV light, the decomposition rate of the residual peroxide is greatly accelerated. The time period of the transient yellowing is associated with the time period of active Lupersol 101 decomposition, whether it be thermal or accelerated by direct UV exposure. Indications from the JPL test results suggest that the decomposition of : e residual peroxide proceeds harmlessly.

In general, the EVA aging trends observed at Springborn and at JPL were similar. At JPL, exposure of Elvax 150 to 6 suns of UV at $30^{\circ} \mathrm{C}$ resulted in visible deterioration within 600 hours. The material turned yellow and developed a sticky surface, and chemical analysis revealed that some crosslinking had occurred, ger, rating an insoluble gel phase. By contrast, a control sample of Elvax 150 aged in the dark at $30^{\circ} \mathrm{C}$ experienced no changes. Specimens of cured A-9918 EVA exposed to 6 suns UV for 1400 hours at $30^{\circ} \mathrm{C}$ experienced only two detected changes: depletion of the residual Lupersol 101 


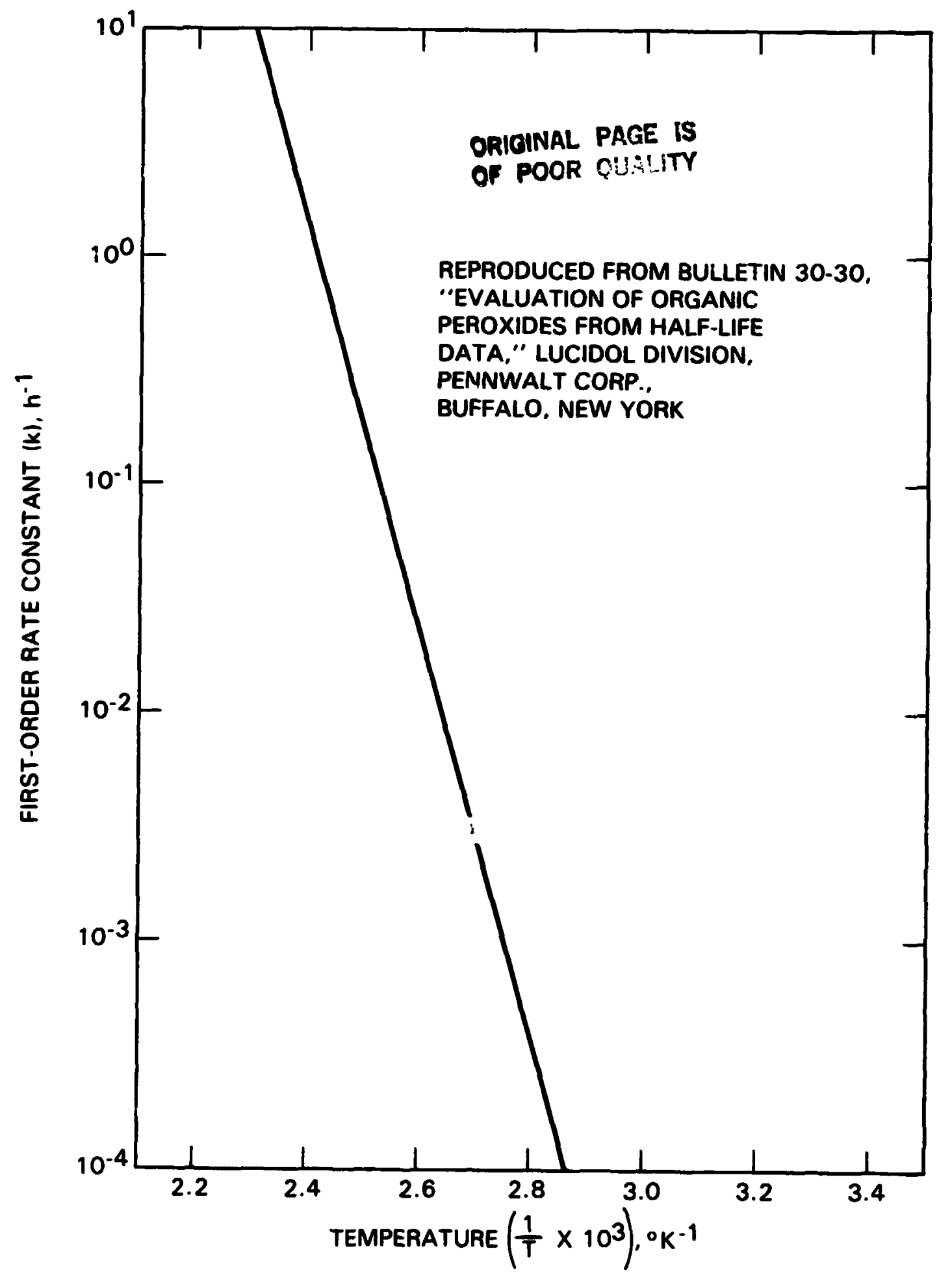

Figure 23. Thermal Decomposition of Lupersol 101 Peroxide

peroxide curing agent, and trace formation of hydroxyl groups. By contrast, a control sample of cured A-9918 aged in the dark for 1400 hours at $30^{\circ} \mathrm{C}$

experienced no detectable changes of any kind, including the residual peroxide 
curing agent. This is readily explainable, as extrapolation of the Lupersol 101 thermal decomposition rate curve to $30^{\circ} \mathrm{C}$ (Figure 23) yields a halfife estimate for thermal decomposition of more than $5000 \mathrm{yr}$. The apparent stability of the Lupersol 101 against thermal decomposition in the dark at $30^{\circ} \mathrm{C}$ is not surprising. On the other hand, the Lupersol 101 in the A-9918 EVA exposed to 6 suns UV at $30^{\circ} \mathrm{C}$ rapidly decomposed, as shown in Figure 24, which is a plot of Lupersol 101 concentration versus irradiation time (Reference 10). The initial concentration of residual peroxide is about 0.13 wt $\%$, which decays to virtually zero concentration within 50 to 60 hours. The data curve of Figure 24 is replotted semi-iogarithically in Figure 25 , yielding a straight line, which suggests that the UV-enhanced decomposition reaction is first-order. The estimated half-life from this figure is 15 hours for the UV-enhanced decomposition, which can be compared with the half-life estimate of more than $5000 \mathrm{yr}$ for thermal decomposition at $30^{\circ} \mathrm{C}$. The trarsient yellowing associated with the UV-enhanced peroxide decomposition peaked in about 80 to 90 hours of irzadiation, and essentially decayed to zero within 200 hours. Some of the Lupersol 101 decomposition products are alcohols, which may account for the hydroxyl groups detected in the UV-exposed A-9918 EVA.

Samples of cured A-9918 EVA exposed to 6 suns of UV for 400 hours at $70^{\circ} \mathrm{C}$ and for 800 hours at $85^{\circ} \mathrm{C}$ survived in excellent condition. Specimens exposed to UV at both temperatures experienced the UV-enhanced decomposition of the Lupersol 101 peroxide. No yellowing associated with UV photooxidation or thermal oxidation was detected in specimens UV-exposed at either $70^{\circ} \mathrm{C}$ or $85^{\circ} \mathrm{C}$. These results indicate that the Cyasorb UV-531 in the concentration used $(0.3$ wt $\%$ ) is adequate to protect the EVA against UV-activated reactions, even at 6 suns of UV intensity. Therefore, if it is assumed that the UV protection afforded by the Cyasorb UV 531 reduced the aging of cured A-9918 EVA at $85^{\circ} \mathrm{C}$ to that of thermal aging only, then 800 hours of survivability at $85^{\circ} \mathrm{C}$ is expected on the basis of the survivability of the A-9918 EVA after a longer period of 10 mo ( 7200 hours) of thermal aging at Springborn.

Control samples of cured A-9918 EVA thermally aged in the dark for 400 hours at $70^{\circ} \mathrm{C}$ and for 800 hours at $85^{\circ} \mathrm{C}$ were in excellent condition, with no detection of any yellowing associated with thermal oxidation. No transient yellowing associated with the peroxide decomposition was detected, not surprisingly, as the estimated half-life (Figure 23) for thermal decomposition at $70^{\circ} \mathrm{C}$ is more than 23,000 hours, and is more than 1700 hours at $85^{\circ} \mathrm{C}$. Samples of cured A-9918 sandwiched between the UV-filtering Pyrex glass covers and exposed to 6 suns UV for 400 hours at $70^{\circ} \mathrm{C}$ and for 800 hours at $85^{\circ} \mathrm{C}$ also survived in excellent condition. Transient yellowing associated with peroxide decomposition was not detected in these samples, providing a clue that it may be avoided in hermetically sealed superstrate designs.

Aging of cured A-9918 EVA at $105^{\circ} \mathrm{C}$, however, resulted in most of the measurable and observable changes from which fundamental chemical information on A-9918 EVA aging can be currently derived. The yellowing behavior (Figure 26) of the samples thermally aged in the dark, and ior those samples exposed to 6 suns of UV, both direct and those between the Pyrex glass covers, exhibited the low-intensity transient yellowing associated with the decomposition of the residual Lupersol 101 peroxide curing agent. The half-life for the thermal decomposition of Lupersol 101 et $105^{\circ} \mathrm{C}$ is in the order of 90 hours, and the peak yellowing intensity (minimum transmission) occurred at 


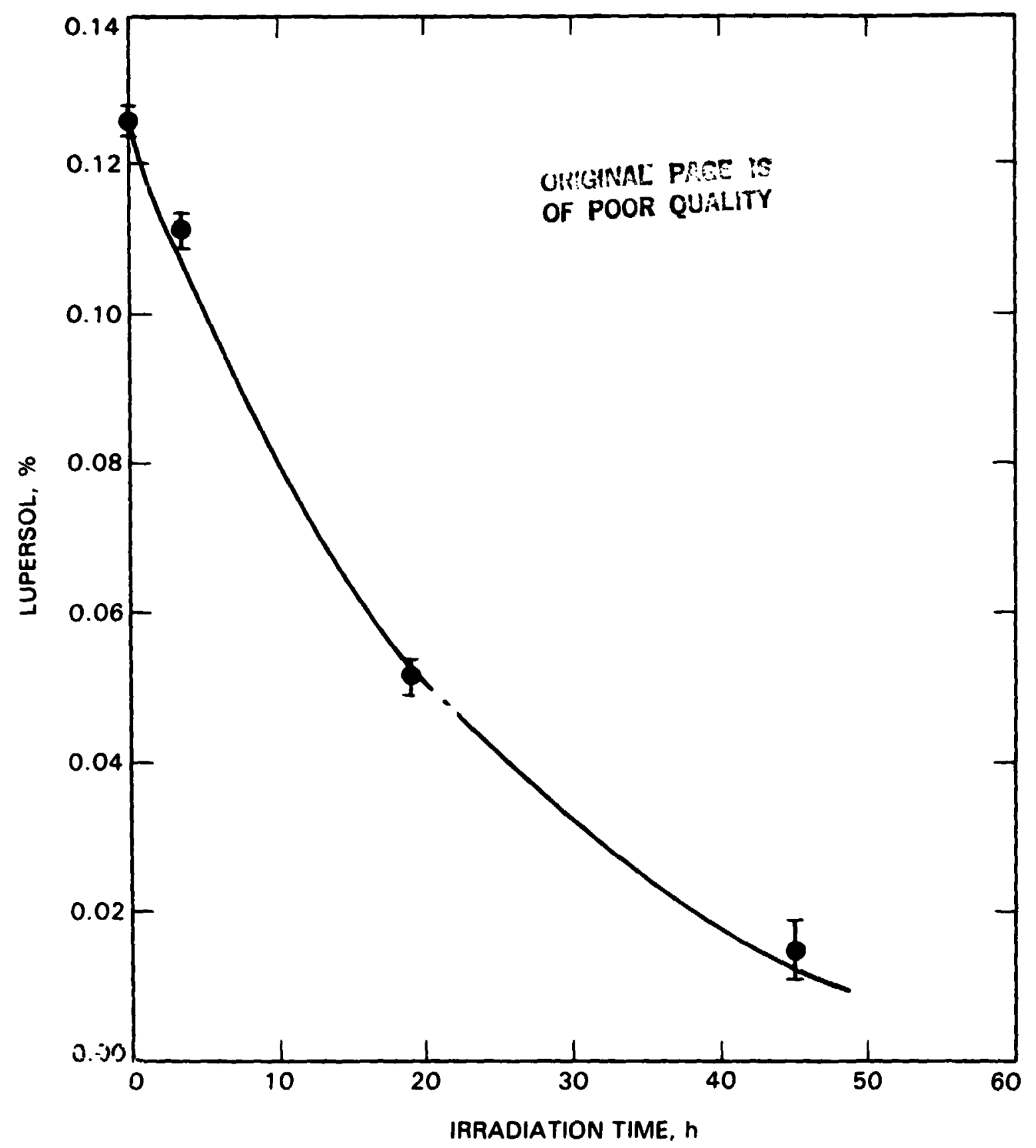

Figure 24. Concentration of Residual Lupersol 101 Peroxide Curing Agent in EVA A-9918 as a Function of Photothermal Aging at 6 suns, $30^{\circ} \mathrm{C}$, in $\mathrm{Air}$

about 100 hours to 120 hours. Thereafter, the transient yellowing gradually disappeared. Chemical analysis of these aged specimens identified the presence of hydroxyl groups, and barely detected minute traces of acetic acid. The hydroxyl groups may be associated with the alcohols generated from Lupersol 101 decomposition products, and with the acetic acid from the thermal 


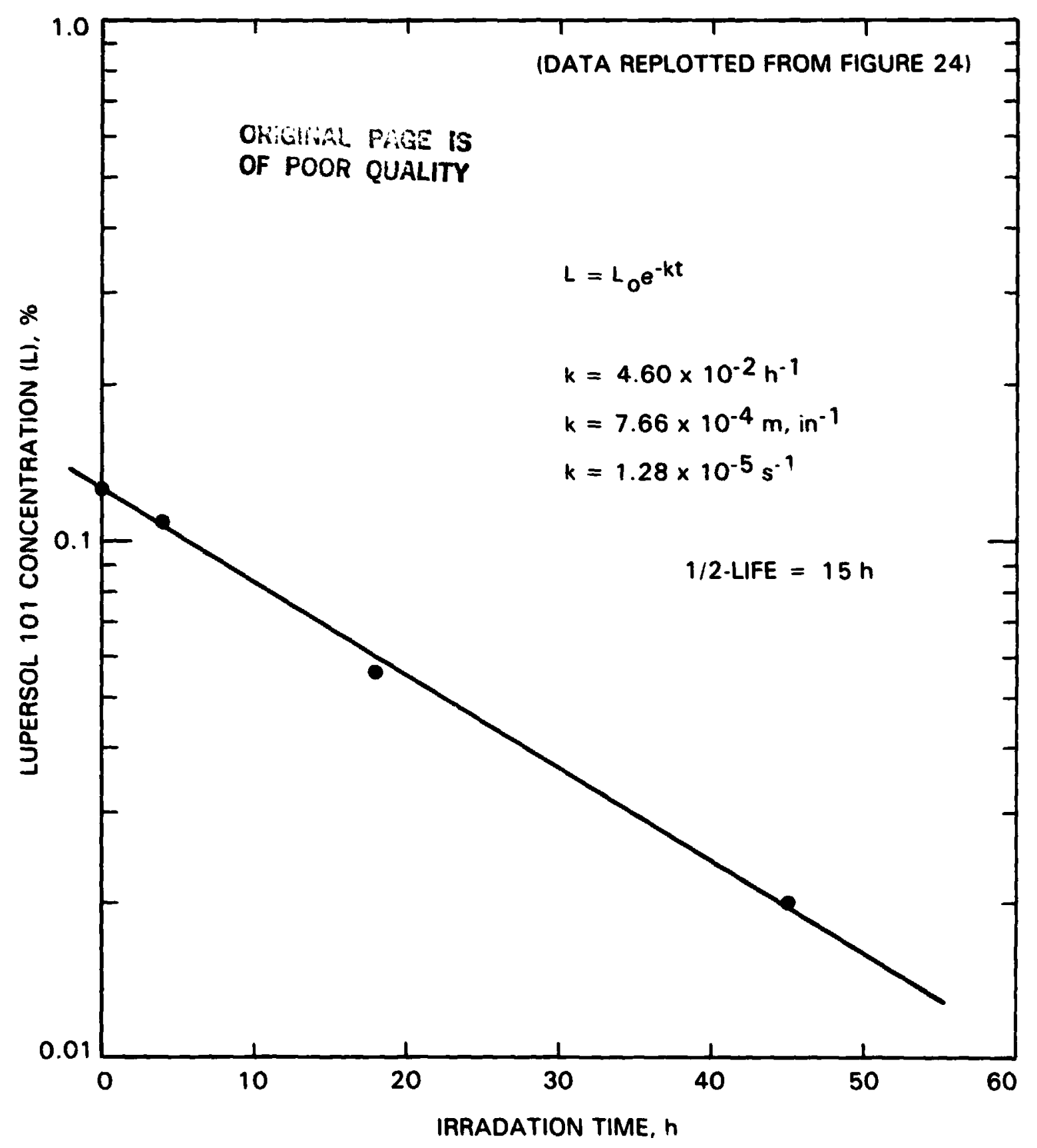

Figure 25. Depletion of Lupersol 101 From Crosslinked EVA A-9918 at $30^{\circ} \mathrm{C}, 6$ suns in Air-Circulated Oven

degradation of the acetate groups in the EVA. Over the time period of this test exposure, no yellowing from either photooxidation or thermal oxidation was detected for the cured A-9918 EVA specimens sandwiched between the Pyrex glass covers. 
The yellowing of the A-9918 EVA specimens thermally aged in the dark at $105^{\circ} \mathrm{C}$ began early in the aging test, and progressed to become increasingly intense with continued aging. Although not separately resolved, it is speculated that the early onset of yellowing is associated with the transient peroxide yellowing, and that the later, more intense yellowing is associated with thermal oxidation. No specific test to analyze chemically for the antioxidant concentration in these specimens as a function of aging time was made, and therefore its role in the oxidation process is not known. The evidence suggests that the antioxidant was very rapidly consumed, therefore providing only brief protection. It is known that the protective lifetime of an antioxidant, called the induction period, decreases with increasing temperature. The absence of visible yellowing in A-9918 EVA specimens thermally aged up to 10 mo ( 7200 hours) at $90^{\circ} \mathrm{C}$ in the Springborn test, and the development of visible yellowing within a few hundred hours at $105^{\circ} \mathrm{C}$ suggest the following, or combinations of the following:

(1) The protective induction period of the antioxidant decreases rapidly over the $15^{\circ} \mathrm{C}$ range from $90^{\circ} \mathrm{C}$ to $105^{\circ} \mathrm{C}$.

(2) The tendency for physical loss increases rapidly over the $15^{\circ} \mathrm{C}$ range from $90^{\circ} \mathrm{C}$ to $105^{\circ} \mathrm{C}$.

(3) The natural resistance of Elvax 150 to thermal oxidation may decrease sharply at some threshold temperature between $90^{\circ} \mathrm{C}$ and $105^{\circ} \mathrm{C}$.

Detailed studies in these activity areas are being initiated, which will include longer-term thermal aging at temperatures such as $85^{\circ} \mathrm{C}$ and $90^{\circ} \mathrm{C}$. A concern, for example, is that the 10 mo of thermal aging at $90^{\circ} \mathrm{C}$ may still have been within the protective induction period of the antioxidant.

The apparent absence of oxidative yellowing at $105^{\circ} \mathrm{C}$ of the A-9918 EVA specimens sandwiched between the Pyrex glass covers, in contrast with the rapid oxidative yellowing of the dark-thermally aged specimens, is believed to be related to adequate UV filtering by the Pyrex glass, and to the restricted access of oxygen influx and possibly antioxidant outflux at the narrow open edge of the sandwich specimens. For example, no acetic acid was detected chemically in the samples that were thermally aged in the dark at $105^{\circ} \mathrm{C}$, yet there is no reason to believe that some acetic acid was not liberated. It is presumed that the liberated acetic acid was volatilized out of these specimens, but not out of the sandwich specimens because of restricted access.

The yellowing of cured A-9918 EVA directly exposed to 6 suns UV at $105^{\circ} \mathrm{C}$, as shown in Figure 26, began early in the aging exposure, became quickly visible, and to about 250 hours was yellowing at a rate faster than the specimens being thermally aged in the dark. At 250 hours of exposure, a reversal in yellowing occurred, and the A-9918 EVA began to lose its yellow color and to become progressively clearer. Simultaneously, absorbance at $360 \mathrm{~nm}$ was decreasing (which also began early in the aging exposure) with the interpretation that Cyasorb UV-531 was being lost. The early and more rapid onset of yellowing is thought to be possibly related to the transient yellowing associated with the rapid, UV-accelerated decomposition of the residual Lupersol 101 peroxide curing agent. Thereafter, and although not completely studied, the current evidence suggests that the visible yellowing is still the 


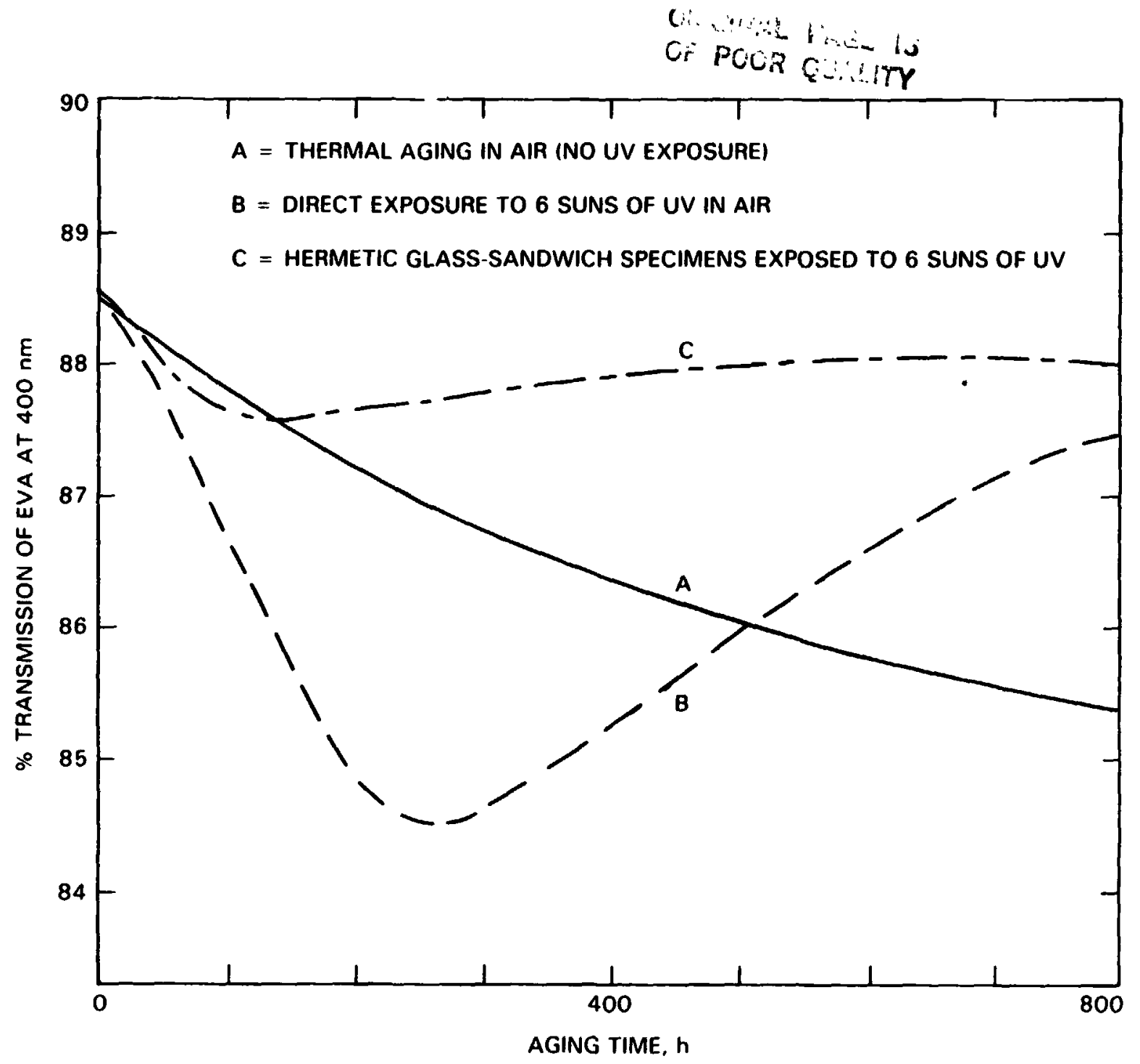

Figure 26. Change in Percentage of Transmission at $400 \mathrm{~nm}$ of EVA A-9918 Films as a Function of Dark Thermal Aging at $105^{\circ} \mathrm{C}$, and of Photothermal Aging at 6 suns, $105^{\circ} \mathrm{C}$

result of thermal oxidation, which is not appreciably accelerated by UV radiation despite gradual loss of the Cyasorb UV-531. The point is that the UV wavelengths deleterious to Elvax 150 appear to be those less than $360 \mathrm{~nm}$, and since Cyasorb UV-531 absorbs up to $370 \mathrm{~nm}$, gradual loss would permit gradual penetration of wavelengths which admittedly would be progressively shorter and shorter than $370 \mathrm{~nm}$ but still would provide UV protection until a sufficient loss of Cyasorb UV-531 had occurred to permit penetration by wavelengths $\leq 360 \mathrm{~nm}$. Rather, the evidence suggests that UV wavelengths somewhere between 310 and $370 \mathrm{~nm}$, now penetrating the oxidized EVA because of partial loss of the Cyasorb UV-531, act in turn to photooxidize the yellow thermal oxidation products, the result of the reaction being yet another degradation product that does not have a visible color -- in other words, UV bleaching. 
The experimental aging data at $105^{\circ} \mathrm{C}$ also detected depletion of Cyasorb UV-531 from the cured A-9918 EVA specimens being thermally aged in the dark; in these specimens, however, there would be no UV bleaching. At the lower aging temperatures of $85^{\circ} \mathrm{C}, 70^{\circ} \mathrm{C}$, and $30^{\circ} \mathrm{C}$, the rates of depletion of Cyasorb UV-531 are apparently so much slower, if they exist, hat a positive verification of loss over the aging time periods could not be made in these tests.

\section{Aging Sumary}

Elvax 150 car be degraded by UV photooxidation, thermal oxidation, and by purely thermal decomposition of the acetate groups to acetic acid. These degradation reactions are stated in order of decreasing severity, and as protection against each in order is provided, the 1 ife and associated peak service temperature of EVA encapsulant can be extended.

Fundamental analysis of Elvax 150 suggests that the UV wavelengths deleterious to this material, and necessary for UV photooxidation, are those shorter than $360 \mathrm{~nm}$. Isolation of Elvax 150 from these UV wavelengths, with UV-filtering outer covers and/or compounding additives such as Cyi 30 rb UV-531, stops UV photooxidation, and reduces the aging characteristics of Elvax 150 to thermal effects. This basic and very simple concept was established as a fundamental module design philosophy, and no problem with this concept has been identified in the experimental aging results to date.

For example, testing of EVA samples in the RS/4 UV chambers it $55^{\circ} \mathrm{C}$ included the following combinations:

(1) Elvax 150 without any protection, either additives or UV-screening film overlays.

(2) Elvax 150 with a UV-screening film overlay, but having no antioxidant or UV-absorbing additives.

(3) Fully compounded and cured A-9918 EVA, having an antioxidant and UV-absorbing additive, but with no UV-screening film overlay.

The Elvax 150 sample (No. 1) without any protection yellowed visibly and degraded within $1000 \mathrm{~h}$ of exposure, whereas samples Nos. 2 and 3 with UV protection as indicated have to date survived $20,000 \mathrm{~h}$ to $30,000 \mathrm{~h}$ of exposure without any degrading incidences. Accepting that the UV protection for these latter two samples acted to isolate or protect them from deleterious UV wavelengths, then their aging at $55^{\circ} \mathrm{C}$ was reduced to that of thermal aging. And further, as no aging affects were detected in these two samples, with or without an antioxidant, these tests indicate strongly that Elvax 150 at $55^{\circ} \mathrm{C}$ is either naturally resistant to thermal oxidation, or undergoes negligibly slow thermal oxidation.

If it can be assumed that a module having Elvax 150 as a pottent provides the necessary UV protection, and if it can be assumed that such a module may be at or near a daily array peaking temperature of $55^{\circ} \mathrm{C}$ for about $5 \mathrm{~h}$ each day, then $20,000 \mathrm{~h}$ to $30,000 \mathrm{~h}$ of accumulated thermal aging in the RS/4 chambers corresponds to 11 to 16 years of potential outdoor service. For module applications having daytime peaking temperatures near $55^{\circ} \mathrm{C}$, it appears that the 1 ife of the EVA encapsulant is related more to the life of 
the UV protection schemes and less to either the thermal behavior of the EVA or thermal protection schemes (for example, antioxidants).

Between $55^{\circ} \mathrm{C}$ and $93^{\circ} \mathrm{C}\left(200^{\circ} \mathrm{F}\right)$ there is no direct experimental or literature information on the thermal aging behavior of Elvax i50. Unresolved questions relace to knowing if a threshold temperature exists for Elvax 150, above which thermal oxidation begins, tc knowing the temperature-dependence of the rates of thermal oxidation of Elvax 150, and to knowing the effectiveness of antioxidants and the associated temperature-derendence of their protecti:e induction periods. Although the 10 mo ( 7200 hours) of thermal stability observed at $90^{\circ} \mathrm{C}$ for the dark-thermal aging of cured A-9918 EVA is encouraging, it is not known whether this is natural to the Elvax 150, or that $10 \mathrm{mc}$ was still within the protective induction period of the antioxidant. In addition, the concentration of Cyasorb UV-531, a critical element of the UV protection scheme, was not monitored in these thermally aged specimens.

The potential for long service 1 ite of EVA in modules at rooftop temperatures $\left(\mathrm{e} . \mathrm{g} ., 8^{\circ} \mathrm{C}\right)$ looks encouraging, but predictions of lifetime would be premature. As at $55^{\circ} \mathrm{C}$, UV protection and permanence of the UV protection is a must. After that, it is not clearly established which of the thermally driven processes is mos. critical. These processes include the basic thermal oxidacion prope:ties of the Elva. 150, of antioxidants and the associated temperature depentorry of their protective induction periods, and the temperature dependence $c^{\prime}$ any finsical loss and depletion $c f$ the protective compounding additives themselves, such as the UV and thermal stabilization additives.

The phenomenon of the UV bleaching of the yellow thermal oxidation products, observed in accelerated testing at $105^{\circ} \mathrm{C}$, suggest possibilities for reducing the amount of UV tiltering as currently employed in order to permit some of the UV bleaching wavelengths to penetratc throughout the $H J A$. In t.ais way, allowable service temperatures of the EVA wight be raised, permitting physical ana mechanical deterioration by thermal oxidation to proceed at known rates related to lifetime expectations, but maintaining optical clarity iy the UV bl zaching effect.

A program to identify physiral-loss mechanisms cf the EVA compounding additives is being initiated, and the first activity of this program is intended to assess the high-temperature volatility of all of these materia!s. A preliminary experiment with Cyasorb UV-531 at $90^{\circ} \mathrm{C}$ has been carried out (Reference 15). For this preliminary experiment, $20 \mathrm{~g}$ of Cyasorb UV-531 in a 3-in.-dia aluminum dish was put into an air-circulated oven set at $90^{\circ} \mathrm{C}$, and the weigh: of the material was measured periodically. The weight loss data are given in Table 17. This preliminary cxperiment also included an evaluation of the barrier properties of Acrylar and Tedlar plastic films in retarding or stopping the volatile loss of Cyasorb UV-531. In this experimt:nt, standard 3-in.-dia aluminum perm-cups containing $20 \mathrm{~g}$ each of cyasorb UV-531 were covered with the plastic films. Th? perm-cups are equipped with a perimeter gasket and clamp fixture in order to seal the edges against direct leakage. The weight loss data for the volatile loss through the Acrylar and Tedlar films are also given in Table 17. 
Table 17. Volatile Loss of Cyasorb UV-5j at $90^{\circ} \mathrm{C}$

\begin{tabular}{cccc}
\hline & \multicolumn{3}{c}{ Weight Loss, $~$} \\
\cline { 2 - 4 } Days, $90^{\circ} \mathrm{C}$ & $\begin{array}{c}\text { Ted lar } \\
\text { 100Br.30UT }\end{array}$ & $\begin{array}{c}\text { Acrylar } \\
\text { X-22417 }\end{array}$ & Control \\
\hline 3 & 0.5 & 0.5 & 0.45 \\
7 & 0.7 & 0.65 & 0.75 \\
10 & 0.7 & 0.71 & 0.80 \\
14 & 0.75 & 0.77 & 1.00 \\
18 & 0.75 & 0.77 & 1.00 \\
22 & 0.75 & 0.81 & 1.11 \\
$26^{\mathrm{a}}$ & 0.71 & 0.68 & 1.06 \\
30 & 0.86 & 0.83 & 1.25 \\
34 & 0.91 & 0.86 & 1.25 \\
38 & 0.89 & 0.88 & 1.35 \\
\hline
\end{tabular}

The gain in weight at this point correlated with a change in ovens; the cause is not known.

In all three experiments, a more volatile but unknown component cr comnonents accounting for about 0.5 wt $\%$ of the sample was rapidly boiled of within the first three days, and thereafter the evaporative weight-loss behavior became essentially linear with time. The steady-state rate of loss of Cyasorb UV-531 from the uncovered control cup averaged about 0.14 wt $\%$ per wek, and abcit 0.048 wt $z$ per week from the covered cups. These preliminaly data demonstrated that Cyasorb UV-531 is volatile at $90^{\circ} \mathrm{C}$, but at a very low rate, and that the UV filtering plastic films would only slow but would not stop migration and volatile loss of Cyasorb uv-531.

\section{H. ADVANCED EVA STUDIES}

The available evaluation-ready IVA (A-9918) has been received favorably by the industry. However, its status is still considered to be experimental. To advance EVA toward application readiness, severa developmental tasks to impiove on quality and durabl. $1^{\circ}$ remain to be compleced:

(1) Faster processing, prmarily in the cure schedule, which involves a reduction in cure $t$ ime and temperature; the minimum cure temperature will be dictated by the requirement that the curing system must not become active during film extrusion. 
(2) Optimization of the UV-stabilization additives and achievement of resistance against physical loss; the present additives were selected based on literature citation and industrial experience with polymers similar to EVA.

(3) Identification of the peak-service temperature allowed for EVA in a module application, to ensure 20-yr life.

(4) Industrial evaluation of the desirability of having a self-priming EVA, recognizing the possibility of an additional cost component (cost-benefit-per formance trade-off).

Briefly described herein are some of the early considerations and/or experimental trends resative to the first two of those tasks, (1) and (2). Not discussed herein, but planned, are extended experimental studies of the currently used antioxidant, in order to identify the limits of its protective capabilities, and to identify and evaluate, if necessary, potentially higher perforwance antioxidant materials.

\section{Curing Agent Studies}

These studies are intended to identify alternative peroxide curing agents that would reduce cure times and temperatures, as compared with Lupersol 101 , in order to realize a faster lamination cycle at loser temperatures for higher-volume fabrication operatisns. In addition, there appear to be roomtemperature shelf-life limitations associated with the use of Lupersol 101. It has been observed that A-9918 EVA slowly loses its ability to cure if it is stored as unrolled cut sheet. Further, this tendency to lose curability has been observed for the outer layer of rolled EVA. The time in which this behavior manifests itself can be in the order of a few days to several weeks. It is speculated that this behavior may be a resul: of a gradual volatjle loss of the Lupersol lil, or from rapid decomposition of the Lupersol 101 resulting f rom exposure to short-wavelength UV light $(<360 \mathrm{~nm})$, which may be generated by room lighting. Occasionally a faint yellow color is observed in uncured A-9918 EVA film that is exposed to room lighting; as observed in the EVA aging studies, this may be associated with the decomposition of the Lupersol 101 .

Three other peroxide curing age if , all available trom the Lucidol Division of the Pennwalt Corp., Buffalo: NY, are being investigated. Their commercial designations are:

(1) Lupersol 99.

(2) Lupersol 331-80B.

(3) Luperso 1 TBEC.

These agents were substituted for the Lupersol 101 in the A-9918 EVA (see Table 3) and " rre used at the same concentration of $1.5 \mathrm{phr}$ as used for the Luperso1 101. The modified A-9918 EVA containing these peroxide curing agents were cured at various combinations of time and temperature, and the efficiencies of cure were monitored by measurement of the resultant gel content of the cured EVA. 
The cure data for these three peroxide curing agents, along with Luperso 1 101 cure data for comparison, are given in Table 18. Compared with Lupersol 101, all three of the other peroxides are more efficient, resulting in faster cures at lower temperatures, which achieve or exceed the minimum required gel content of 65 to 70 wt $z$ in the cured EVA. These results indicate that, when compared to cure with Lupersol 101 , one of the new peroxides may be capable of resulting in equivalent cure in 1/3 to 1/10 the time, depending on the temperature selected. A high degree of cure at a lower temperature is desirable because of energy savings and reduced time required for heat transfer during lamination. For example, the recomended cure condition for A-9918 -YA with Lupersol 101 is 10 to $15 \mathrm{~min}$ at $150^{\circ} \mathrm{C}$, in order to achieve the minimum required gel content. This same level of gel content can be achieved in 10 to 15 min at $120^{\circ} \mathrm{C}$ with Lupersol $331-80 \mathrm{~B}$, or with any of the three alternative peroxides cited above, in $5 \mathrm{~min}$ or less at $150^{\circ} \mathrm{C}$.

A guideline for selecting peroxide curing agents as alternatives to Lupersol 101 is to recognize that the lowest temperature alluwable for EVA cure is dictated by the requirement that no cure of the compounded EVA occur during film extrusion. As the temperature of the EVA within the barrel of the film extruder can be at a temperature of $115^{\circ} \mathrm{C}$ for a few minutes, the use of a curing agent that would result in measurable cure at this temperature is to be avoided. Allowing for a safety margin of about $5^{\circ} \mathrm{C}$ above the peak extrusion temperature establishes an allowable lower-bound cure temperature of about $120^{\circ} \mathrm{C}$. Thus, of the three peroxides evaluated to date, and solely on the basis of cure data, Lupersol 331-80B would appear to be the choice as an alternative to Lupersol 101 .

However, if it is assumed that one of the shelf-life limitations of A-9918 EVA formulated with Lupersol 101 is related to volatile loss of this peroxide, then an alternative peroxide should also be less volatile compared with Lupersol 101. All four of these Lupersol peroxides are liquids, but their boiling points cannot be measured because chemical decomposition occurs before any evidence of boiling is observed. Further, vapor pressure at room temperature has not been measured, nor found in published literature. Horever, the flash points of cach of these four peroxide liquids are given in Pennwalt technical sales literature for these products; these flash points are listed in Table 19. If : $t$ can be assumed that comparison of flash points provides a relative measure of volatility, then Lupersol 331-80B is unfortunately the most volatile of the four, and Lupersol TBEC is the least volatile. Comparing the flash points of Lupersol 101 and Lupersol 331-80B suggest comparable volatility, and thus, although substitution of Lupersol 331-80B for Lupersol 101 may result in faster curing at lower temperatures, improvements in shelf life may not be realized; it may even be worse. Therefore, based on volatility behavior suggested by flash-point data, Lupersol TBEC becomes a preferred alternative to Lupersol 101 .

Continuing work with these and other curing agents yet to be identified will involve vapor-pressure measurements, shelf-life characteristics, and effecte, if any, of the alternate curing agents on module fabricability, other comp Jing additives, efficiency and performance of adhesives and primers developed for EVA, and weather aging of EVA encapsulated modules. 


\section{ORIGINAL PAGE IS \\ OF POOR QUALITY}

Table 18. Cure of A-9918 EVA at Various Times and Temperatures with Four Different Peroxide Curing Agents as Monitored by Gel Content in wt $\%$

Lupersol 101

\begin{tabular}{|c|c|c|c|c|c|}
\hline \multirow[b]{2}{*}{$\begin{array}{l}\text { Cure Time, } \\
\text { min }\end{array}$} & \multicolumn{5}{|c|}{ Degree of Cure, $z$ Gel } \\
\hline & $130^{\circ} \mathrm{C}$ & $140^{\circ} \mathrm{C}$ & $150^{\circ} \mathrm{C}$ & $160^{\circ} \mathrm{C}$ & $170^{\circ} \mathrm{C}$ \\
\hline 1 & & & $\mathbf{0}$ & 2.1 & 28.8 \\
\hline 2 & & 1.0 & 4.1 & 29.5 & 74.2 \\
\hline 5 & & 11.8 & 21.1 & 73.0 & 81.2 \\
\hline 10 & 1.0 & 23.5 & 63.2 & 82.6 & 92.7 \\
\hline 15 & 2.3 & 59.3 & 88.3 & & \\
\hline 30 & 3.4 & 68.2 & & & \\
\hline 60 & 32.1 & 80.6 & & & \\
\hline
\end{tabular}

Lupersol 99

\begin{tabular}{|c|c|c|c|c|c|c|}
\hline \multirow[b]{2}{*}{$\begin{array}{c}\text { Cure Time, } \\
\text { min }\end{array}$} & \multicolumn{6}{|c|}{ Degree of Cure, $\% \mathrm{Gel}$} \\
\hline & $110^{\circ} \mathrm{C}$ & $120^{\circ} \mathrm{C}$ & $130^{\circ} \mathrm{C}$ & $140^{\circ} \mathrm{C}$ & $150^{\circ} \mathrm{C}$ & $160^{\circ} \mathrm{C}$ \\
\hline 2 & & & & & :ow & 75.2 \\
\hline 5 & & & & low & 10.7 & 79.0 \\
\hline 10 & 0 & low & low & 72.2 & 77.7 & 79.9 \\
\hline 15 & 0 & 8.1 & 69.5 & 74.9 & 78.4 & \\
\hline 30 & low & 76.0 & 82.1 & 77.7 & 79.9 & \\
\hline
\end{tabular}


ORIGINAL PAGE IS

OF POOR QUALITY

Table 18. Cure of A-9918 EVA at Various Times and Temperatures with Four Different Peroxide Curing Agents as Monitored by Gel Content in wt \% (Cont'd)

Lupersol $331-80 \mathrm{~B}$

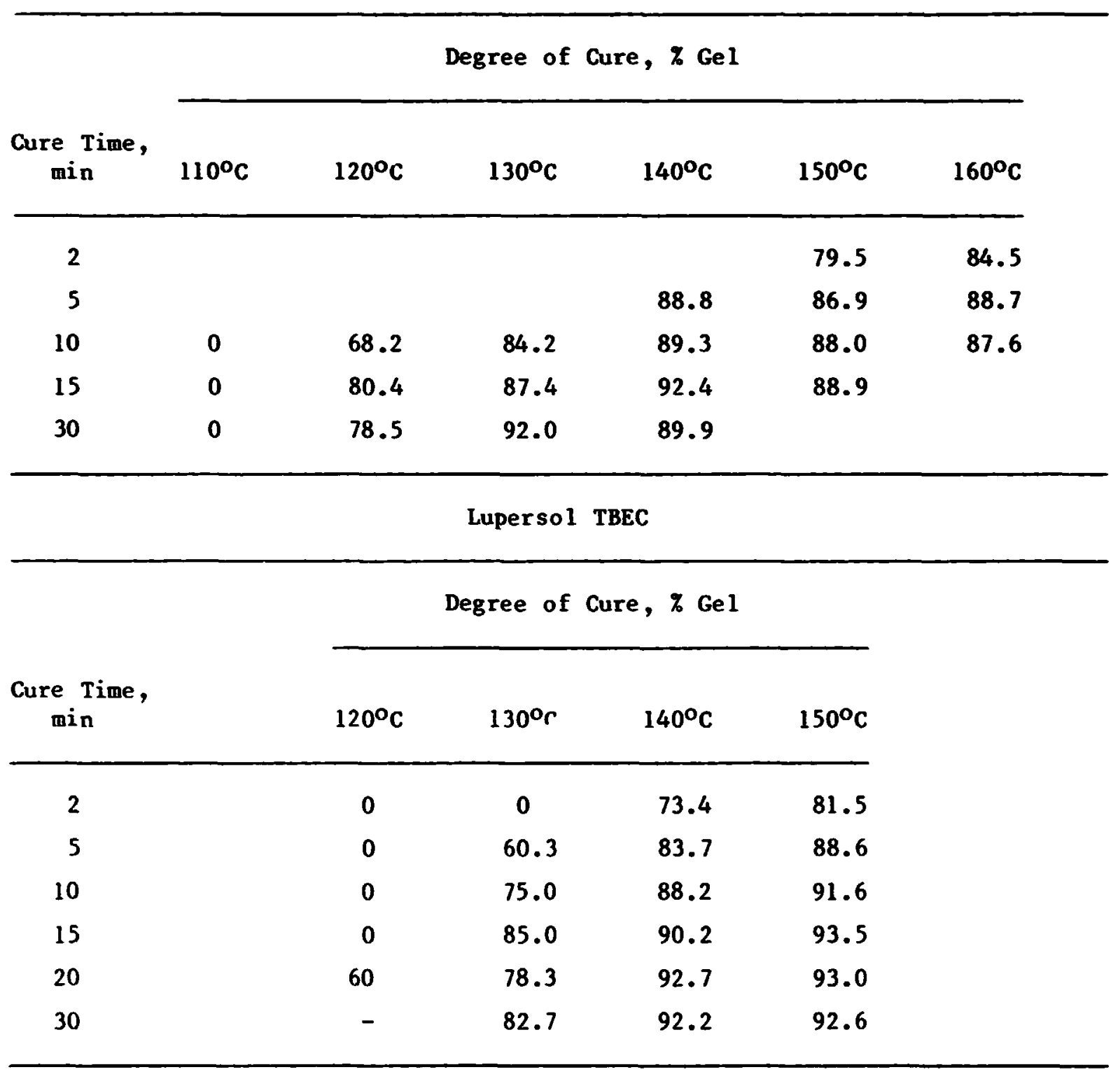

2. UV-Absorbing Additives

The EVA aging studies described in this paper strongly indicate that UV protection of the EVA is essentially assured as long as the Cyasorb UV-531 UV-absorbing additive remains physically within the EVA. However, the jing studies carried out at $105^{\circ} \mathrm{C}$ indicate a tendency toward gradual physical loss of this additive, presumably by volatility. 
Table 19. Flash Points of the Four Lupersol Peroxide Curing Agents

\begin{tabular}{ll} 
Flash Point & (Volatility) \\
\hline
\end{tabular}

\begin{tabular}{llr}
\hline Lupersol & 101 & $43^{\circ} \mathrm{C}$ \\
Lupersol & $331-80 \mathrm{~B}$ & $40^{\circ} \mathrm{C}$ \\
Lupersol & 99 & $77^{\circ} \mathrm{C}$ \\
Lupersol & TBEC & $101^{\circ} \mathrm{C}$
\end{tabular}

A major premise for the durability of low-cost, UV-sensitive pottants is that protection will be ensured by UV filtering through the glass superstrate, or through UV-screening plastic-film front covers, and that any harmful UV that does pass through the filters will be absorbed harmlessly within the pottant itself by uniformly dispersed UV screening agents. Loss of UV protection for the pottant by either chemical consumption of the screening agents or by physical loss from bleeding, migration, rainwater leaching, etc., could limit module longevity.

Fortunately, commercial UV screening agents in widespread use, and those used in the pottants and front-cover plastic films, are not susceptible to chemical consumption. They are not chemically destroyed when absorbing UV radiation; rather, they convert UV photon energy into heat. Thus these agents perform their UV-screening function as long as they are retained in the film and/or the pottant.

UV screening agents can be divided into two classes: those that are only physically dispersed throughout the bulk volume of a carrier medium, and those that are dispersed throughout the bulk volume of the carrier medium and also are chemically bound to the carrier. Those that are only physically dispersed can be further classified on the basis of their molecular weight, or on the basis of whether hey are small molecules or polymer molecules.

Smal1-molecule UV-screening agents such as Cyrsorb UV-531 are the most susceptible to physical loss by migration, bleeding, evaporation, leaching, etc. Efforts to diminish these physical-10ss tendencies by making the molecules bigger, but not polymeric, increases the problem of uniform dispersal compatibility because the UV screening agents tend to agglomerate into tiny discrete globules. If this occurs in a pottant, no protection may be afforded. Thus there is an inverse relationship between uniform dispersal and molecule size.

Although the physical-loss tendencies for small-molecule UV screening agents are recognized, it is important 0 also recognize that a pottant will be sandwiched between front and hack-cove: ing materials, thereby introducing some partial or total barrier resistance to physical 1088 of the UV screening agents. No physical $108 \mathrm{~s}$ is expected for a glass-superstrate module with a 
metal-foil back cover. However, a loss possibility exists for a design with other than a metal-foil back cover and for a substrate design with a plastic-film front cover.

At this state in developing encapsulation technology for specific additives, it cannot be stated with any certainty that deleterious losses can be predicted over the 20-yr desired lifetime of terrestrial modules.

Thus, a program to develop and evaluate permanent UV screening by chemical attachment has become a major activity. Table 20 summarizes three monomeric chemically attachable UV screening agents of present interest. Permasorb MA is available in limited quantities from National starch and Chemicals Corp.; vinyl tinuvin is just barely out of the laboratary, with small quantities being produced at Springborn, and the 2-hydroxy-3-allyl-4, $4^{\prime}-$ dimethoxybenzophenone is still at the laboratory development level. Preliminary work suggests that vinyl tinuvin will chemically attach to EVA without difficulty.

An additional approach is to produce polymeric UV absorbers, copolymerizing the monomeric UV screening agent (see Table 20) with a polymeric material that is compatible with the intended carrier medium. Efforts are still at the laboratory level. Physically dispersed polymeric v: screening agents should be significantly more resistant to physical-loss mechanisms than are small-molecule UV screening agents.

Table 20. Chemically Attachable Ultraviolet Screening Igents

\begin{tabular}{|c|c|c|}
\hline Agent & Status & Source \\
\hline Permasorb MA & Limited availability & $\begin{array}{l}\text { National Starch and } \\
\text { Chemical Corp. }\end{array}$ \\
\hline Vinyl Tinuvin & $\begin{array}{l}\text { Laboratory-scale } \\
\text { production }\end{array}$ & $\begin{array}{l}\text { Asahi Chemicals; } \\
\text { University of } \\
\text { Massachusetts; } \\
\text { Springborn }\end{array}$ \\
\hline $\begin{array}{l}\text { 2-hydroxy-3-allyl-4, } 4^{\prime}- \\
\text { dimethoxybenzophenone }\end{array}$ & Experimental & JPL \\
\hline
\end{tabular}




\section{REFERENCES}

1. Willis, P., et al., Investigations of Test Methods, Material Properties, and Processes for Solar-cell Encapsulants, Annual Report, ERDA/JPL954527, Sp-ingbrrn Laboratories, Inc., Enfield, Connecticut, Iu iy 1977.

2. Cuddihy, E.F., Encapsulation Material Trends Relative to 1986 Cost Goals, JPL Document No. 5101-61, Jet Propulsion Laboratory, Pasadena, California, April 13, 1978.

3. Willis, P., Baum, B., and White, R., Investigations of Test Methods, Material Properties, and Processes for Solar-Cell Encapsulants, Annual Report, ERDA/JPL-954527, Springborn Laboratories, Inc., Enfield, Connecticut, July 1978.

4. Cuddihy, E.F., Baum, B., and Willis, P., Low-Cost Encapsulation Materials for Terrestrial Solar Cell Modules, JPL Document No. 5101-78, Jet Propulsion Laboratory, Pasadena, California, September 1978, and Solar Energy, Vol. 22, p. 389, 1979.

5. Cuddihy, E.F., Encapsulation Materials Status to December 1979, JPL Document No. 5101-144, Jet Propulsion Laboratory, Pasadena, Califr rnia, Januarv 15, 1980.

6. Willis, P., and Baum, B., Investigations of Test Methods, Material Properties, and Processes for Solar-Cell Encapsulants, Annual Report, ERDA,'JPL-954527, Springborn Laboratories, Inc., Enfield, Connecticut, July 1979.

7. Willis, P., et al., Investigations of Test Methods, Material Properties, and Processes for Solar-Cell Encapsulants, Ann" Report, ERDA/JPL-954527, Springborn Laboratories, Inc . ield, connecticut, July 1980 .

8. Cuddihy, E., et al, Photovoltaic Module Encapsulation Design and Materials Selection: Volume I, JPL Publication 81-102, JPL Document No. 5101-1, 7 , DOE/JPL-1012-56, Jet Propulsion Laboratory, Pasadena, California, June 1, 1982.

9. Spectrolab, Inc., Phase I Technical Report for FSA Contract 955567, November 1981 .

10. Liang, R., et al, Photothermal Characterization of Encapsulant Materials for Photovoltaic Modules, JPL Publication 82-42, JPL Document No. 5101-210, DOE/JPL-1012-72, Jet Propulsion Laboratory, Pasadena, California, June 1, 1982.

11. Stultz, J.W., and Wen, L. C., Thermal Performance Testing and Analysis of Photovoltaic Modules in Natural Sunlight, JPL Document No. 5101-31, Jet Propulsion Laboratory, Pasadena, California, July 29, 1977.

12. Stultz, J.W., Thermal and Other Tests of Photovoltaic Modules Performed in Natura 1 Sunlight, JPL Document No. 5101-76, DOE/JPL-1012-78/9, Jet

Propulsion Laboratory, Pasadena, California, July 31, 1978. 
13. Griffith, J.A., Rathod, M.S., and Paslaski, J., "Some Tests of Flat Plate Photovoltaic Module Cell Temperatures in Simulated Field Conditions," presented at 15th IEEE Photovoltaic Specialists Conference, Kissimmee, Florida, May 12-15, 1981.

14. Rogers, C., "Permeability and Chemical Resistance," Chapter 9 in Engineering Design for Plastics, E. Baer, editor, Reinhold Publishing Co., New York, 1964.

15. Willis, P., et al, Investigation of Test Methods, Material Properties, and Processes for Solar-Cell Encapsulants, Annual Report, ERDA/JPL-954527, Springborn Laboratories, Inc., Enfield, Connecticut, July, 1981 .

16. Duncan, R.E., and Bergerhouse, J.E., "EVA and VAE Copolymers for Hot Melt PSA's," Adhesives Age, PP. 37-41, March 1980.

17. The Vanderbilt Rubber Handbook, edited by George G. Winspear, R.T. Vanderbilt Co., Inc., New York, 1968.

18. Allen, G., Gee, G., and Wilson, J., Polymer, Vol. 1, p. 456, 1960.

19. Fox, T.G., Bulletin of the American Physical Society, Vol. 1, No. 3, p. $123,1956$.

20. Polyethylene, Edited by R.A.V. Raff and J.B. Allison, High Polymer Series, Volume XI, Interscience Publishers, Inc., New York, (1952).

21. Myers, C.S., J. Polymer Science, Vo1. 13, Pp. 549-564, 1951.

22. Pleuddemann, E.P., Chemical Bonding Technology for Terrestrial Solar Cell Modules, JPL Document No. J101-132, Jet Propulsion Laboratory, Pasadena, California, September 1, 1979.

23. Chen, C.P., Fracture Strength of Silicon Solar Ce1ls, JPL Publication 79-102, JPL Publication 79-102, JPL Document No. 5101-137, DOE/JPL-1012-32, Jet Propulsion Laboratory, Pasadena, California, October $15,1979$.

24. Cuddihy, E.F., Deve lopment of Reduced-Variable Master Curves for Estimating Tensile Stresses of Encapsulated Solar Cells Caused by Module Deflection or Thermal Expansion, JPL Document No. 5101-182, Jet Propulsion Laboratory, Pasadena, California, October 1, 1981.

25. Hoffman, A.R., and Maag, C.R., "Airborne Particulate Soiling of Terrestrial Photovoltaic Modules and Cover Materials," Proceedings of the Institute of Environmental Sciences, Philadelphia, Pennsylvania, May 11-14, 1980, Institute of Environmental Sciences, Mt. Prospect, Illino is, 1980 .

26. Hoffman, A.R., and Maag, C.R., Photovoltaic Module Soiling Studies, May 1978 to October 1980, JPL Publication 80-87, JPL Document 5101-131, DOE/JPL-1012-49, Jet Propulsion Laboratory, Pasadena, California, November 1,1980 . 
27. Cuddihy, E.F., "lineoretical Considerations of Soil Retention," Solar Energy Materials, Vol. 3, pp. 21-33, 1980.

28. Photovoltaic Module Design, Qualification and Testing Specification, JPL Document No. 5101-65, DOE/JPL-1012-78/7A, Jet Propulsion Laboratory, Pasadena, California, March 24, 1978.

29. Block V Solar Cell Module Design and Test Specification for Residential Applications-1981, JPL Internal Document No. 5101-161, Jet Propulsion Laboratory, Pasadena, California, February 20, 1981.

30. Estey, R.S., Measurement of Solar and Simulator Ultraviolet Spectral Irradiance, JPL Internal Document No. 5101-58, Jet Propulsion Lauoratory, Pasadena, California, March 15, 1978.

31. Terrestrial Service Environments for Selected Geographic Locations, ERDA/JPL-954328-76/5, Battelle Columbus Laboratories, Columbus, Ohio, June 24, 1976. 